University of Louisville

ThinkIR: The University of Louisville's Institutional Repository

Electronic Theses and Dissertations

$9-2002$

\title{
The effects of cycling shoe outsole material on plantar stress.
}

Nathan Edward Jarboe

University of Louisville

Follow this and additional works at: https://ir.library.louisville.edu/etd

\section{Recommended Citation}

Jarboe, Nathan Edward, "The effects of cycling shoe outsole material on plantar stress." (2002).

Electronic Theses and Dissertations. Paper 680.

https://doi.org/10.18297/etd/680

This Master's Thesis is brought to you for free and open access by ThinkIR: The University of Louisville's Institutional Repository. It has been accepted for inclusion in Electronic Theses and Dissertations by an authorized administrator of ThinkIR: The University of Louisville's Institutional Repository. This title appears here courtesy of the author, who has retained all other copyrights. For more information, please contact thinkir@louisville.edu. 


\title{
THE EFFECTS OF CYCLING SHOE OUTSOLE MATERIAL ON PLANTAR STRESS
}

\author{
By \\ Nathan Edward Jarboe \\ B.S., Biology, University of Kentucky, 1994 \\ B.S., Mechanical Engineering, University of Louisville, 2001
}

\begin{abstract}
A Thesis
Submitted to the Faculty of the

University of Louisville

Speed Scientific School

as Partial Fulfillment of the Requirements

for the Professional Degree

MASTER OF ENGINEERING

(M.Eng.)

Department of Mechanical Engineering
\end{abstract}

September, 2002 



\section{THE EFFECTS OF CYCLING SHOE OUTSOLE MATERIAL ON PLANTAR STRESS}

Submitted by:

Nathan Edward Jarboe

A Thesis Approved on

(Date)

by the Following Reading and Examination Committee

Peter M. Quesada, Ph.D., Thesis Director, Mechanical Engineering

Waldemar Karwowski, Ph.D., Industrial Engineering

Claudia Angeli, Ph.D., Frazier Rehab, Adjunct Faculty

William Hnat, Ph.D., Mechanical Engineering 


\section{ACKNOWLEDGMENTS}

First and foremost I thank God for the ability and strength to continue through any and every challenge encountered during my graduate career. I thank my parents, Joe and Betty Sue Jarboe, of Hardinsburg, Kentucky for encouragement and for instilling the desire to better myself through higher education. Mr. Arthur John Schwaniger, a retired NASA engineer and good friend, is also to be commended for providing plush accommodations in exchange for inexpensive rent during my graduate career and during the completion of this project. Mr. Schwaniger's assistance with mathematics was also appreciated.

My first cousin Marty Vessels and my Uncle Donnie Jarboe have each been especially helpful and deserve recognition. Scott Gard of Lawrenceburg, Kentucky provided extreme hospitality when I went out of town for my second and third co-ops. I thank other acquaintances such as Bruce Montana, Laura Mannis, Daniele' Denoncourt, Linda Carr, Marianna Lemieux, Diego Montoya-Durengo, Andrea Jones, and so many other friends in Louisville. Richard Roselli deserves special thanks for being an especially good and supportive friend. Tara Alfiero proofread this document thoroughly for errors and improvements, of which I am thankful.

Thanks are also reserved for Dr. Quesada for guidance and direction during the project; I appreciated his suggestions along the way. Dr. Glen Prater, the department chair of mechanical engineering, has done a fine job of obtaining the needed computers and resources for our mechanical engineering program making the completion of this project possible. 


\begin{abstract}
Past cycling-related literature noted that metatarsalgia and local paraesthesias are common among cyclists. The purpose of this investigation was to determine if shoes made with stiff material cause an increase in peak plantar stress over shoes with less stiff material. Plantar stress data were recorded in two different shoe types in an effort to form an association between cycling shoe stiffness and peak plantar stress experienced by cyclists' feet.
\end{abstract}

Two pairs of shoes of the same size and manufacturer, identical except for outsole material and stiffness, were tested. Shoe stiffness measurements were collected under controlled conditions and in two different configurations using a dynamic hydraulic tensile testing machine. The first test configuration occurred in a longitudinal bending arrangement as specified by ASTM standard F-911. The second shoe test arrangement was a custom three-point bending arrangement.

It was anticipated that shoes made with carbon fiber materials would increase the peak stress experienced by the feet during normal cycling while more compliant shoes, made from other plastics, would reduce peak stress by exerting the stress over a greater area due to increased shoe deformation. Measurements of plantar stress were taken while subjects pedaled in a seated position at a controlled power output. Power output was set at a constant value of $400 \mathrm{~W}$ across all subjects by a magnetic resistance trainer unit that was thoroughly tested and calibrated for repeatability prior to use. Capacitive-based sensor insoles were placed in the shoes to measure the peak stress under each foot during pedaling. The stress distribution in carbon-fiber-composite shoes during cycling was compared to cycling shoes made with more traditional plastic soles.

The shoes made with carbon fiber produced peak plantar stresses 18\% higher than those of a more traditional plastic design (121.2 kPa vs. $103.0 \mathrm{kPa}, \mathrm{p}$-value $=0.005)$. Carbon fiber shoes presented stiffness values $42 \%$ and $550 \%$ higher than plastic shoes in longitudinal bending and three-point bending, respectively. 


\section{TABLE OF CONTENTS}

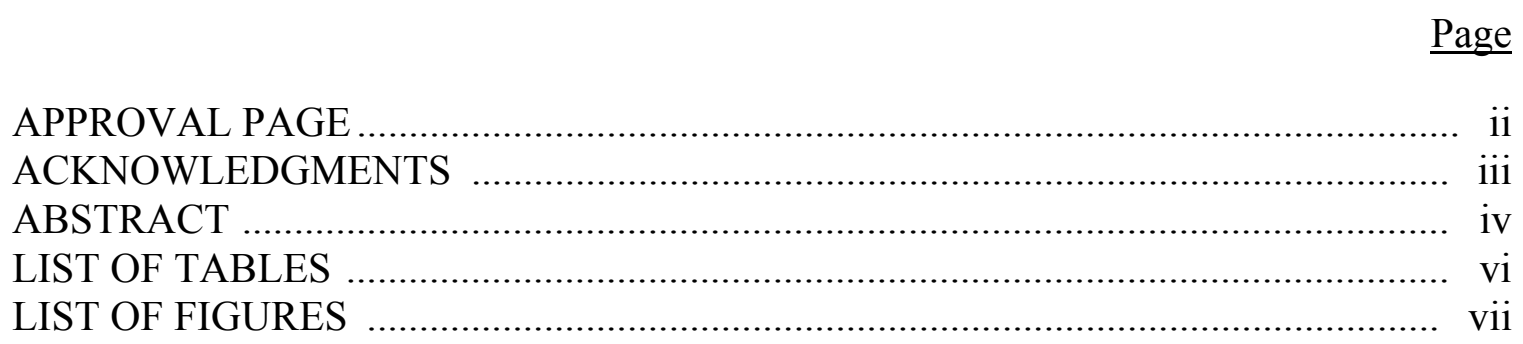

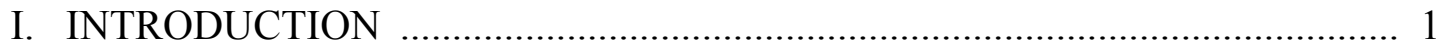

II. RELATED LITERATURE ..................................................................... 3

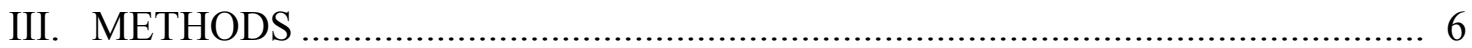

A. MEASUREMENT EQUIPMENT VERIFICATION .............................. 6

1. Testing Apparatus for Magnetic Resistance Unit ............................ 6

2. Router Apparatus for Testing Magnetic Resistance Unit ................ 12

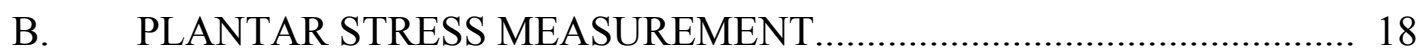

1. Plantar Stress Data Collection Apparatus ....................................... 18

2. Plantar Stress Data Collection Protocol........................................ 20

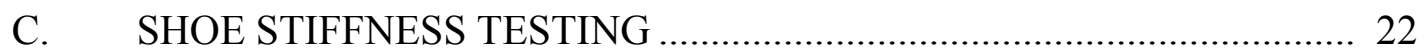

1. Testing Apparatus for Longitudinal Bending Stiffness .................. 23

2. Testing Apparatus for Forefoot Three-Point Bending Stiffness ....... 25

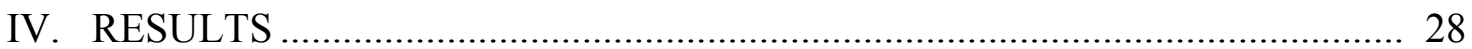

A. RESISTANCE DEVICE TEST RESULTS ........................................ 28

B. PLANTAR STRESS RESULTS......................................................... 30

1. Plantar Stress Statistical Analysis................................................... 36

C. CYCLING SHOE STIFFNESS TEST RESULTS ................................. 37

1. Longitudinal Bending Stiffness Results ..................................... 37

2. Three-Point Bending Stiffness Results ......................................... 41

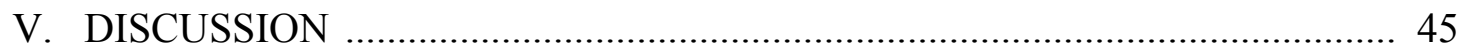

VI. CONCLUSIONS AND RECOMMENDATIONS ....................................... 47

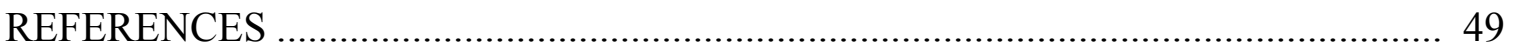

APPENDIX I. TRAINER TEST DATA............................................................ 51

APPENDIX II. PEAK PLANTAR STRESS DATA ….......................................... 59

APPENDIX III. CYCLING SHOE STIFFNESS AND DAMPING .......................... 61

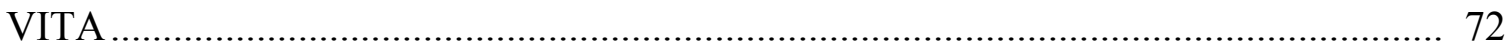




\section{LIST OF TABLES}

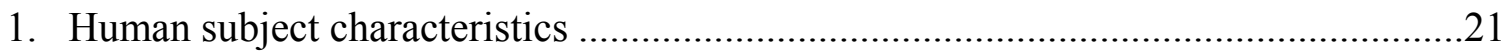

2. Random resistance unit test results collected at 8050 RPM .........................................29

3. Statistical results of a two-way ANOVA with repeated measures ...............................37

4. Average shoe stiffness in longitudinal bending per ASTM F-911 …..........................40

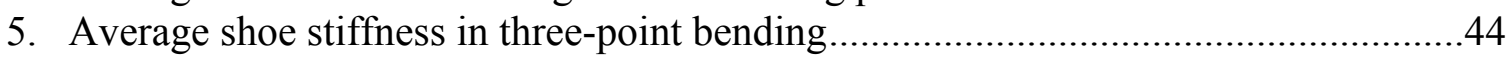

6. Magnetic resistance unit testing data collected at various shaft speeds ......................51

7. Repeatability parameters recorded at varying shaft speeds and at 400 Watts ..............51

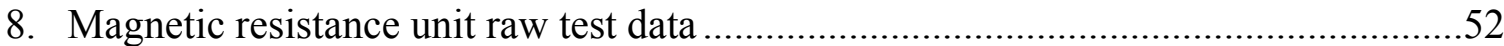

9. Magnetic resistance unit calculation spreadsheet example ........................................55

10. Average peak plantar stress collected at 400 Watts..................................................59

11. Averaged peak stress data with left and right shoes combined .................................60

12. Damping of cycling shoes in longitudinal bending per ASTM F-911 .......................69

13. Damping of cycling shoes in three-point bending .................................................... 


\section{LIST OF FIGURES}

1. Medial view of the right foot showing the first metatarsal bone ................................ 1

2. Dorsal view of the right foot................................................................................ 2

3. Magnetic resistance unit ....................................................................................... 7

4. Computer input/display module ............................................................................ 7

5. Magnetic resistance unit connectors ....................................................................... 8

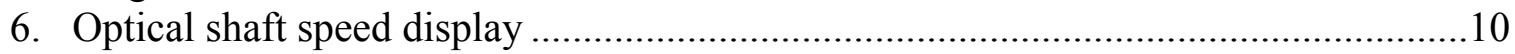

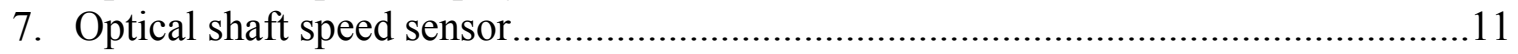

8. Strain gage force transducer ..............................................................................11

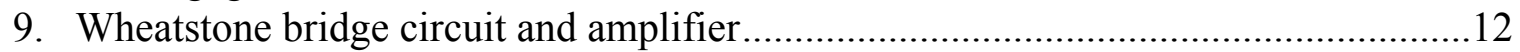

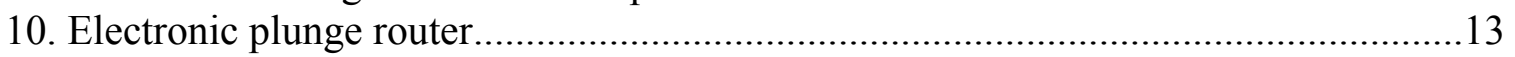

11. Rewiring of router motor for reverse rotation .......................................................13

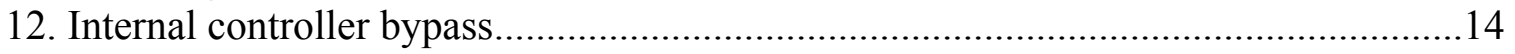

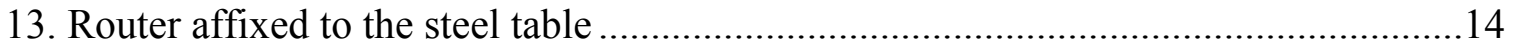

14. Adapter used to connect the router motor to the magnetic resistance unit...................15

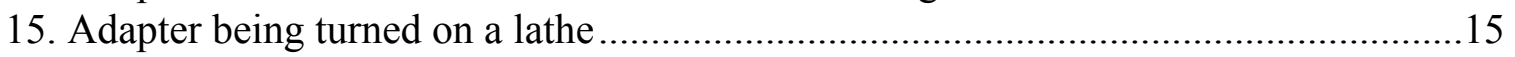

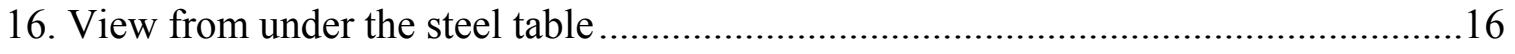

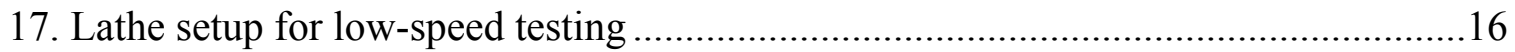

18. Wooden dowel rod used to simulate a bicycle crank..................................................17

19. Controller unit and electric motor used to turn the simulated crank ..........................18

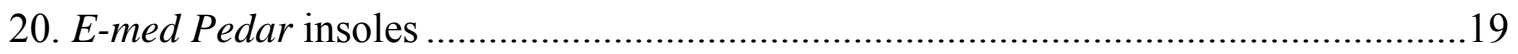

21. Bicycle and Tacx magnetic resistance unit .........................................................20

22. Bicycle rear wheel in contact with magnetic resistance unit ......................................20

23. ASTM F-911 shoe testing arrangement ...............................................................23

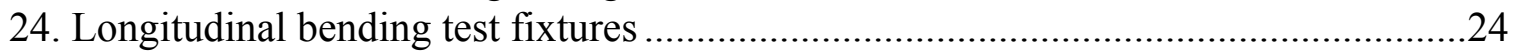

25. MTS machine in longitudinal bending arrangement ...............................................24

26. Longitudinal bending arrangement with shoe ……….............................................25

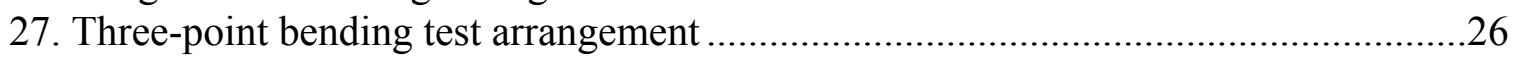

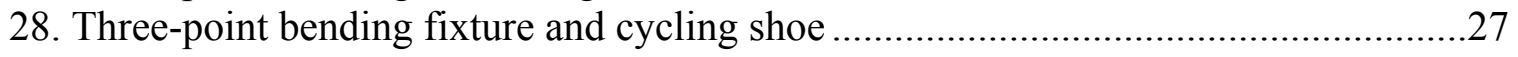

29. MTS machine in three-point bending ……………..............................................2

30. MTS three-point bending arrangement with shoe in place ..........................................28

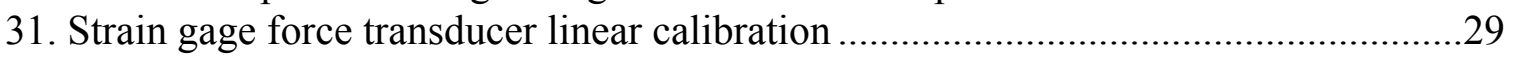

32. Force and peak plantar stress plot over a typical collection sequence .........................30

33. Force and peak plantar stress plot, close-up view ......................................................

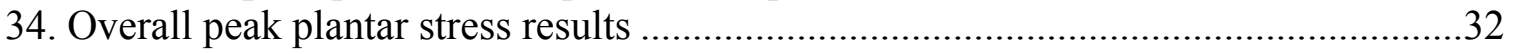

35. Average peak plantar stress results, left feet............................................................33

36. Average peak plantar stress results, right feet ...........................................................33

37. Two-dimensional plantar stress plot from Pedar software..........................................35

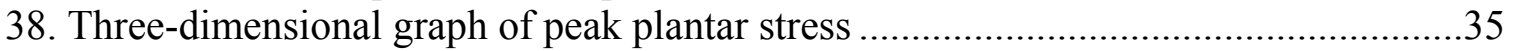

39. Force/Displacement curve of a cycling shoe in longitudinal flexure ...........................38

40. Force/Displacement curve with corresponding linear trendline ....................................39

41. Stiffness values of two types of cycling shoes in ASTM F-911 ..................................40

42. Force/displacement curve of a shoe in three-point bending ........................................41

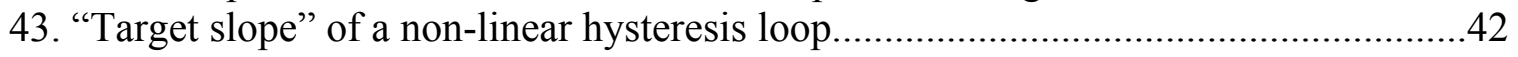

44. Drawing tangency lines to a non-linear hysteresis loop .............................................43 
45. Final stiffness determination for a non-linear hysteresis loop 43

46. Stiffness values of two types of cycling shoes in three-point bending ........................44

47. Area inside a hysteresis loop ...................................................................................63

48. Force/displacement hysteresis curve upper boundary polynomial ...............................64

49. Force/displacement hysteresis curve lower boundary polynomial ...............................64

50. Hysteretic damping constant (h) of shoes in longitudinal bending ..............................67

51. Hysteretic damping ratio $(\beta)$ of shoes in longitudinal bending .....................................67

52. Logarithmic decrement $(\delta)$ of shoes in longitudinal bending ...................................68

53. Equivalent viscous damping ratio $(\zeta)$ of shoes in longitudinal bending .......................68

54. Hysteretic damping constant $(\mathrm{h})$ of shoes in three-point bending ..............................69

55. Hysteretic damping ratio $(\beta)$ of shoes in three-point bending .....................................70

56. Logarithmic decrement $(\delta)$ of shoes in three-point bending .....................................70

57. Equivalent viscous damping ratio $(\zeta)$ of shoes in three-point bending........................71 


\section{INTRODUCTION}

It is proposed by this study that stiffer cycling shoes, specifically those containing carbon fiber composites, produce higher forefoot average peak plantar stress during cycling than shoes without carbon fiber. The impetus for this research comes from personal and painful experience with stiff cycling shoes. Anecdotal evidence, gathered from informal conversation with other cyclists, revealed that cyclists experience pain and problems with circulation, mostly near the first metatarsal head, especially with extremely stiff carbon-soled shoes.

Anatomical diagrams demonstrating the position of the first metatarsal bone, an area of the foot where many cyclists experience pain, are shown in Figures 1 and 2. Since no current scientific journal articles compared stiffness among cycling shoes to differences in plantar stress, it was concluded that this subject warranted further consideration. High plantar stress is noted in the literature as a risk factor for certain foot conditions such as metatarsalgia (pain in the "ball"of the foot) and ischemia (reduced blood flow).

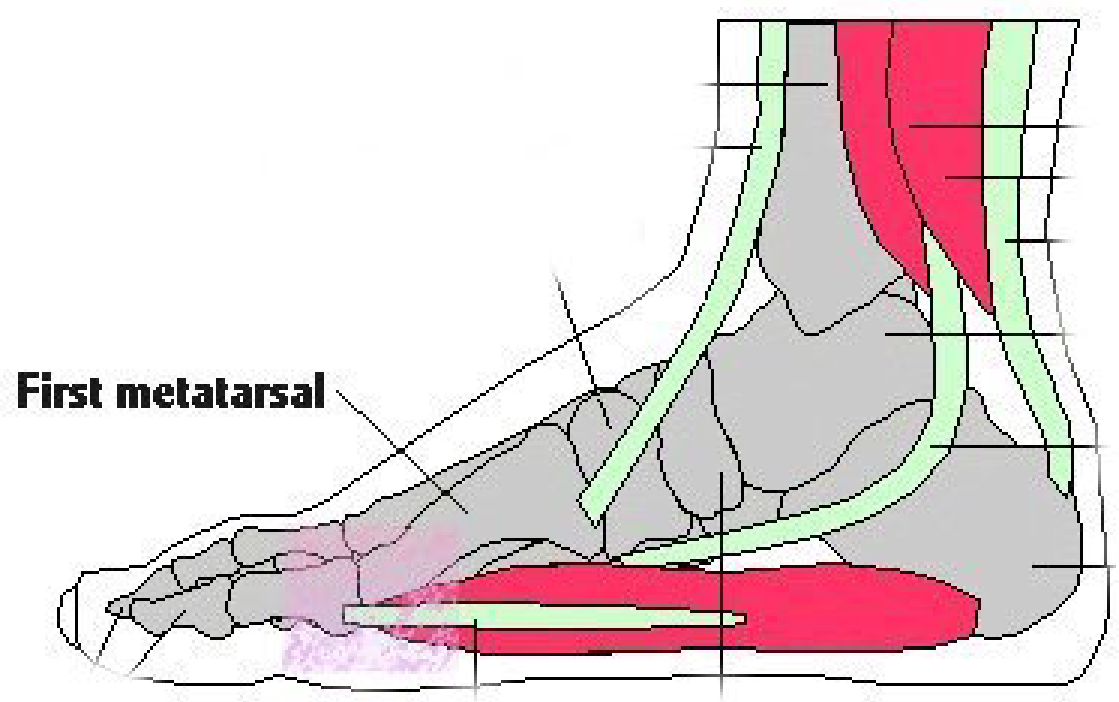

Figure 1. Medial view of the right foot showing the first metatarsal bone. The shaded portion represents the MTP (Metatarsophalangeal) joint, which is a location of pain in many cyclists. Diagram courtesy of the Calgary Foot Clinic. 


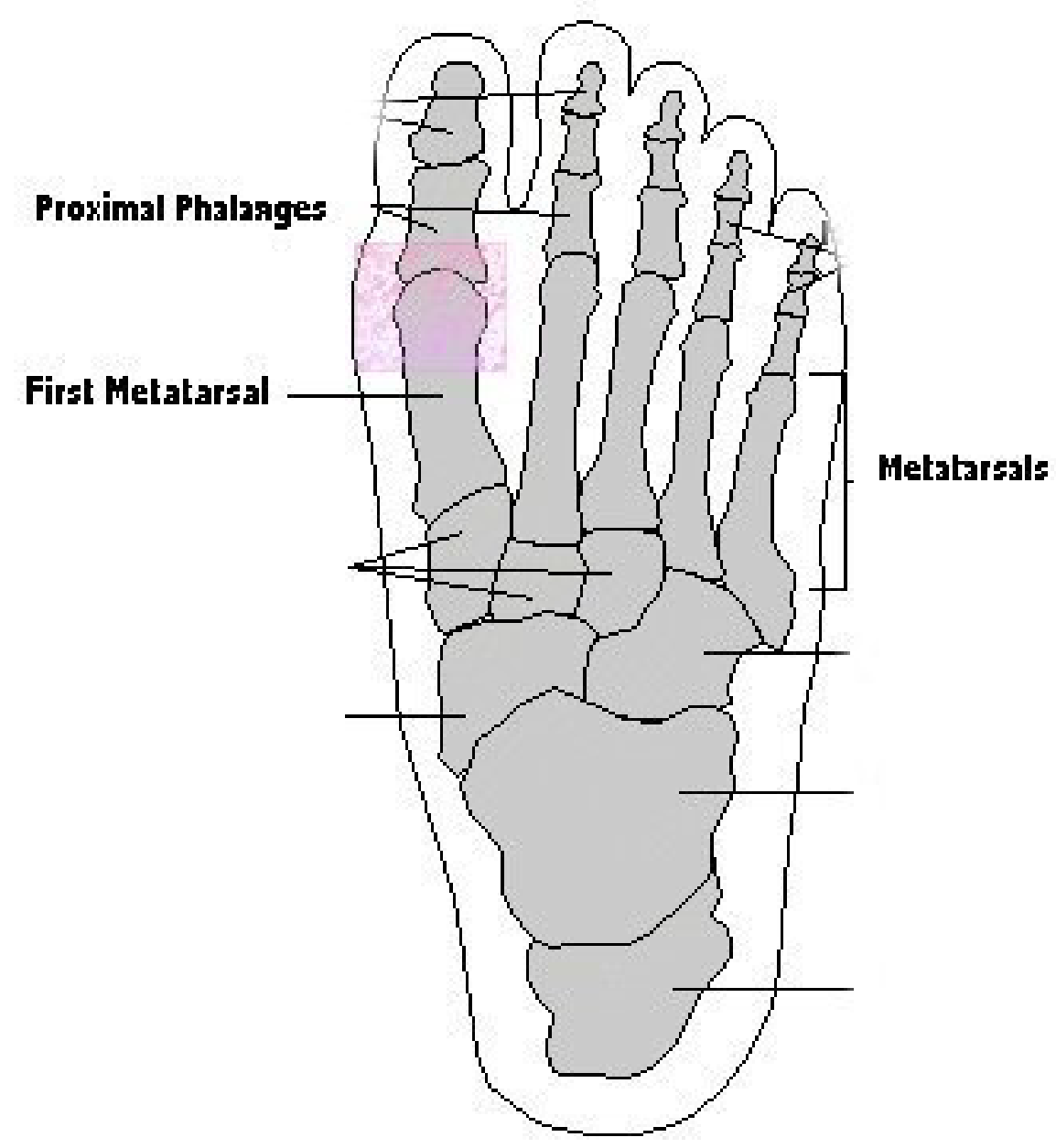

Figure 2. Dorsal view of the right foot. The shaded portion represents the MTP (Metatarsophalangeal) joint. Diagram courtesy of the Calgary Foot Clinic.

Older model cycling shoes, i.e. those of the 1980's and early 1990's, were composed of a homogenous material throughout the outsole, mostly a plastic or Nylon material. Ultra-stiff carbon fiber composites are now being placed into the outsole of both road and mountain bike racing shoes to reduce weight while simultaneously stiffening the shoes.

From a performance standpoint, low weight makes shoes desirable for racing for two reasons: less weight conserves energy when cycling up hills, and less mass results in less rotational inertia about the cranks. Less mass in the cranks, pedals, gears, and especially rims and tires, enable the cyclist to accelerate quicker due to the lower moments of inertia. 


\section{RELATED LITERATURE}

Several studies have examined plantar stress (Sanner and O'Halloran , 2000; Sanderson and Cavanagh, 1987), although none have examined the specific association between different types of cycling shoes and plantar stress. According to popular cycling magazines and cycling-related advertisements, stiffer soles made from composite materials are designed to transfer energy more efficiently from the legs and feet to the pedals. An example of the latter is seen on the website of a leading cycling footwear manufacturer at http://193.108.239.124/northwave/scheda.asp?id=164\#:

"Resulting from in-depth research in biomechanics Evolve is a layered outsole system, technologically advanced and with performance and comfort properties definitely above average. The main structure is made of (manufacturer's brand name) nylon and fiberglass (a stiff material), and offers a wide supporting base with minimum inclination, which ensures great comfort and allows the foot to transmit full power to the pedal."

While the introduction of stiff materials may increase performance, and may help the shoes to sell well to the public, the investigator suspects there may be an increased risk of injury to a cyclist using such shoes. The intent was not to make allegations that specific shoes tested in this study are dangerous, but rather to objectively evaluate whether or not there exists any quantifiable differences in peak plantar stress using the carbon-fiber-soled shoes versus the more traditional plastic ones. In response to allegations that a leading footwear manufacturer produced faulty or dangerous footwear, a representative proclaimed that the company spent \$100 million, in 1998 alone, on footwear research (Chappell, 1998) and is thus making every effort to make safe shoes. It is, nevertheless, theorized that the inability of certain cycling shoes to flex under load and thereby conform to foot contours could increase the peak stress incurred by the feet. This increase in plantar stress could be a result of a reduced contact area between the plantar surface of the feet and the shoes, which could lead to injury after prolonged and intense use.

Sanner and O'Halloran (2000) state that stiffer "touring" cycling shoes protect feet from cycling pedals and are more efficient than recreational shoes. This statement refers to the difference between regular walking shoes and cycling specific shoes, and is not a direct comparison among cycling shoes. Sanner and O'Halloran also state that a rigid shoe can help a cyclist's foot stability by resisting torsion and not allowing excessive 
pronation of the foot during cycling. When commenting on numb feet, or paraesthesia, the stiffness of the shoe sole was discussed as a contributing factor to comfort. The article also noted that cycling shoes are often more narrow than the foot itself, which could compress nerves within the forefoot. The Sanner also stated that soft soled shoes, such as running shoes, can raise the stress on the plantar surface of the forefoot, and that stiffer soles should be used to alleviate this problem. A comment was also made that "Often the firm-soled cycling shoe protects the foot from the pedal but contributes to the forefoot discomfort because it is so firm." (pg. 375). A suggestion was made in the article to use a foot orthosis within the shoe to distribute pressure over a larger area of the foot.

Gregor, et al (1994) examined the biomechanical factors associated with shoe/pedal interfaces and determined that clipless pedals helped alleviate knee discomfort by allowing the knee to "float" during the pedal stroke. Foot and ankle overuse injuries were also mentioned in this study. Metatarsalgia, generalized pain in the "ball" of the foot, was also addressed in the Gregor study. Listed as one of the causes of metatarsalgia was an "increased localized pressure" (pg. 118) due to the stiffness of the sole and also different pedal/cleat types.

Sanderson and Cavanagh (1987) compared the in-shoe pressure distribution during cycling in conventional cycling shoes and running shoes. Localized ischemia (diminished blood flow) and paraesthesia (tingling and numbness) was mentioned as a common problem among long distance cyclists. The dominant sites of plantar loading were found to be the hallux (big toe) and the first metatarsal, regardless of shoe. Very little load was carried by the heel or arch. Deformation of the running shoes was theorized as the cause for lower peak stress in running shoes versus cycling shoes, although the stress differences between the running shoes and cycling shoes were not found to be statistically significant.

Mellion (1991) stated in the summary portion "the increasing participation in the athletic forms of bicycling warrants expanded physical attention to the traumatic and overuse injuries experienced by cyclists.” (pg. 53). Mellion stated that foot paraesthesias and metatarsalgia are both common among cyclists (pg 53). The etiologies stated for paraesthesia were tight toe straps over the cyclist's shoe and increased pedal pressure (pg. 65). Metatarsalgia was associated with poor foot position on the pedal, poor positioning of shoe cleats, and increased pedal pressure resulting from pedaling a large 
gear slowly under heavy load, called "mashing" among cyclists. Although Mellion does not specifically mention peak stress during his article, using a higher pedal cadence is listed as a solution to metatarsalgia and paraesthesia, which implies that peak stress is a contributing factor to metatarsalgia and paraesthesia (pg. 66).

Sanderson and Hennig (1992) also examined in-shoe pressure distribution in cycling shoes and running shoes during steady-state cycling. Sanderson and Hennig found that the rigid shoes decreased the localized stress experienced by the metatarsal heads and distributed the load to other areas of the foot better than did the running shoes. The results of the Sanderson study appear to contradict the results expected by this shoe stiffness study; however the conditions that were tested are fundamentally different because running shoes represent an extreme end of the shoe stiffness spectrum since they are dramatically more flexible than even the traditional plastic-soled cycling shoes.

A study by Anderson and Sockler (1990) studied the effects of orthoses on selected physiologic parameters in cycling. While no differences were found due to the orthoses, a small difference was noted between stiff-soled-cycling shoes and running shoes; the cycling shoes resulted in a lower heart rate at a given power output, suggesting that stiff cycling shoes save energy and help the cyclist to pedal more efficiently than running shoes.

Sanderson, et al. (2000) evaluated the influence of cadence and power output on force application and in-shoe pressure distribution during cycling by competitive and recreational cyclists. Pedal cadences of 60, 80, and 100 RPM and power outputs of 100, 200,300 , and 400 Watts were used in this study. A pedal cadence of $90 \mathrm{rpm}$ and a power output of 400 watts were used in the current study so that adequate comparisons could be made to existing literature. A major finding in the Sanderson, et al. study was that as power output increased, the percentage and magnitude of stress borne by the first metatarsal and hallux increased. This increase in stress measured at the first metatarsal head and hallux due to increased power output occurred across all pedal cadences regardless of cycling experience. 


\section{METHODS}

\section{A. MEASUREMENT EQUIPMENT VERIFICATION}

\section{Testing Apparatus for Magnetic Resistance Unit}

To collect significant plantar stress data it was necessary to test all subjects under identical pedaling conditions and under identical workload. To better control the conditions, each cyclist pedaled while seated and with the seat height set to the same height relative to their leg length. In addition, the pedaling resistance was controlled in a manner that was repeatable across all subjects by using a magnetic resistance training device, which was tested and verified according to the procedures outlined in the rest of this section.

A commercially available stationary magnetic resistance training unit, a Tacx basic model T1911 (Technishe Industrie Tacx BV, Wassenar the Netherlands), was used to provide a controlled pedaling resistance across all subjects. A picture of the resistance unit is shown in Figure 3. The magnetic unit has a steel rotating shaft, mounted on bearings, that mounts to a steel frame (not shown). The frame and magnetic unit are connected to the bicycle via the rear wheel in a manner that places the tire of the rear wheel in contact with the steel shaft for control of cycling resistance during use. The resistance unit has, inside it, an array of permanent magnets and coils, an aluminum disk that rotates in close proximity to the coils, a magnetic RPM sensor, and a control circuit. The resistance unit also includes two external devices: a crank speed sensor, and an input/ display computer module that is programmable to \pm 10 Watts.

As the cyclist sits atop the stationary trainer device and pedals the bicycle, the rear wheel of the bicycle spins against the solid steel axle of the resistance unit. The aluminum disk, which is connected to the axle, spins within the control unit sandwiched between six permanent magnets and six electromagnetic coils. The control unit varies the current passing through the coils to control the resistance, and operates based on the setting programmed into the input/display computer module, shown in Figure 4. The resistance unit also has a crank sensor that indicates current crank RPM. The crank sensor has two parts, one part that mounts to the bicycle frame and one part that mounts to the crank. The connectors and their attachments to the resistance unit are shown in Figure 5. The connector furthest to the right, the phone jack connector, is for the 
input/display computer module. The center coaxial jack is for the crank speed sensor. The cord on the left is the 110 Volt ac power cord.

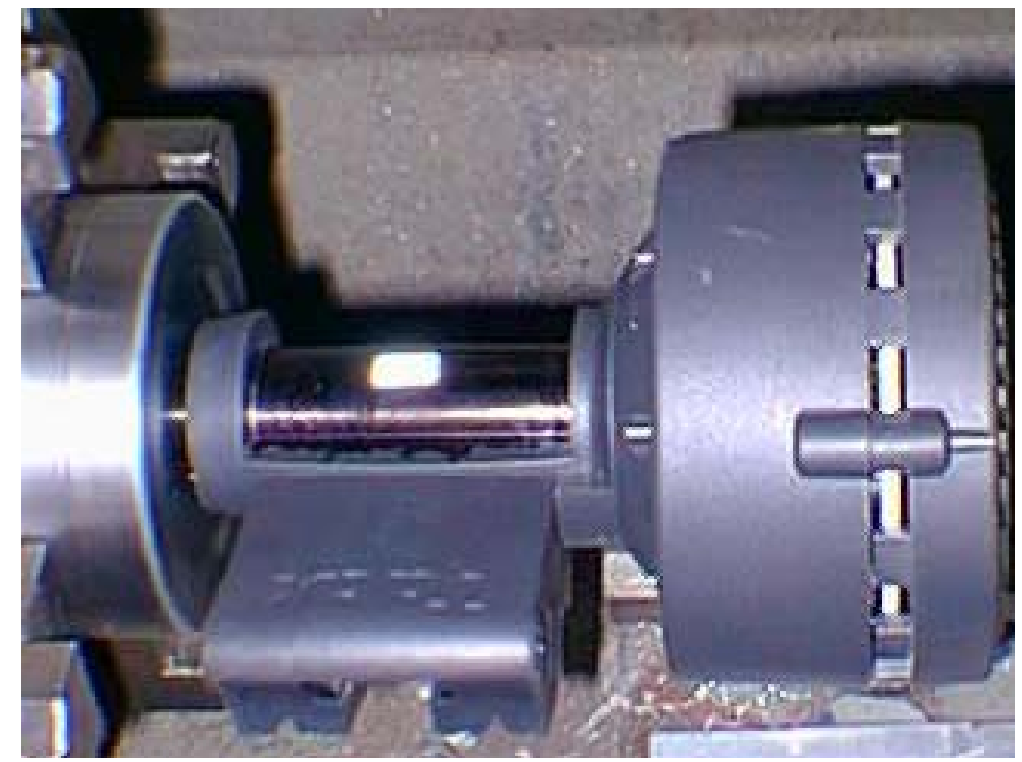

Figure 3. Magnetic resistance unit.

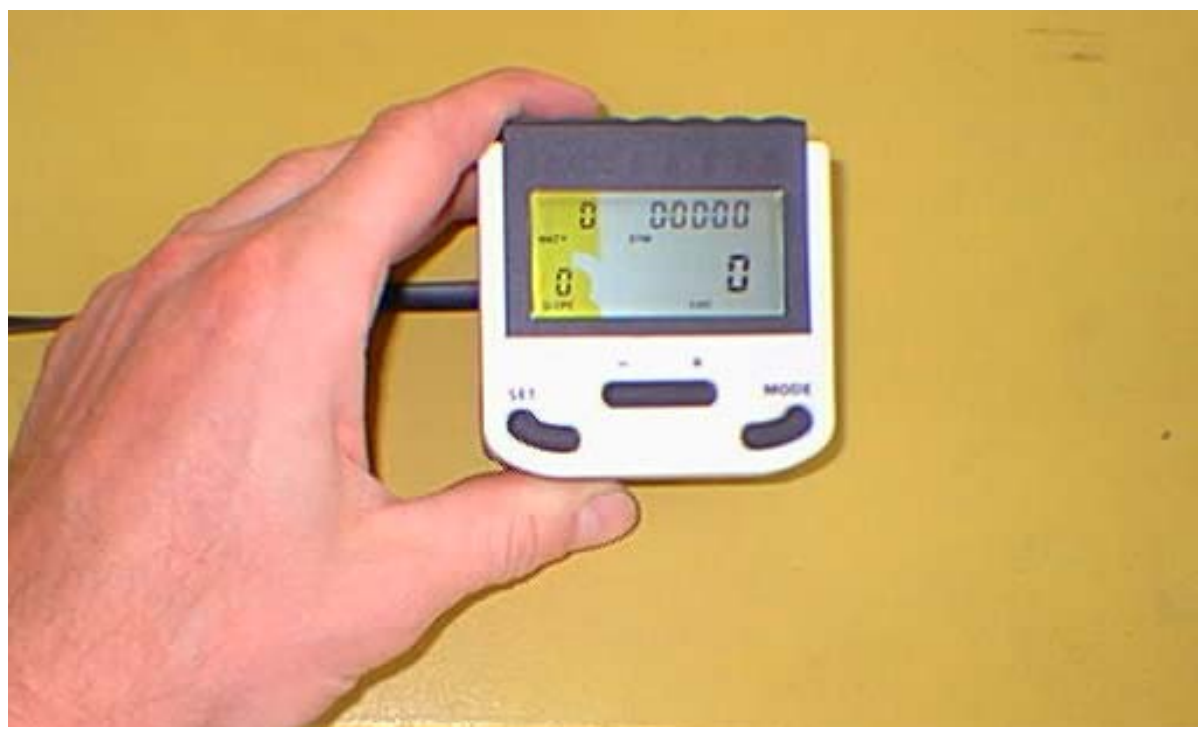

Figure 4. Computer input/display module. 


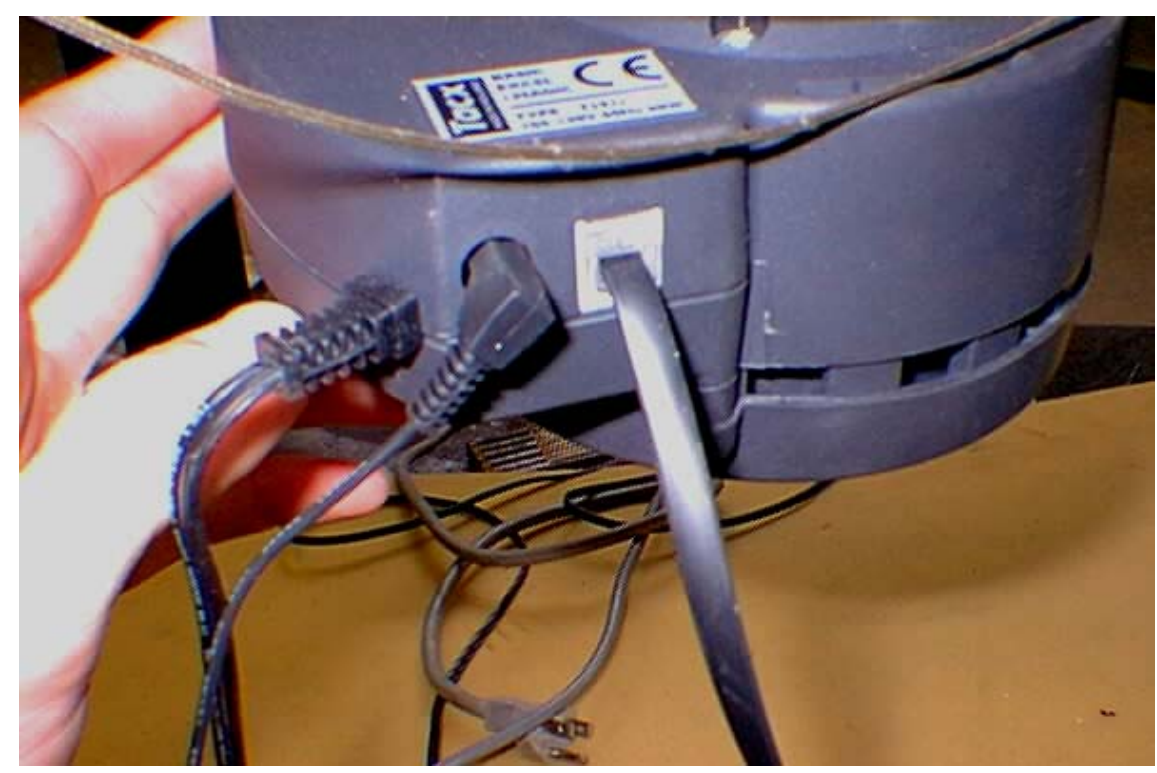

Figure 5. Magnetic resistance unit connectors.

The pedaling resistance is controlled by pushing buttons on the computer input/display module. The power output at the rear wheel of the bicycle is given by

$$
P=T \omega
$$

where $\mathrm{P}$ is the power in Watts, $\mathrm{T}$ is torque in $\mathrm{N} \cdot \mathrm{m}$, and $\omega$ is angular speed in $\mathrm{rad} / \mathrm{sec}$. Equation 1 was applied to the small steel shaft of the resistance unit for all calculations. The magnetic resistance unit works as a brake to control resistance at the rear wheel of the bicycle. The unit is designed to vary resistance with speed to maintain a constant cycling power output by adjusting the braking effect the resistance unit imparts on the steel shaft. The internal RPM sensor, mounted inside the control module and not visible from the outside, senses the shaft speed and adjusts the resistance according to the sensed shaft speed and the programmed power of the input/display module. Referring to Equation 1, as the speed of the shaft increases the braking torque provided to the shaft by the resistance unit and circuitry must decrease in order to maintain a steady overall power rating. The goal of these preliminary tests was to regulate torque at different speeds, while operating within the range similar to the range used during data collection.

Two unique test configurations were arranged to verify the reliability and accuracy of the resistance device. The low-speed setup was arranged on a lathe, with the flywheel of the magnetic resistance device clamped directly into the four-jaw chuck. The high- 
speed arrangement took place at a thick steel table with the resistance device mounted vertically underneath the table and spun by the flywheel, through the table, via a custom adapter mounted in a plunge cut router.

The basic method for recording the braking power of the resistance unit was the same for the lathe setup as it was for the router setup. The distance from the center of the magnetic resistance unit shaft to a point on the plastic housing was recorded. The shaft was then spun at varying rates while the outer housing was prevented from rotating by a force transducer acting through a known lever arm. The force transducer value, multiplied by the known distance between the transducer and the center of the shaft resulted in a calculation of braking torque. Torque was calculated using

$$
T=F d
$$

in which $\mathrm{T}$ is torque in units of $\mathrm{N} \cdot \mathrm{m}, \mathrm{F}$ is force in units of $\mathrm{N}$, and $\mathrm{d}$ is distance from the force transducer to the center of the resistance unit shaft, in meters. The measured torque was combined with the measured shaft speed to calculate power output. Calculated power was then compared to the expected power setting, that which was programmed into the input/display module, to see if the device indeed produced the expected power rating.

Calculations indicated the magnetic resistance device required testing at a rotational speed of about 8000 RPM to best simulate the speeds the research subjects would later pedal. Calculations used to determine the needed shaft speed and torque are displayed in Appendix I. It is important to note that the rotational speed of 8000 RPM refers to the speed of the small steel shaft on the resistance unit, not the rotational speed of the bicycle rear wheel, nor the bicycle crank speed. A lathe was readily available in the mechanical engineering workshop and was used to collect some preliminary torque and resistance data. The lathe worked well for a first try, to make sure the strain gage force transducer was effective, but the lathe had an upper rotational speed limit of about 2000 RPM, so another approach was formulated. An electronic plunge router was later used to reach more appropriate speeds of up to 10,000 RPM for high-speed testing.

The force transducer used in testing and verification was made from a steel bar of $3.175 \mathrm{~mm}$ (0.125 inches ) thick by $25.4 \mathrm{~mm}$ (one inch ) wide and $304 \mathrm{~mm}$ (12 inches ) 
long. The bar was instrumented with two axial strain gages (model CEA-06-240UZ-120, Measurements Group, Inc., Raleigh, NC) on one side and two axial gages on the other. The transducer was calibrated in the range needed for the testing (see Appendix I) i.e. 2.2 to $18 \mathrm{~N}$ ( $0.5 \mathrm{lbf}$ to $4 \mathrm{lbf}$.) by hanging dead weights on the end of the bar. The strain gage bar can be seen in Figure 8. Each strain gage was $5 \times 10 \mathrm{~mm}$ rectangular in size and of $120 \Omega$ resistances. Strain gages were attached to a model 2120 Wheatstone bridge circuit with shunt resistors (Measurements Group, Inc., Raleigh, NC), shown in Figure 9, and balance unit powered by a model 2110 amplifier of the same manufacturer, also shown in Figure 9. Voltages were read from the bridge circuit with a model 54600A 2-channel $100 \mathrm{MHz}$ digital oscilloscope (Hewlett Packard, Palo Alto, CA).

Shaft speed was registered via a TACH-IV model IVR optical sensor (Monarch, INC, Amherst, NH). The shaft was painted matt black to prevent errant reflections from interfering with the optical sensor. A small rectangular reflective strip of $15 \times 15 \mathrm{~mm}$ was placed on the shaft. The optical sensor was "aimed" at the reflective marker so that each time the reflective tape rotated to face the sensor a pulse was recorded within the RPM sensor and compared to a $20 \mathrm{MHz}$ clock for calculation of shaft speed. The RPM display is shown in Figure 6 with the remote sensor shown in Figure 7.

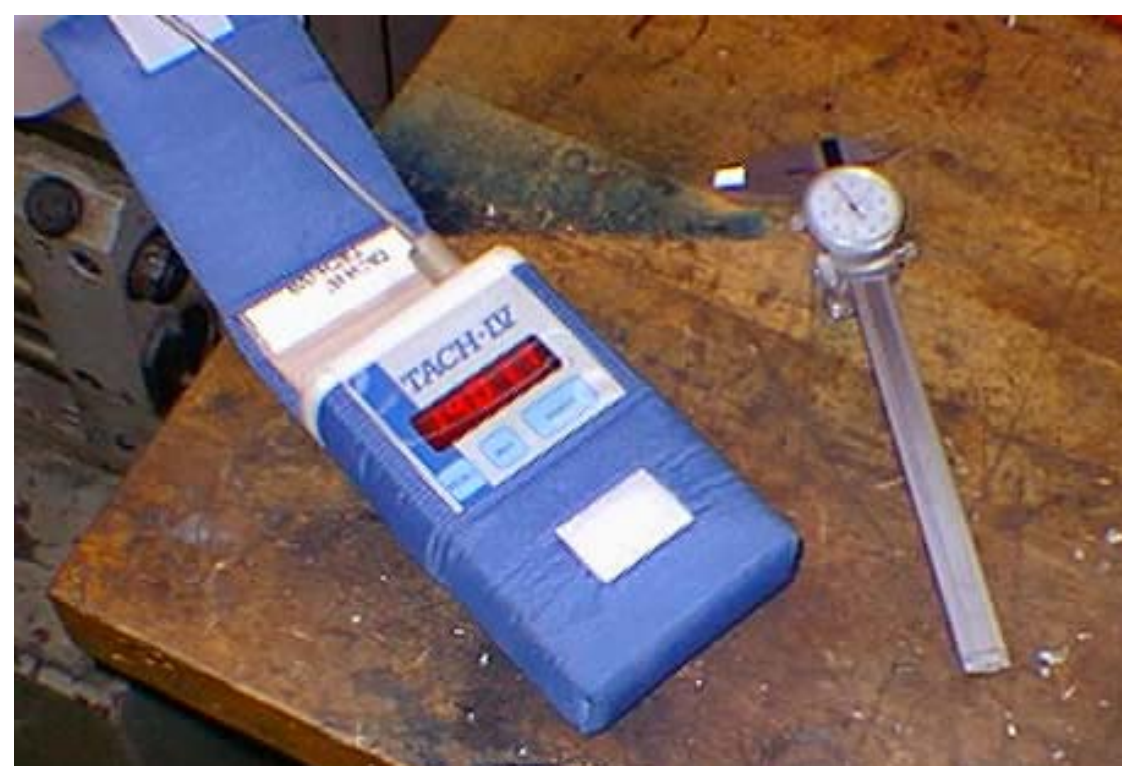

Figure 6. Optical shaft speed display. 


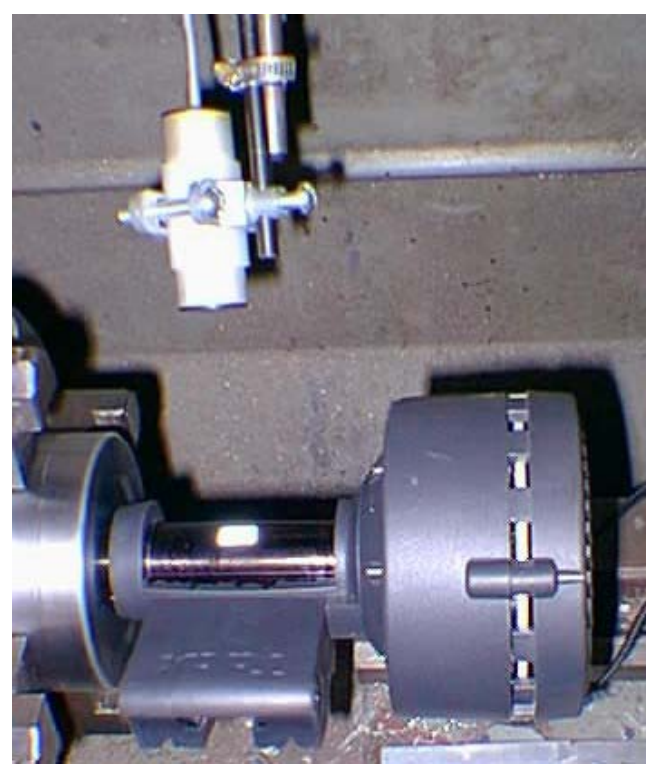

Figure 7. Optical shaft speed sensor. The reflective marker reflected light back to the sensor and compared this pulse to a $20 \mathrm{MHz}$ clock for RPM calculation.

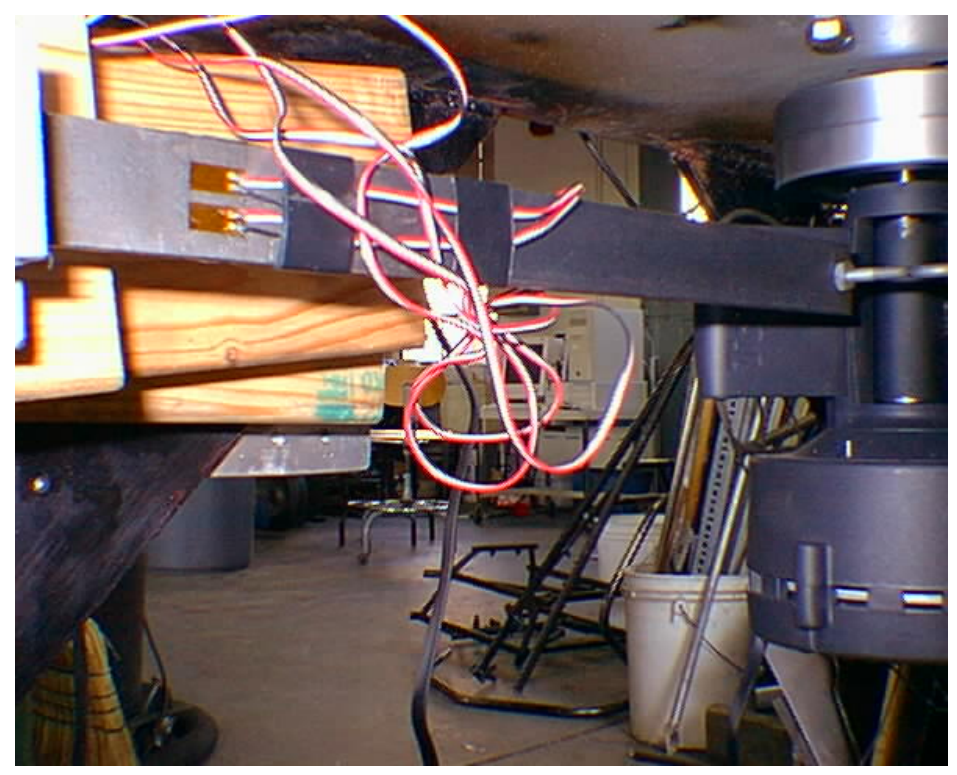

Figure 8. Strain gage force transducer. Transducer was made with four axially mounted strain gages on a steel cantilever beam. The force transducer was clamped on the left and subject to a force on the right due to the braking action of the resistance unit. 


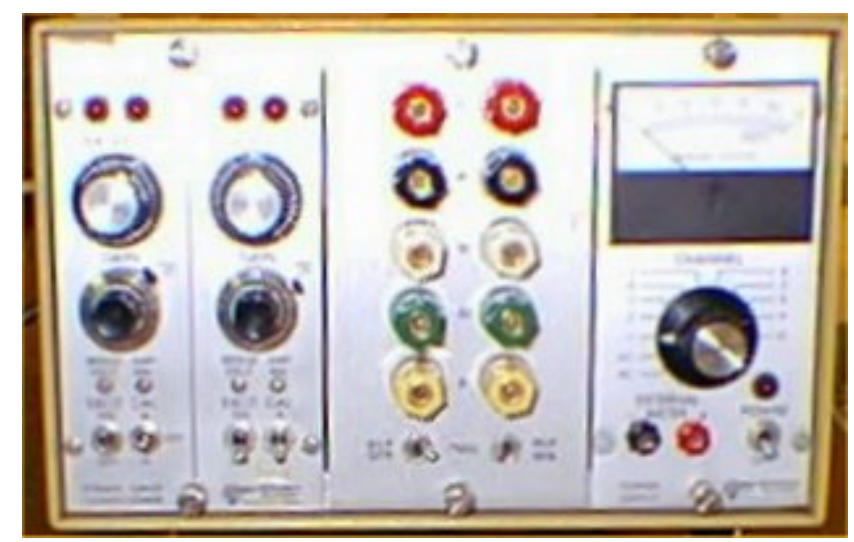

Figure 9. Wheatstone bridge circuit and amplifier.

\section{Router Apparatus for Testing Magnetic Resistance Unit}

A commonly available DeWALT DW 625 electronic plunge cut router (DeWALT Industrial Tool Company, Baltimore, MD), visible in Figure 10, was used to spin the magnetic resistance unit to the speed of over 8000 RPM. These speeds were needed to evaluate the braking power of the magnetic resistance unit within the power and speed range the subjects were anticipated to perform.

The router had a 120 Volt /15 Amp capacity. The router was designed to be plugged into a common 110 Volt alternating current outlet, but the router was operated on direct current during this study for ease of control. The router was controlled via a model D2000-3E Luxtrol controller (Superior Electric Corporation, Bristol, Connecticut). The ac output of the Luxtrol was run through a model KBPC35-06-6W, 600 Volt and 35 Amp, portable bridge rectifier to change the ac voltage to dc voltage.

A large steel table with a $1.27 \mathrm{~cm}$ (0.5 in.) thick steel surface was used to mount the router for magnetic resistance unit testing. A $7.6 \mathrm{~cm}$ (3 in.) diameter hole was drilled through the steel table for the placement of the router motor. After clamping the router motor to the table, as in Figure 13, the internal electronic variable-speed controller was disabled and bypassed by the Luxtrol controller. The wiring to the brushes of the motor had to be reversed in order to get the motor to rotate in the opposite direction. The motor was reversed so that the magnetic resistance unit could be tested in the same direction of rotation that it undergoes during use. Rewiring of the router is shown in Figures 11 and 12. 


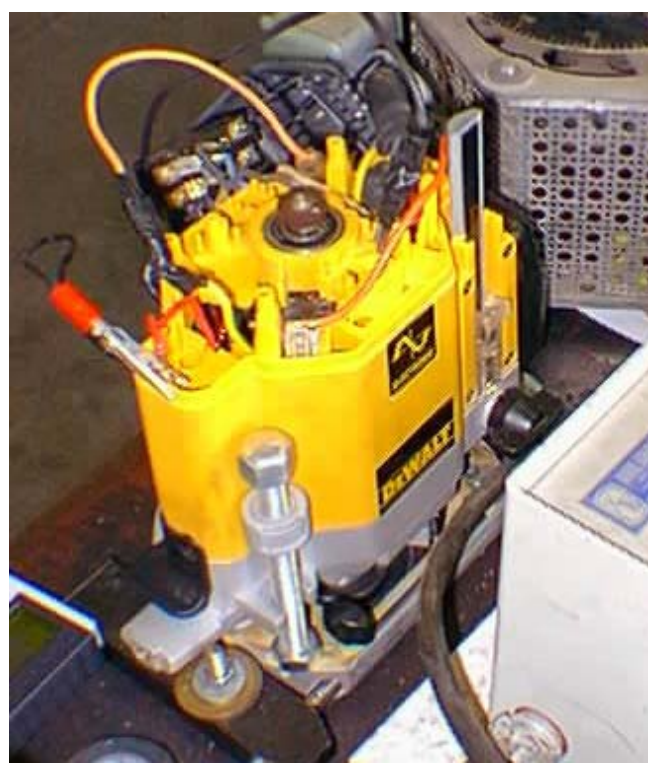

Figure 10. Electronic plunge router used to spin the magnetic resistance unit. The router was chosen because of its ability to reach rotational speeds of up to 22,000 RPM.

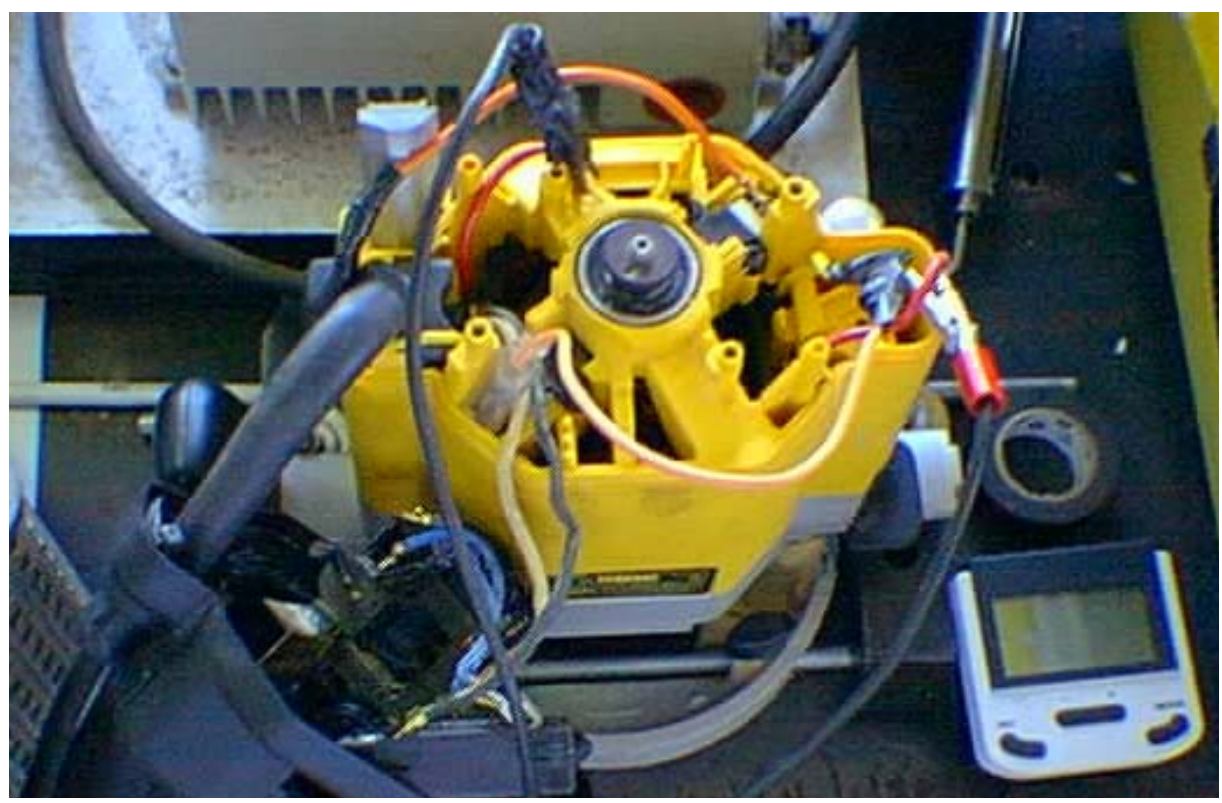

Figure 11. Rewiring of router motor for reverse rotation. 


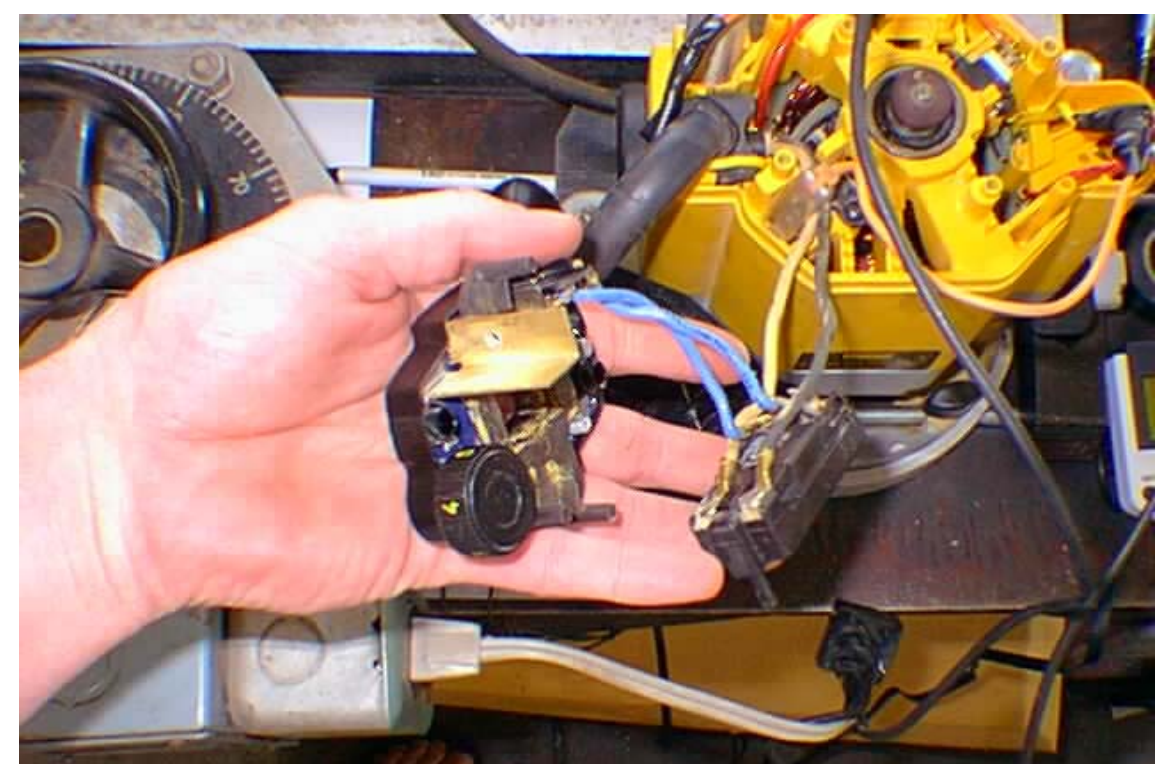

Figure 12. Internal controller bypass.

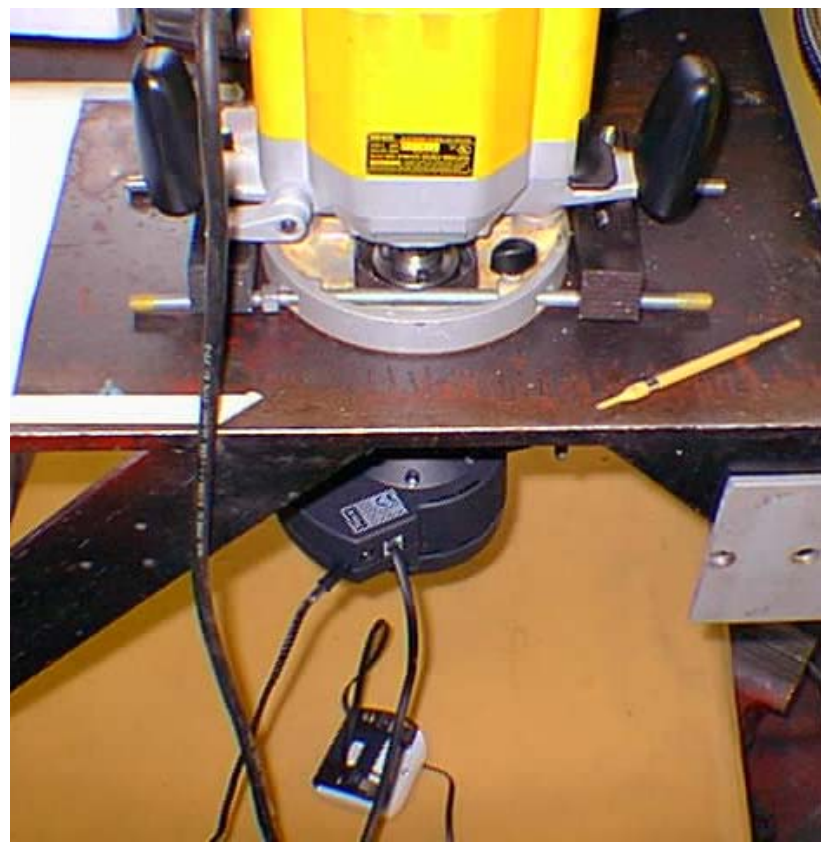

Figure 13. Router affixed to the steel table. The router was secured to the table, and the magnetic resistance unit was attached through the table to the router via a custom machined adapter. 
The adapter used to connect the router to the magnetic resistance unit was custom machined in the mechanical engineering machine shop. The adapter was made using a lathe with a four-jaw chuck to turn a $5 \mathrm{~cm}$ (2 in.) steel rod down to a $1.3 \mathrm{~cm}(0.5 \mathrm{in}$.) shaft on one end while leaving a bolt-on flange on the other. The adapter is shown in Figures 14 and 15.

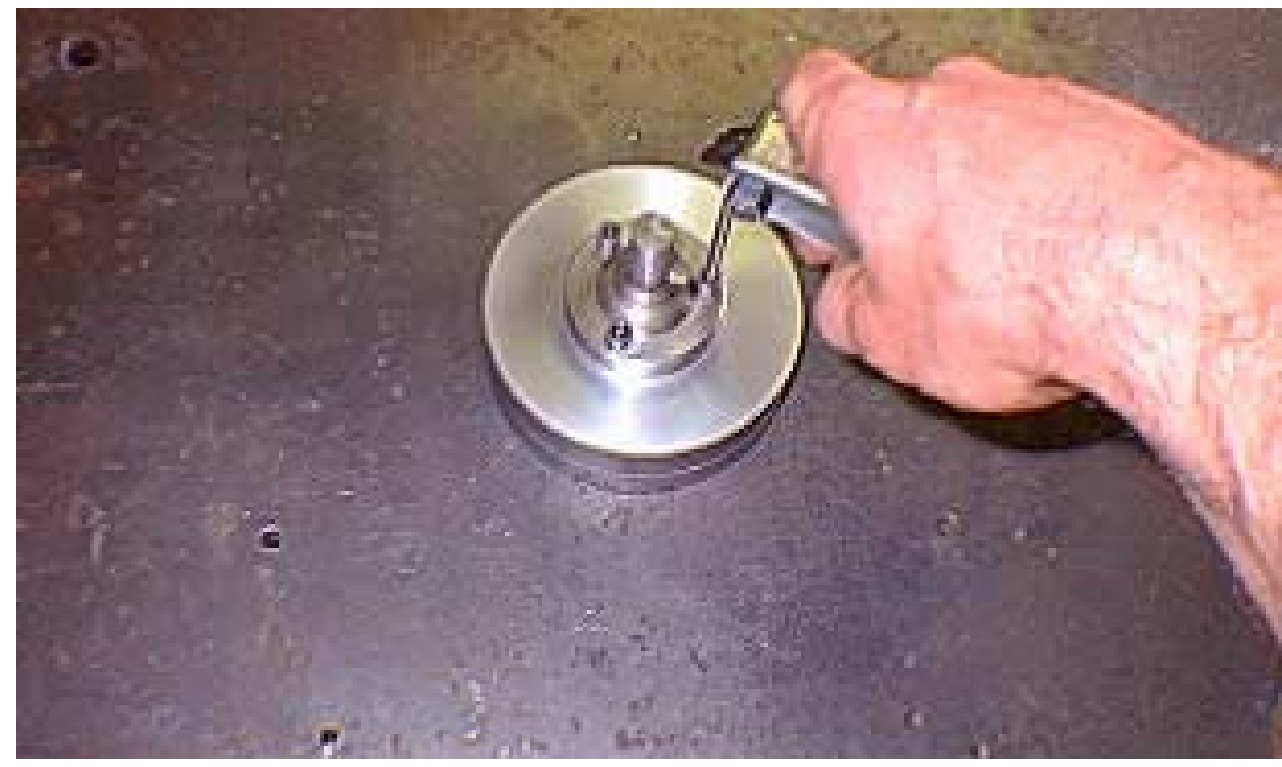

Figure 14. Adapter used to connect the router motor to the magnetic resistance unit.

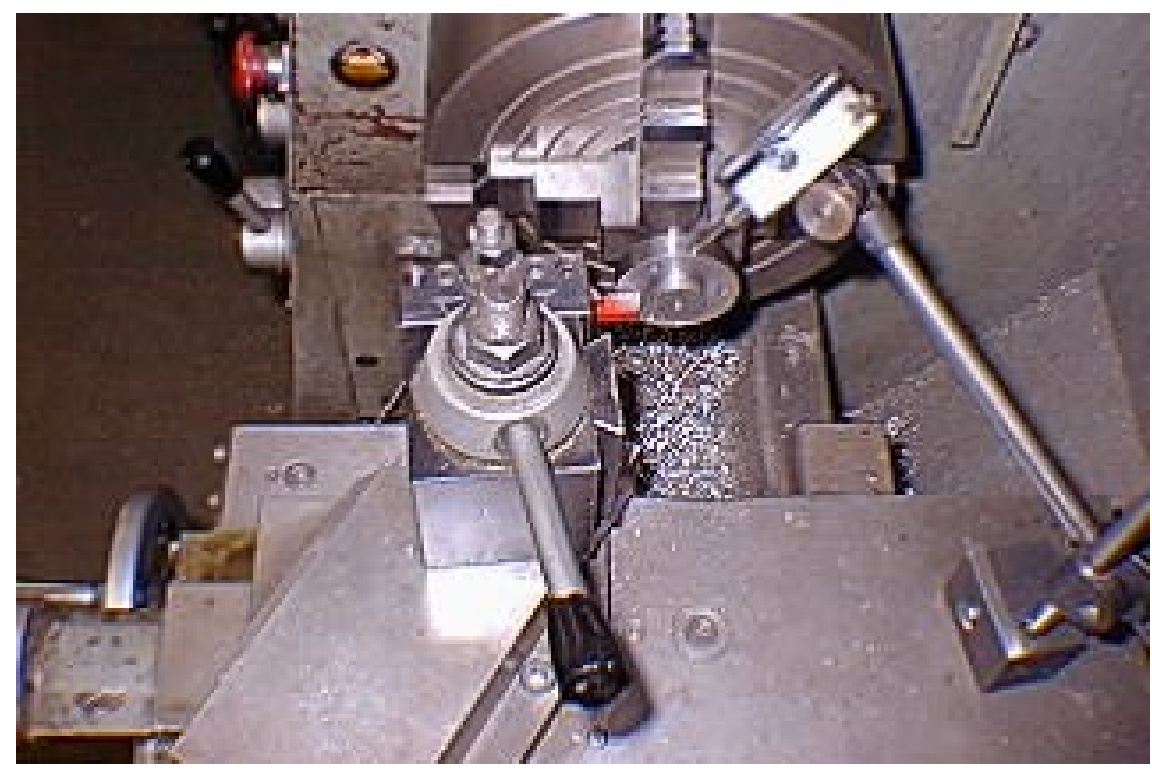

Figure 15. Adapter being turned on a lathe. 
Finally, the router was used at varying speeds to collect data from the force transducer while adjusting the power settings on the input/display module. The calculated power ratings were compared to those target power ratings indicated on the input/display computer module. A view from under the steel table is shown in Figure 16. Preliminary testing was done on a slower speed, on the lathe, as shown in Figure 17.

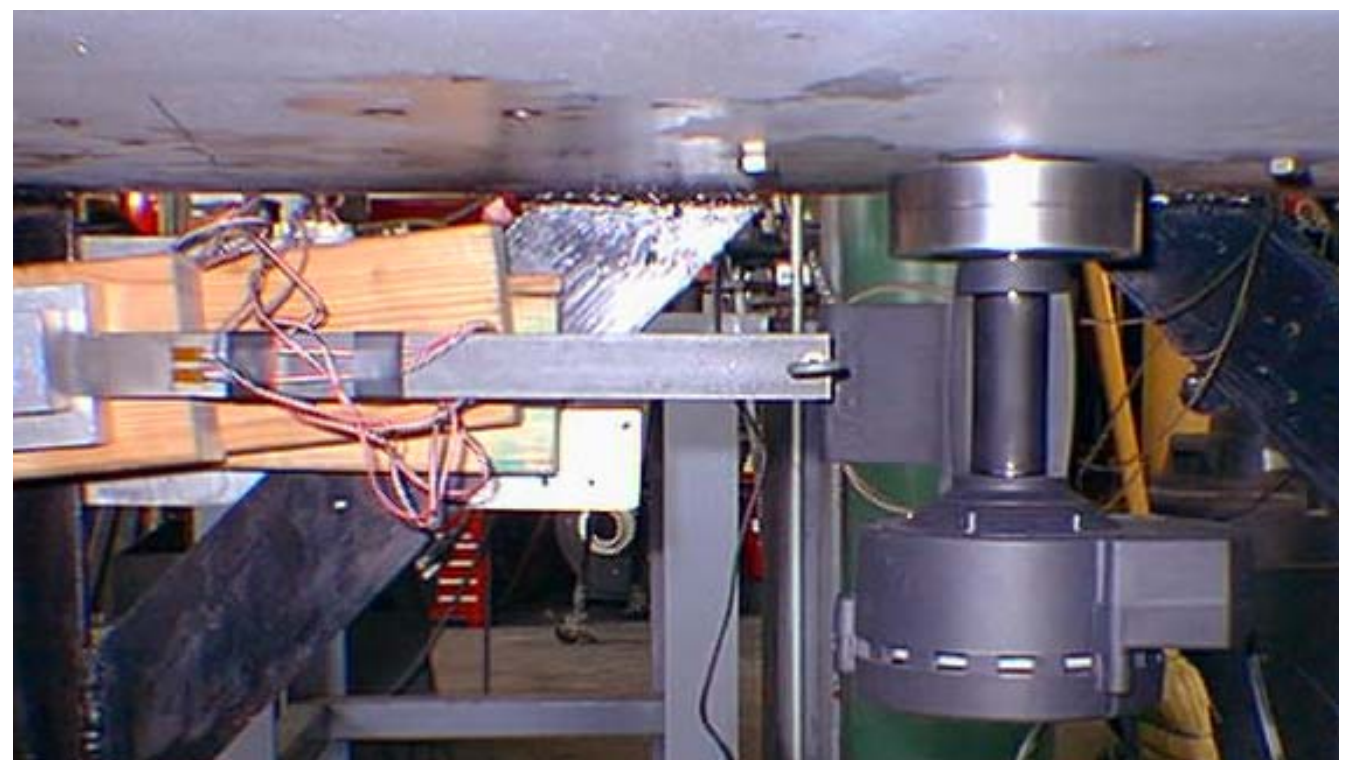

Figure 16. View from under the steel table. The strain gage force transducer is seen on the left. Power rating was calculated using the torque and shaft speed data. The force transducer was clamped by the aluminum blocks on the far left and did not touch the wooden spacers.

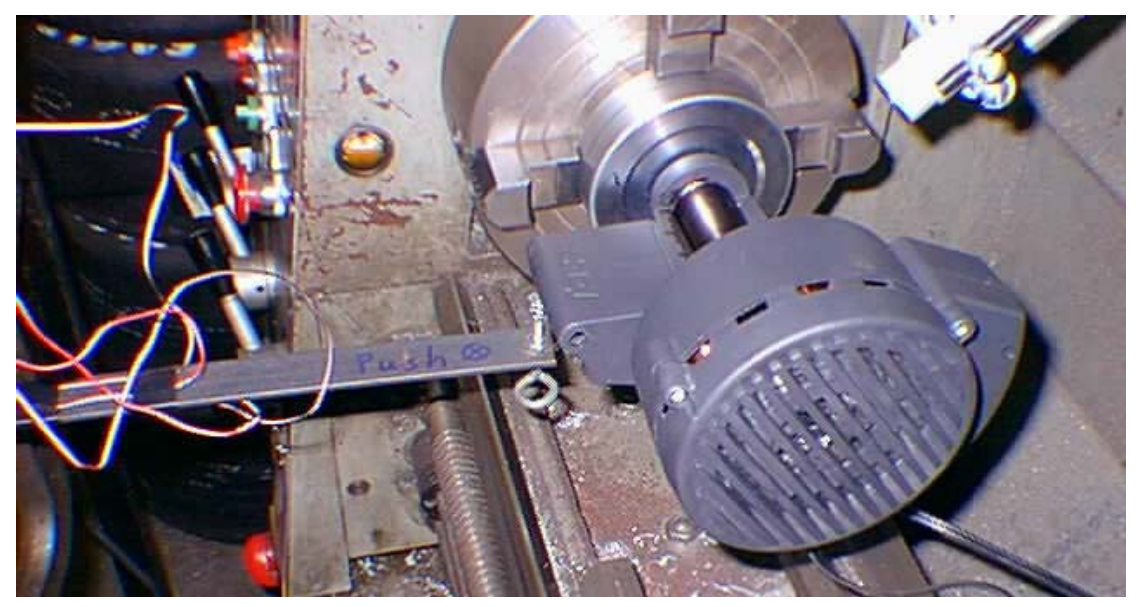

Figure 17. Lathe setup for low-speed testing. The strain gage bar on the left recorded force values as it prevented the plastic housing from rotating under load. The optical RPM sensor can be seen at the top right. 
As data were being collected, it was noted that the magnetic resistance unit was not producing the power resistance values expected. The values indicated on the input/display computer module did not match the measured values. A hypothesis was formulated that the resistance unit circuitry needed input from the crank RPM sensor to calculate power output properly, because wheel speed and crank speed would change if the cyclist changed gears under actual circumstances while training. To examine the crank speed indicator operation and its effect on power production, a crank simulator device was constructed.

The crank was simulated with a wooden dowel rod, shown in Figure 18, and a variable speed electric motor. The simulated crank was rotated by a $1 / 8$ horsepower electric motor (Boston Gear, a North American Rockwell company, Quincy, MA) shown in Figure 19. The speed of the simulated crank was controlled by a Radiotrol model DV2 variable speed motor control (Karol Warner, INC. Highland Park, NJ.). The crank sensor was attached with the stationary sensor held motionless and the magnet attached to the crank, similar to a bicycle. Even though the simulated crank RPM was set at 90 by using a clock, and the input/display module indicated a crank RPM that matched, no difference in measured power values were noted. It was concluded that the device displays crank RPM as training information for the user but does not use the crank speed indicator for resistance adjustments. The resistance unit uses only the internal RPM sensor within the magnetic unit circuitry to vary the resistance.

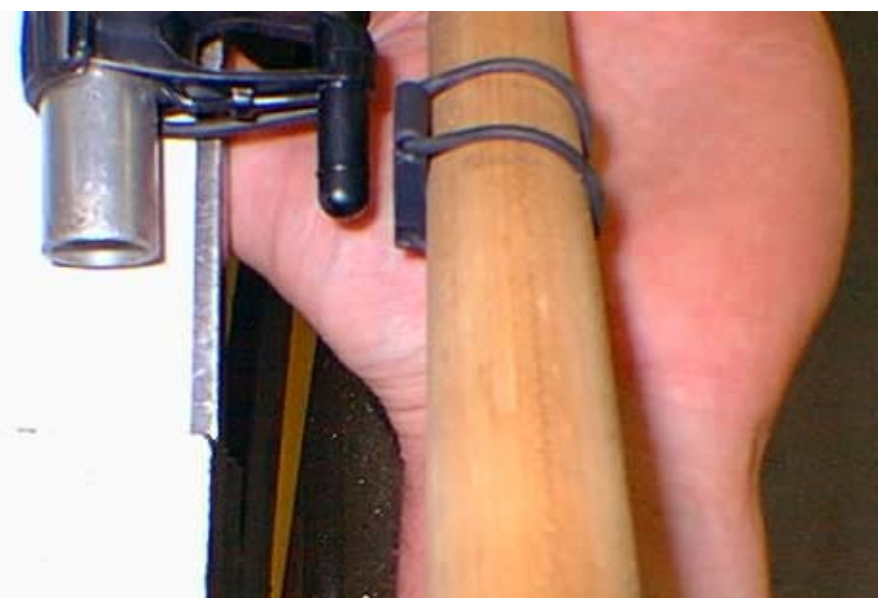

Figure 18. Wooden dowel rod used to simulate a bicycle crank. The device on the left is the crank sensor and the object strapped to the rod is the magnet. 


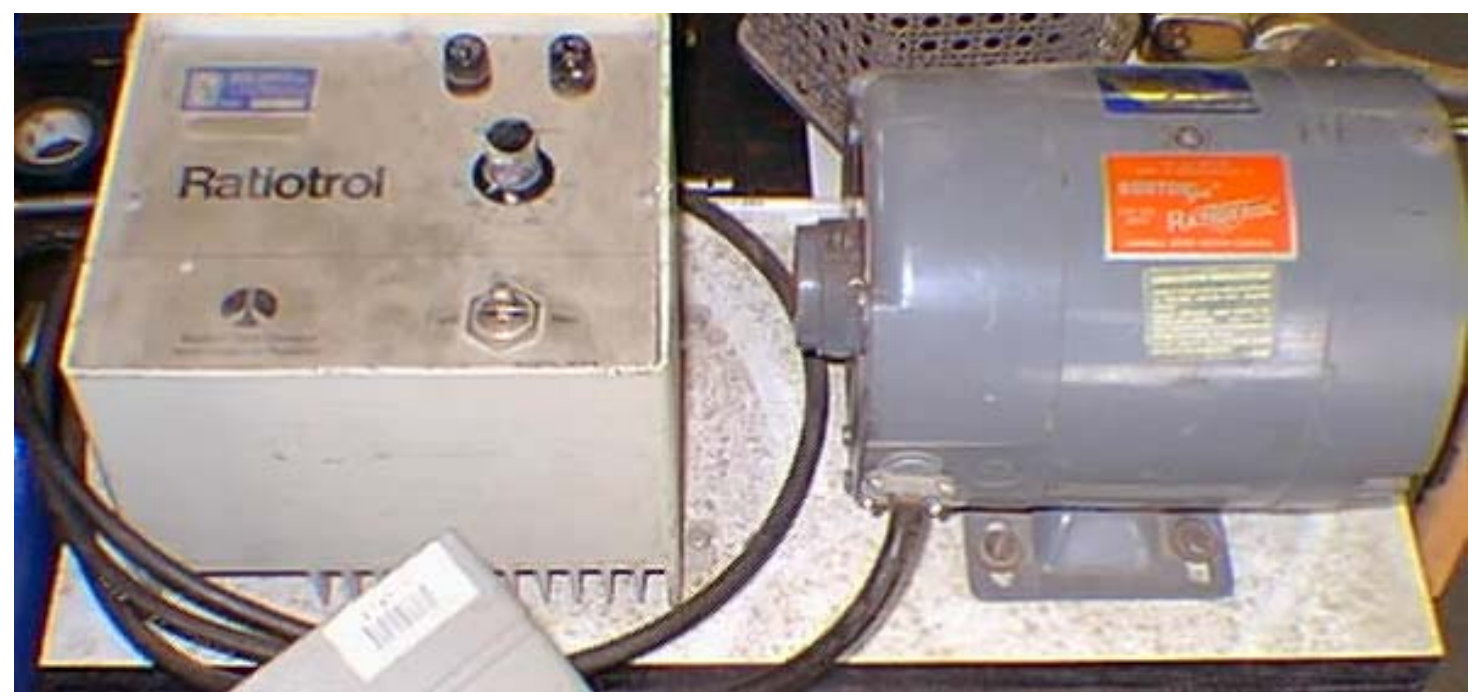

Figure 19. Controller unit and electric motor used to turn the simulated crank mechanism for testing the magnetic resistance unit. The system was adjusted to simulate a 90-RPM crank speed.

\section{B. PLANTAR STRESS MEASUREMENT}

\section{Plantar Stress Data Collection Apparatus}

Two pairs of shoes were tested in this study. Shoes used in this study were Shimano model SH-M152 and SH-M220 (Shimano Corporation, Irvine, CA). The M152 is constructed with a homogeneous plastic sole and the model M220 has a carbon fiber sole. A single Trek 1400 road racing bicycle (Trek Bicycle Corporation, Waterloo, WI) and Tacx Basic stationary training device (Technishe Industrie Tacx BV, Wassenar the Netherlands) were used for all testing. The bicycle was equipped with down-tube 7speed index shifting with Shimano 600 Ultegra rear derailleur, Model 105 cranks and 105 front derailleur (Shimano Corporation, Sakai, Japan). Modolo (Industry Drive, San Vendiamo, Italy) $135 \mathrm{~mm}$ handlebar stem and aluminum handlebars were used. A Salsa saddle (Salsa Cycles, Bloomington, MN) was used along with Time Attack Carbon pedals and cleats (Varennes-Vauzellas, France). Plantar stress measurement insoles are seen in Figure 20.

A Pedar capacitive sensor array insole system (Novel Electronics, Minneapolis, MN) was used to collect plantar stress data. Pedar insoles, shown in Figure 20, contain 99 capacitors each calibrated to change capacitance based on the force applied. The 
electronic amplifier unit, seen above the shoe, was placed near subjects' posterior beltline. Wires were routed along subjects' legs by felt straps secured with Velcro tabs.

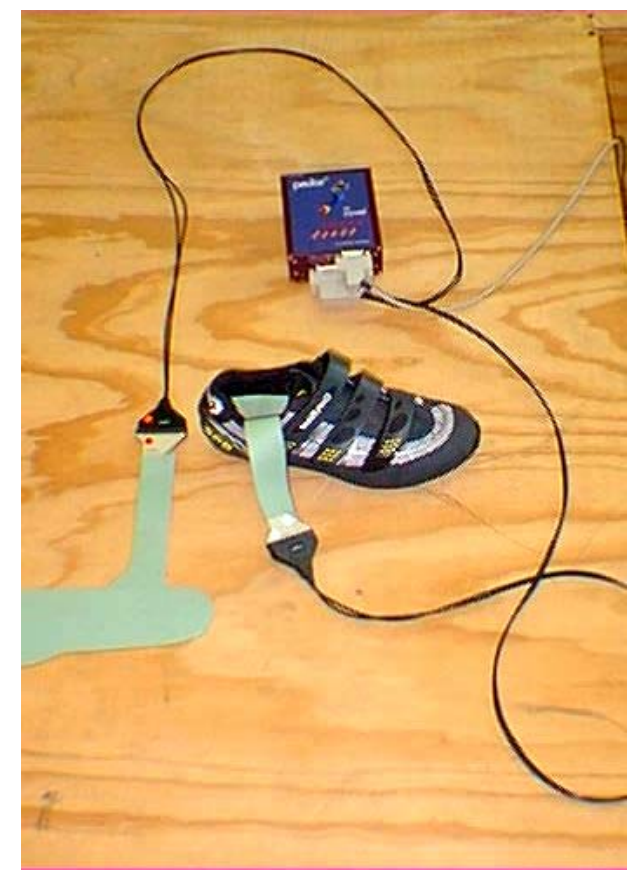

Figure 20. E-med Pedar insoles.

The Tacx magnetic resistance trainer unit was placed in contact with the bicycle wheel for plantar stress data collection. The trainer has an adjustment knob that adjusts the position of the steel axle relative to the bicycle rear tire. To minimize variation due to frictional effects of the tire on the axle, a set position on the adjustment knob was maintained throughout the study. Furthermore, prior to each data collection, air pressure in the rear tire was adjusted to $689.5 \mathrm{kPa}$ (100 psi) to further control the friction between the rear tire and the magnetic resistance unit for greater consistency. Figures 21 and 22 show the bicycle and resistance unit. 


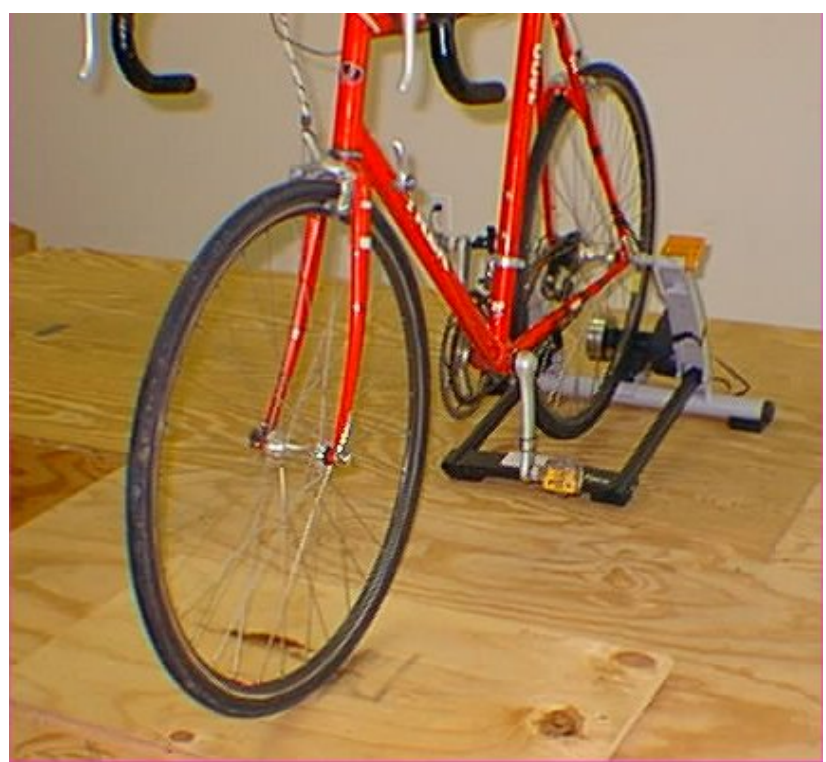

Figure 21. Bicycle and Tacx magnetic resistance unit.

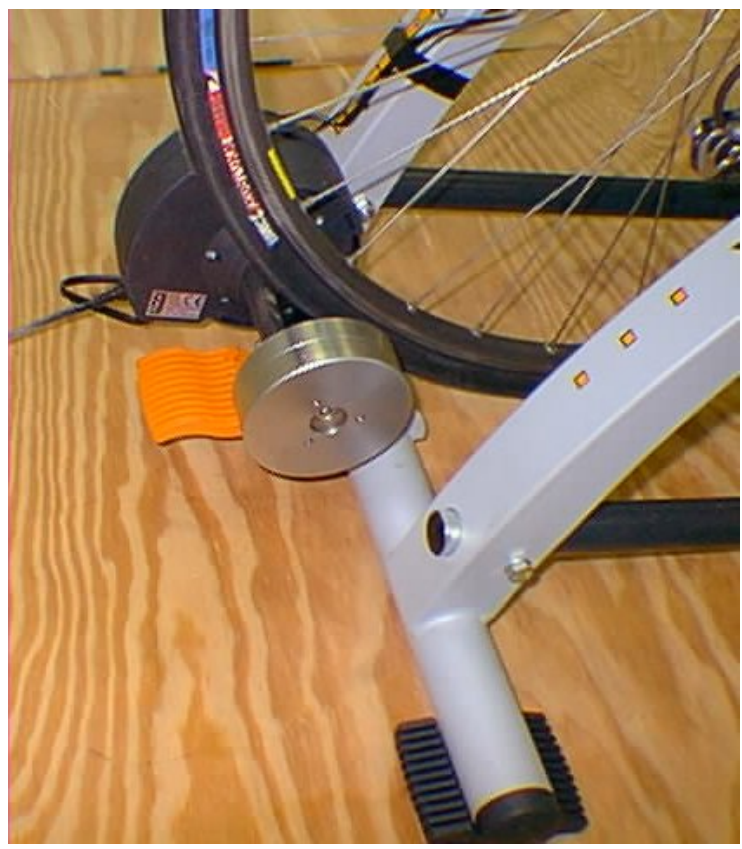

Figure 22. Bicycle rear wheel in contact with magnetic resistance unit.

\section{Plantar Stress Data Collection Protocol}

Ten subjects were invited to participate in this research study. Subjects' age ranged from 22 to 37 years of age. Subject 2 was left-handed while the rest were right-handed. Table 1 provides a more thorough summary of human subjects' demographic 
information. No subjects were competitive cyclists, but several had recreational cycling experience.

\begin{tabular}{|c|c|c|c|c|}
\hline \multicolumn{5}{|c|}{ Table 1. Human subject characteristics. } \\
\hline Subject & $\begin{array}{c}\text { Age } \\
\text { (years) }\end{array}$ & $\begin{array}{c}\text { Height } \\
\text { (Meters) }\end{array}$ & $\begin{array}{c}\text { Weight } \\
\text { (Newtons) }\end{array}$ & $\begin{array}{c}\text { Cycling } \\
\text { experience } \\
\text { (years) }\end{array}$ \\
\hline 1 & 24 & 1.63 & 645 & 1 \\
\hline 2 & 28 & 1.80 & 845 & 0.5 \\
\hline 3 & 22 & 1.75 & 734 & 1 \\
\hline 4 & 25 & 1.73 & 778 & 1 \\
\hline 5 & 37 & 1.70 & 775 & 0 \\
\hline 6 & 35 & 1.68 & 668 & 4 \\
\hline 7 & 26 & 1.70 & 734 & 1 \\
\hline 8 & 24 & 1.73 & 712 & 1.5 \\
\hline 9 & 32 & 1.75 & 823 & 3 \\
\hline 10 & 30 & 1.75 & 765 & 0 \\
\hline
\end{tabular}

All subjects who took place in the study signed a human subject informed consent form reviewed by the Human Subjects Committee (HSC) of the Institutional Review Board (IRB) per University of Louisville policy. The study took place in room 304 of Lutz Hall on the University Belknap Campus. Subjects stood, without shoes, while the distance from the floor to the bony projection on the outside of the hip (greater trochanter) was measured. Seat height was then located at a level $96 \%$ of the greater trochanter height for consistency. Subjects were then asked to put on a pair of cycling shoes with pressure measurement insoles placed inside each shoe. The wires from the insoles were strapped to subjects' legs before subjects mounted the bike so that the wires did not tangle or catch in the bicycle. Subjects were then asked to pedal at a leisurely speed for about 10 minutes to "warm up."

Prior to each ten-second data collection trial, subjects stopped pedaling for a moment while the Pedar insoles were "initialized." Insoles were initialized before each trial by having subjects "clip out" from the clipless pedals and position their feet freely in space, unloaded and away from the bicycle. Initializing was done to account for the compression preload on the insoles caused by the foot being secured inside the shoe by 
the lacing system. A zero force level was established with the foot at rest under no applied external load, yet with the shoes' three-strap Velcro lacing system secured.

The stationary trainer was then set at a level of 400 watts, making the bicycle more difficult to pedal than during the warm-up. Subjects were asked to pedal at this more difficult level for about ten seconds while maintaining a crank speed of 90 RPM (as indicated on a visual display). Subjects then rested for five minutes by either pedaling lightly at a reduced resistance or by remaining motionless atop the bicycle. The rest period was followed by another ten-second data collection at 400 Watts, followed by another 5-minute rest, and then a final ten-second data collection. The entire sequence was then repeated with the second pair of cycling shoes. After data collection was completed for three ten-second intervals, in both types of shoes, subjects departed.

Participation time was about forty minutes per subject, including warm-up, data collection periods, and time spent changing clothes before and after testing. There was one data collection session per subject. Some subjects rode with one type of shoe first, and others rode with the other shoe first. The order of testing was determined by random selection of a slip of paper from a hat.

\section{SHOE STIFFNESS TESTING}

The shoes used in this study were Shimano model SH-M152 and SH-M220 (Shimano Corporation, Irvine, CA). The M152 is constructed with a homogeneous plastic sole and the model M220 has a carbon fiber sole. Two pairs of shoes were evaluated. The shoes have identically structured uppers except for the color scheme and heel counter; the outsole, tread pattern, and materials are the same. The fit adjustment method, sizing, and outsole shape and materials are identical. Although no standardized tests have been established for the testing of cycling shoes, the American Society for Testing and Materials maintains standard F-911 that defines methods and fixture dimensions for the testing of running shoe flexibility. A schematic of the test fixture arrangement is visible in Figure 23. This ASTM standard for running shoes was modified for use in this study to test stiffness and damping of cycling shoes. Suggested fixture dimensions and methods for testing of the shoes were taken from standard F-911 and adapted to the cycling shoes. 


\section{Testing Apparatus for Longitudinal Bending Stiffness}

All fixture dimensions defined in ASTM standard F-911 were used, but the maximum flex angle for the testing of cycling shoes was reduced from 45 degrees to 20 degrees to prevent damage to the cycling shoes due to excessive deformation. The actual test fixtures are shown in Figures 24 and 25. A stationary base plate and clamp of specific dimensions affixed the front section of the shoe at a specific location. The front clamp was tightened down upon the shoe in a secure manner to create a fulcrum located at $70 \%$ of shoe length, measured from rear toward the front, as specified in ASTM F-911. The rear of the shoe was clamped lightly in another device of specific shape and size. The rear clamp included a pivot located directly underneath the platform so the entire clamp could pivot as the shoe flexed. A force transducer, different from the one used for magnetic resistance unit testing, was used to measure the force required to flex shoes.

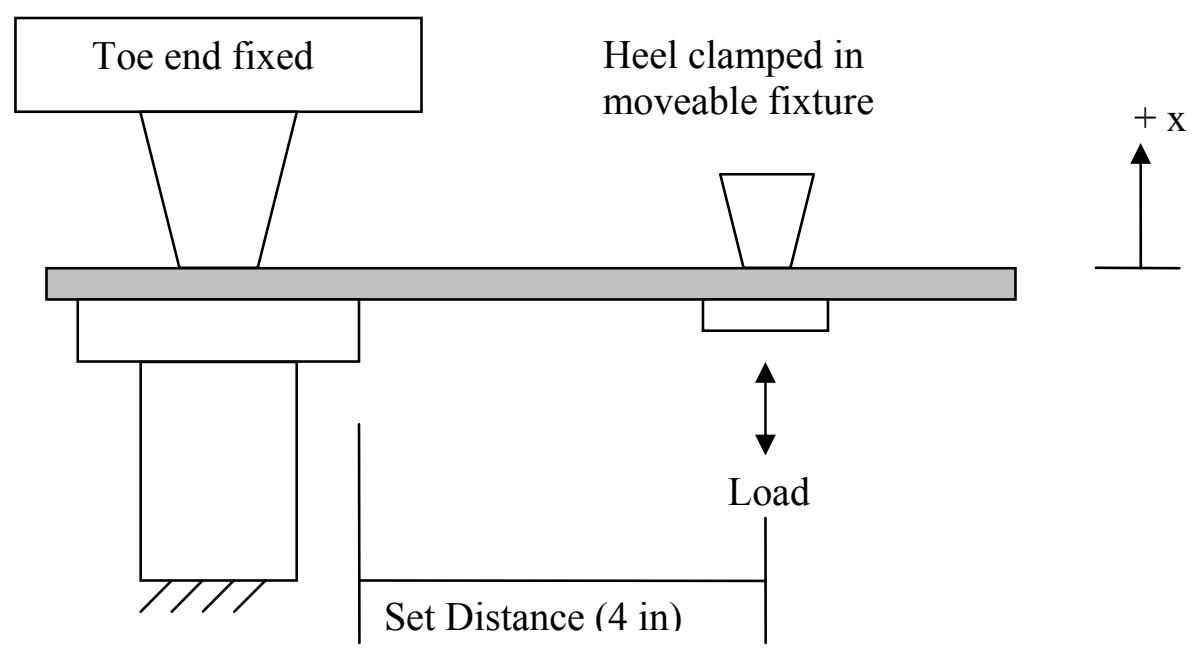

Figure 23. ASTM F-911 shoe testing arrangement. The shaded portion represents the shoe. This test was created for determination of running shoe flexibility, but modified for cycling shoes in this study. 
An MTS machine (Model 810, Material Testing Services, Inc., Minneapolis, MN.), seen in Figures 25 and 26, was used to flex the shoes 2400 times between a minimum and maximum flex angle, as shown in Figure 26. The minimum displacement position was set so that the shoe was under no load (zero force recorded from the force transducer). Maximum displacement occurred when the shoe reached 20 degrees of flexure upward.

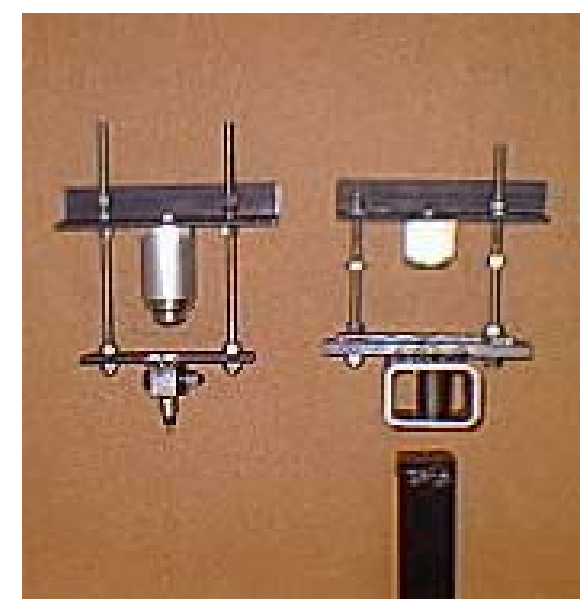

Figure 24. Longitudinal bending test fixtures. The fixtures were constructed per ASTM F-911 test standard.

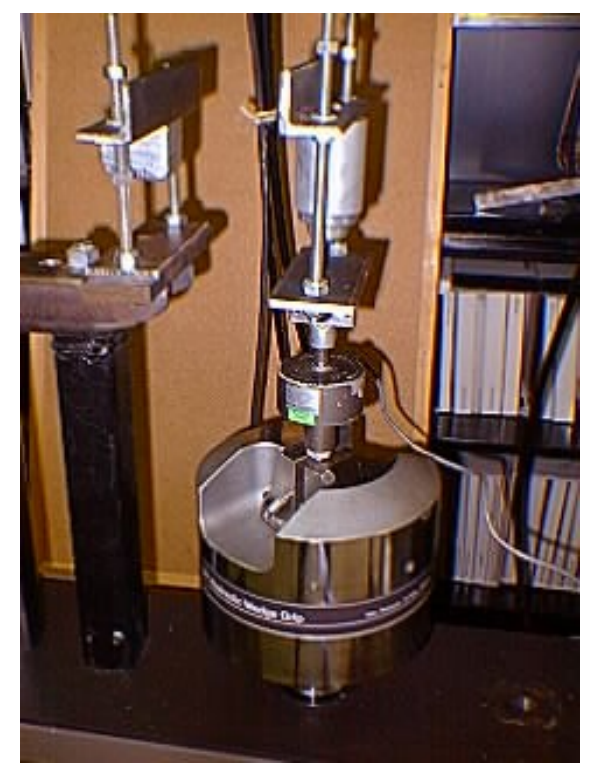

Figure 25. MTS machine in longitudinal bending arrangement. Seen below the fixture is a $200 \mathrm{lbf} .(890 \mathrm{~N})$ strain-gage force transducer. 


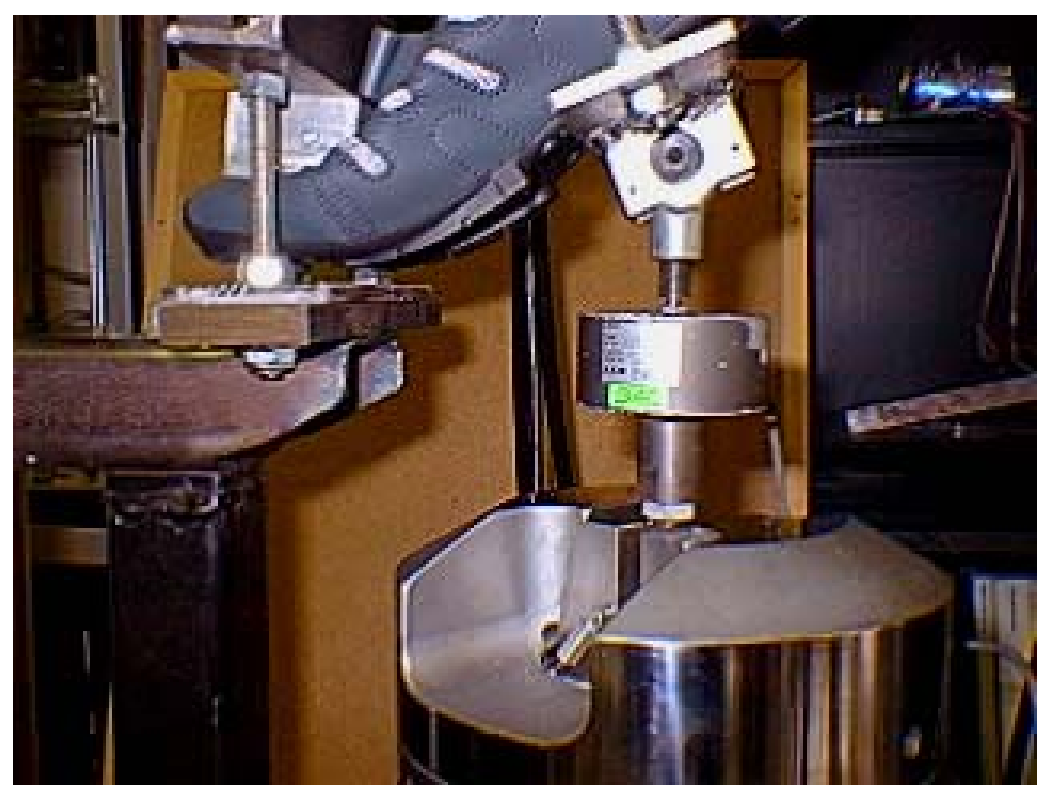

Figure 26. Longitudinal bending arrangement with shoe. Each shoe was flexed to a maximum angle of 20 degrees past the zero flex point.

\section{Testing Apparatus for Forefoot Three-Point Bending Stiffness}

In addition to longitudinal bending, shoes were also tested in a three-point bending arrangement at the forefoot section. Shoes were cycled $1.5 \mathrm{~Hz}$ to simulate a typical 90 RPM crank speed. Force versus displacement curves were created and checked for hysteresis.

A custom three-point bending fixture was machined to test the forefoot stiffness of the shoes. A diagram describing the shape of the testing fixture is included in Figure 27. Photographs of the actual fixture are shown in Figures 28 and 29. Load was applied from underneath the shoe via an actuator, attached to the 0-889 N (200-lbf.) linear actuated transducer, at a point concentrated near the middle of the shoe. The linear force transducer (different than the cantilever beam transducer used for resistance unit testing) is seen in Figure 30. The test fixture was designed in a way that allowed the shoe to deform upward in the center as force was applied. The fixture was designed to function like two cylinders, each with a radius $1.0 \mathrm{~cm}$ (0.394 in.) and length of $5.5 \mathrm{~cm}$ (2.165 in.). Fixture dimensions were chosen so that the fixture would fit inside the shoe and yet would not damage the insoles of the shoes during testing. 
Shoes used in this study are designed specifically for use with "clipless" pedals, meaning that the shoes are designed to lock into place on the surface of the pedals during cycling so that the rider can pull upward on the pedals as well as push downward.

Attachment of each shoe to the pedal is accomplished via a metal cleat that is attached to the bottom of the shoe with two screws. The screws pass through the cleat, through grooves in the shoe outsole, and thread into a factory-provided steel plate on the inside of the shoe.

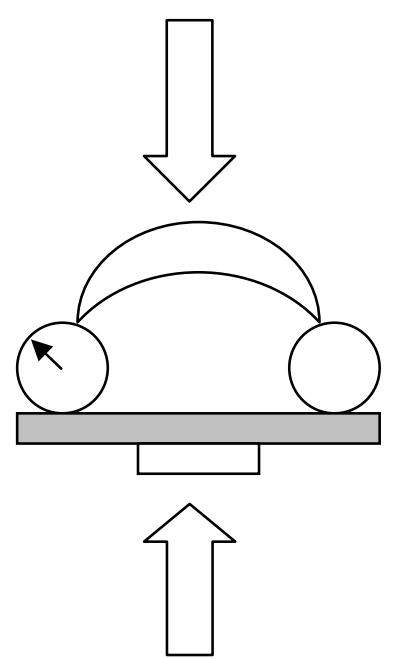

Load applied to cleat

Figure 27. Three-point bending test arrangement. The shaded rectangle represents the shoe midsole. Shoes tested in the three-point bending arrangement were fitted with cleats for use in conjunction with clipless pedals. 


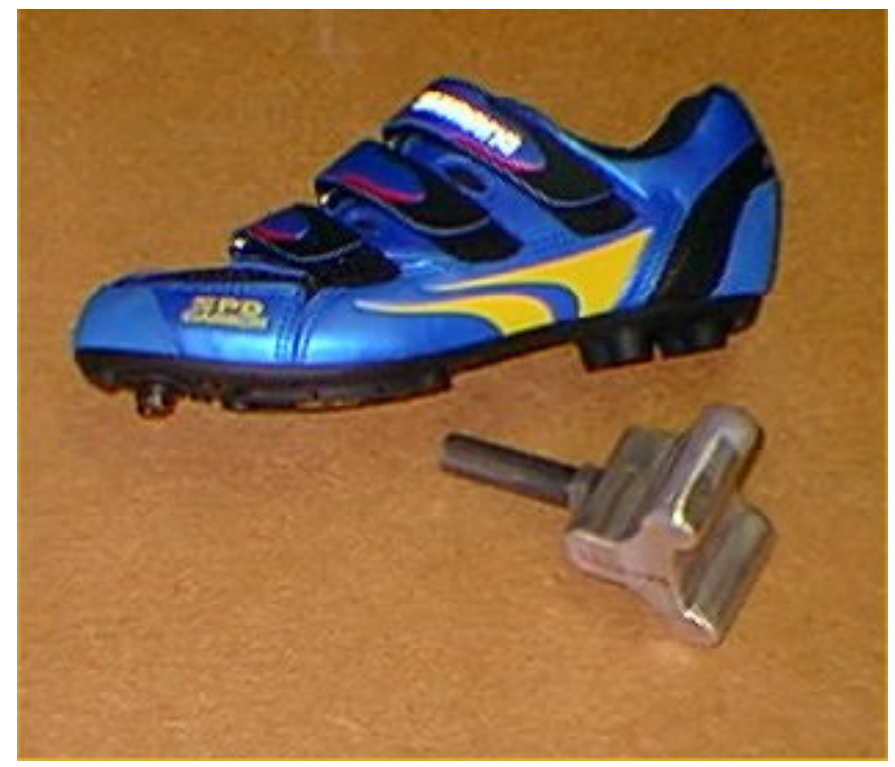

Figure 28. Three-point bending fixture and cycling shoe. Both sides of the fixture were designed as cylinders of radius $1 \mathrm{~cm}$ and length of $5.5 \mathrm{~cm}$ and placed lengthwise in the forefoot of the shoes.

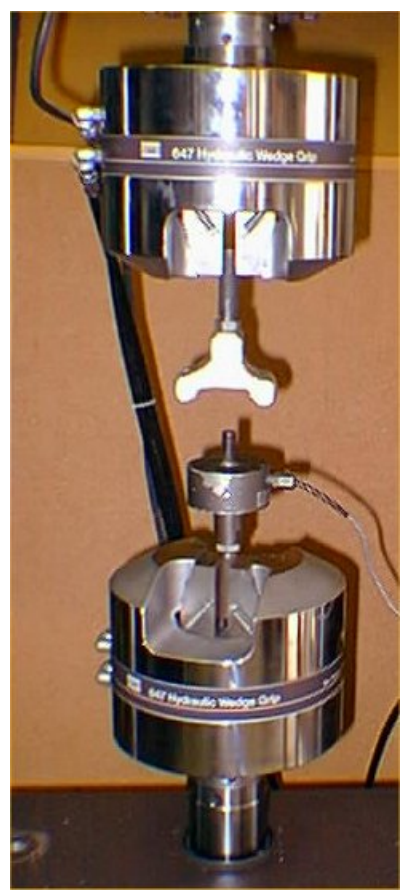

Figure 29. MTS machine in three-point bending. 


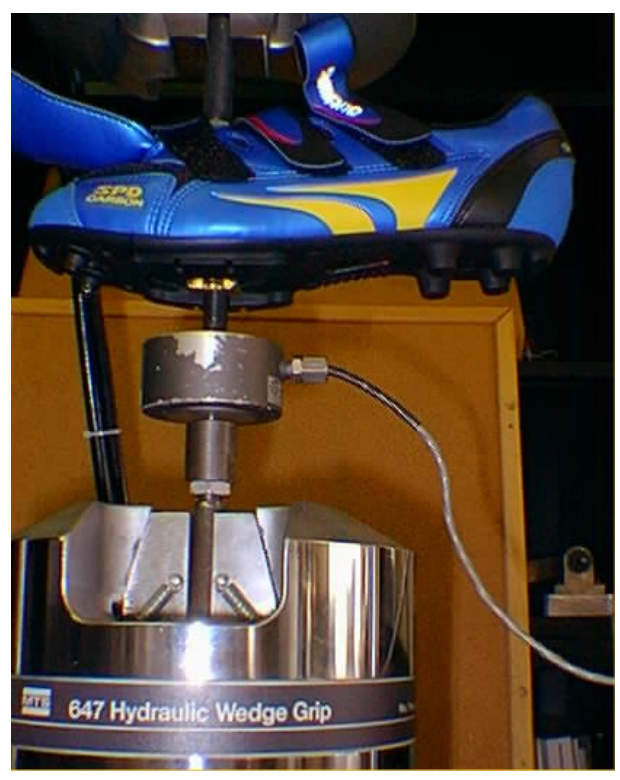

Figure 30. MTS three-point bending arrangement with shoe in place. The fixture was held stationary while the force transducer was thrust upward into the metal cleat.

\section{RESULTS}

\section{A. RESISTANCE DEVICE TEST RESULTS}

The steel bar strain gage force transducer was calibrated before testing by hanging weights on the end of it ranging from $2.2-17.7 \mathrm{~N}(0.5-4 \mathrm{lbf}$.). Weights were applied to the bar via a hook and hanger in the case of the lathe, and by a spring scale in the case of the vertically mounted router. Voltage exiting the Wheatstone bridge configuration was measured using an oscilloscope and plotted versus the force applied, resulting in a linear force/voltage relationship as seen in Figure 31. 


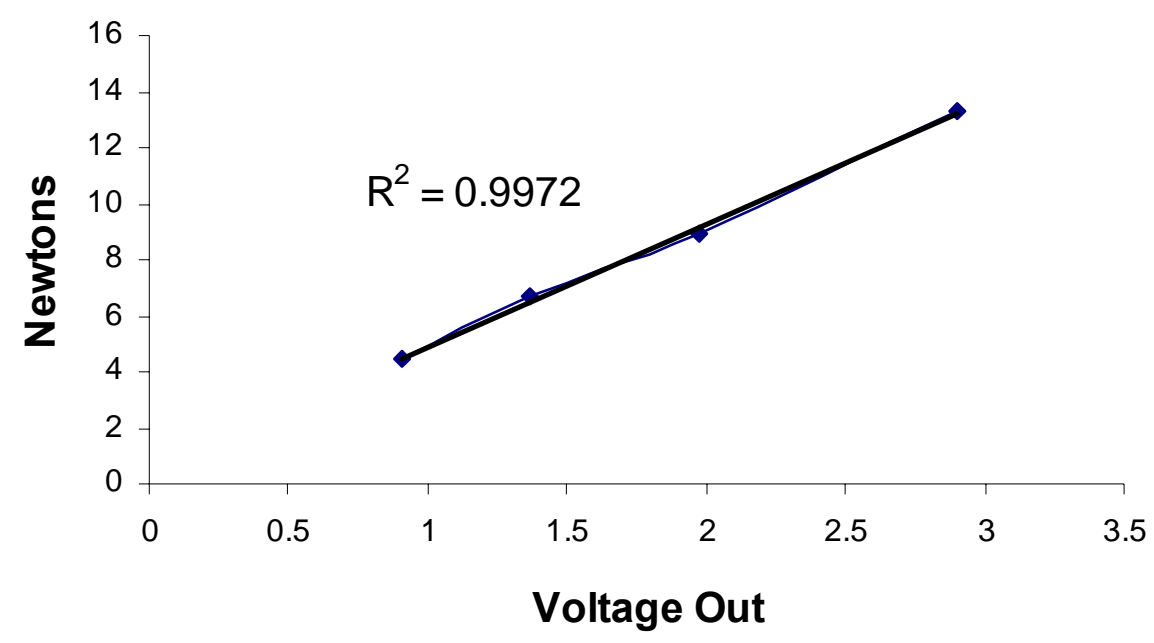

Figure 31. Strain gage force transducer linear calibration. The force transducer was considered linear based on the above data.

The bulk of the trainer test data was placed in Appendix I. Data were collected by recording values, changing speed, recording values again, changing power settings, recording values again, and so on. A select group of data, collected randomly throughout testing using the router setup, at a shaft speed of 8050 RPM and a programmed power output of 400 Watts, is displayed in Table 2. The trainer maintained the power output within $\pm 4 \%$ of the set value as long as the power setting and speed remained constant.

\begin{tabular}{|c|c|}
\hline $\begin{array}{c}\text { Table 2. } \\
\text { Random resistance unit test } \\
\text { results collected at } 8050 \text { RPM. }\end{array}$ \\
\hline Watts displayed & Watts Measured \\
\hline 400 & 213.41 \\
\hline 400 & 203.74 \\
\hline 400 & 230.33 \\
\hline 400 & 213.84 \\
\hline 400 & 210.93 \\
\hline 400 & 223.22 \\
\hline 400 & 217.07 \\
\hline 400 & 213.41 \\
\hline
\end{tabular}

Note: The instruction manual shipped with the magnetic resistance trainer unit indicates that the weight of the individual is factored into the calculation of power output. This study did not consider any effects due to subject size, but instead measured the raw rotational power at the rear wheel. All data were collected with a rider mass of $75 \mathrm{~kg}$ (165 lb.) programmed into the input/display computer module. 


\section{B. PLANTAR STRESS RESULTS}

Peak plantar stress and applied force were collected from the Pedar insoles at a rate of $50 \mathrm{~Hz}$ while subjects cycled at $90 \mathrm{RPM}(1.5 \mathrm{~Hz})$. Data were saved as tab delimited text files that could be opened in Microsoft Excel software for analysis. A "vi" was written in LabVIEW software and used to perform a Fast Fourier Transform (FFT) on the data for the determination of frequency content. It was decided based on the FFT that a Butterworth low-pass filter set at $2.0 \mathrm{~Hz}$ high cutoff frequency would remove unwanted high frequency noise from the signal. Filtered data was then plotted in Excel. Peak values of stress were recorded for each pedal stroke during each 10 -second data collection sequences, resulting in approximately 15 data points from each trial. These values were then averaged to determine an overall average peak stress for that particular trial. An example of this type of process is seen in Figures 32 and 33.

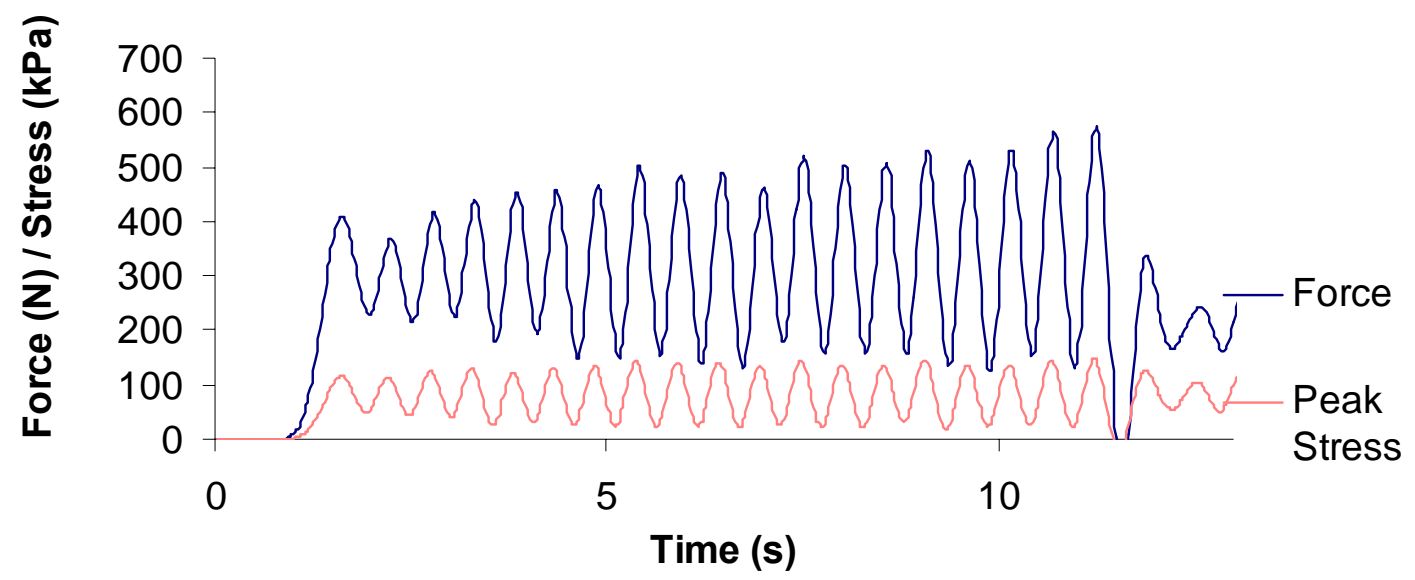

Figure 32. Force and peak plantar stress plot over a typical collection sequence. Data points were manually recorded from peaks of such graphs. 


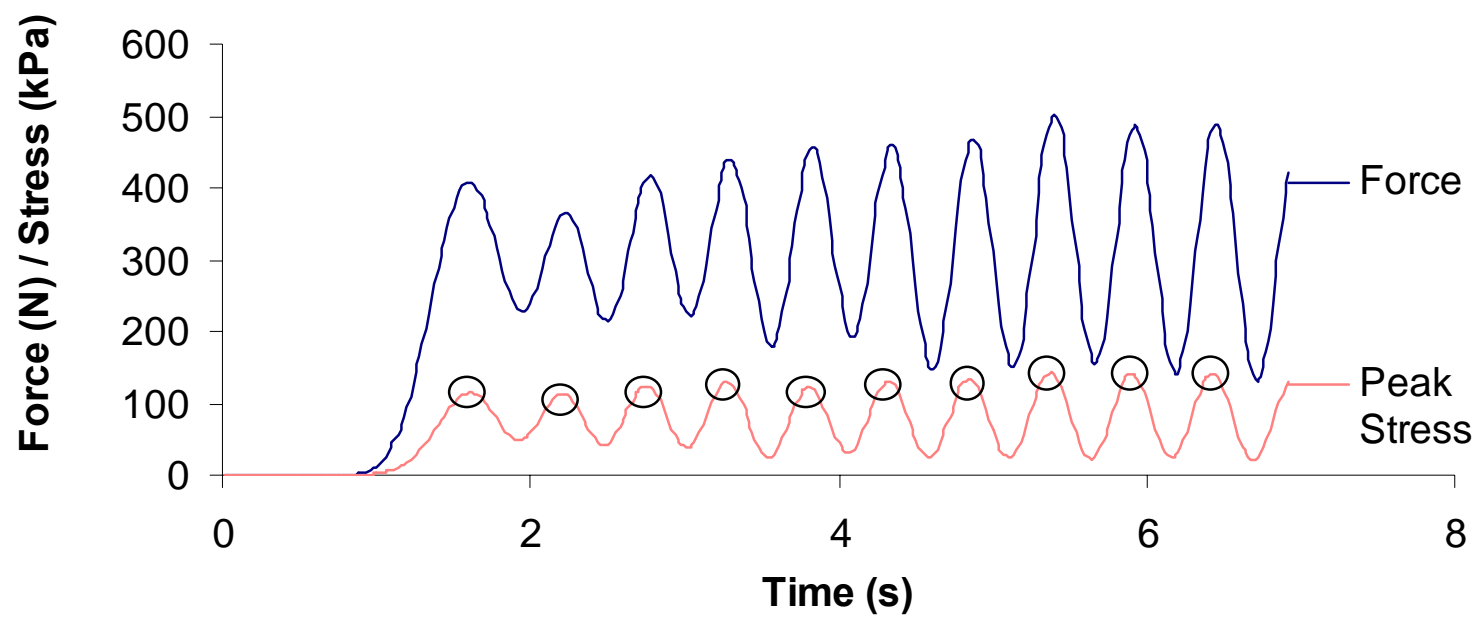

Figure 33. Force and peak plantar stress plot, close-up view. Peak stress values were recorded for each pedal stroke and averaged across the entire ten-second trial. Circles indicate the areas of maximum peak stress.

Ten subjects were tested in both types of shoes on the left and right feet, resulting in a total of 40 peak plantar stress data points. Raw data can be seen in Appendix II. The mean peak stress recorded in shoe type M152 plastic-soled shoe was $103.0 \mathrm{kPa}(14.65$ psi) and the mean for the M220 carbon-soled shoe was $121.2 \mathrm{kPa}(17.58 \mathrm{psi})$. Overall plantar stress results are in Figure 34. 


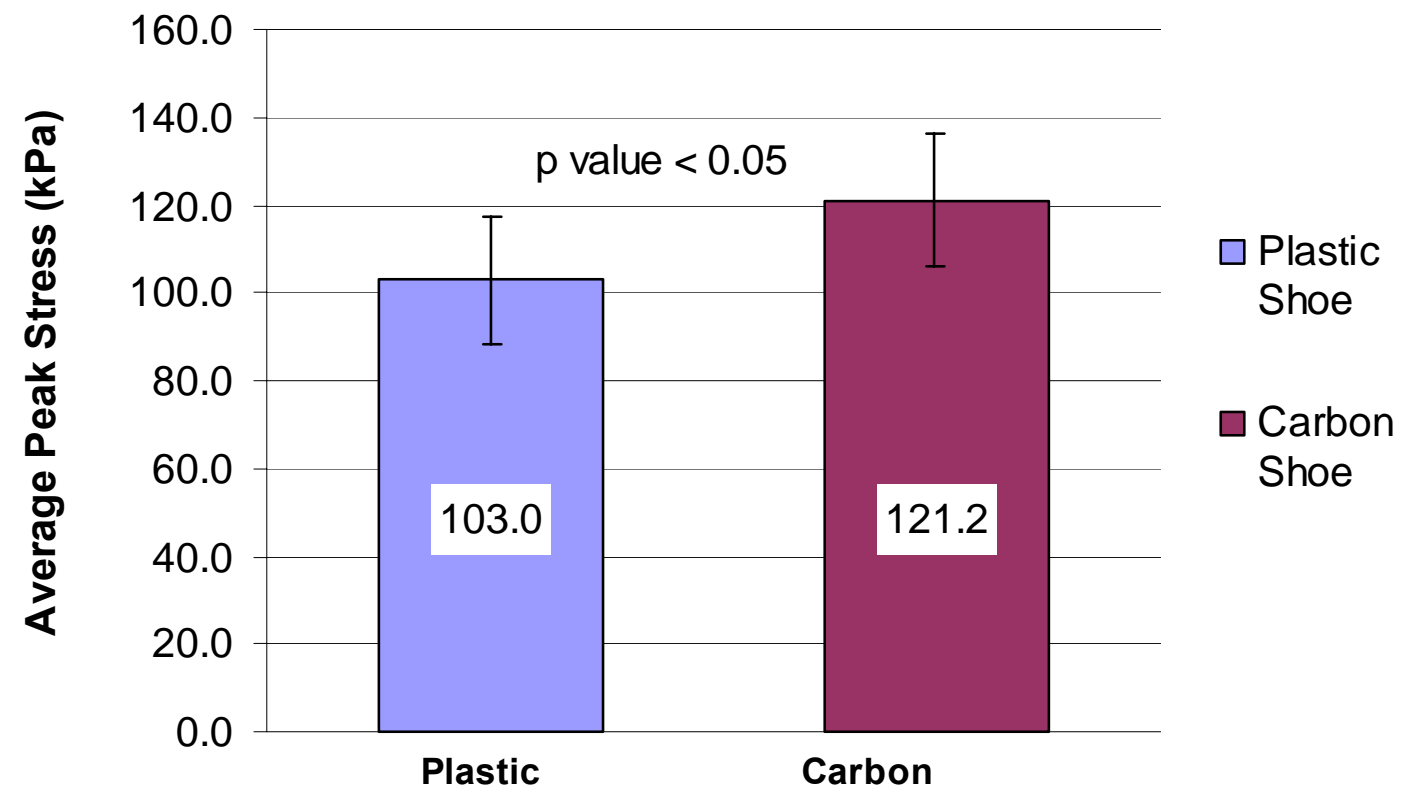

Shoe Type

Figure 34. Overall average peak plantar stress results among ten subjects in two different shoe types. Subjects pedaled at 400 Watts and a cadence of 90 RPM. Error bars indicate one standard deviation.

Figure 34 was constructed by averaging data from both the left and right feet together. Figures 35 and 36 provide a more detailed view of the same data, demonstrating that the same overall trend introduced in Figure 34 exists within most individual subjects. 


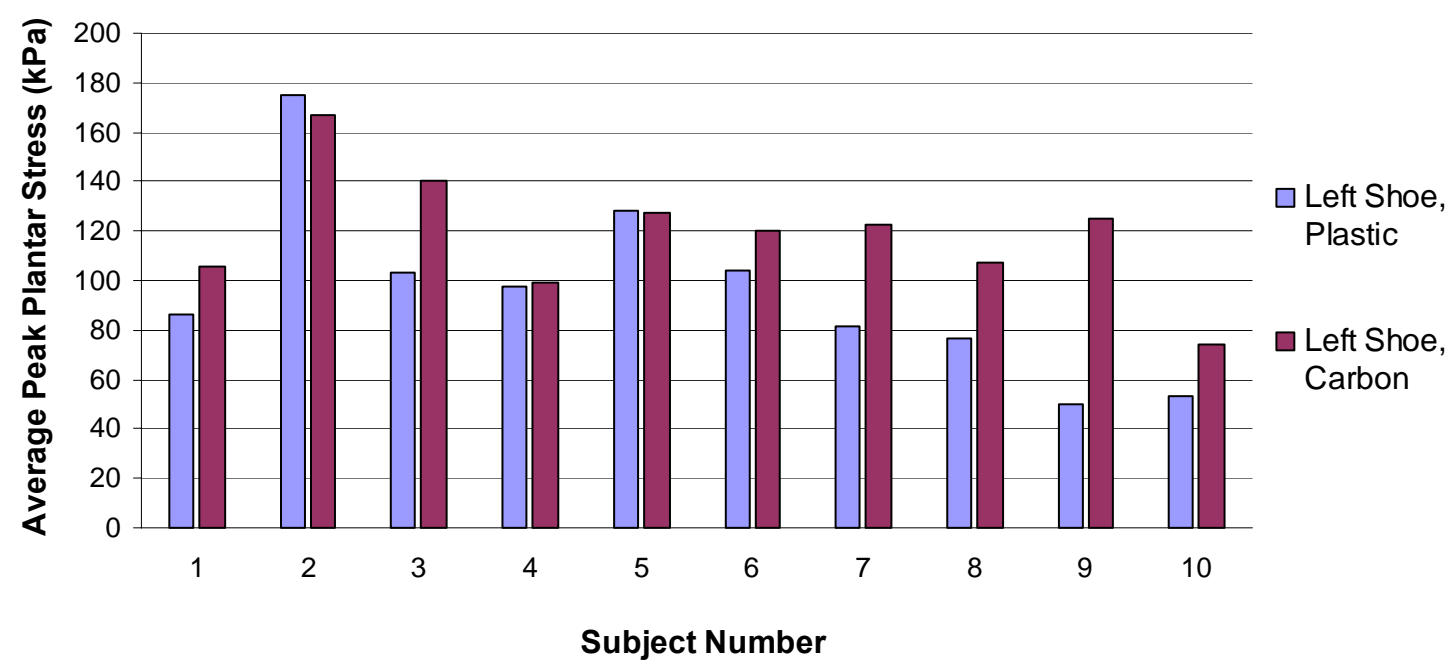

Figure 35. Average peak plantar stress results, left feet. Graph shows the differences in average peak plantar stresses between plastic-soled cycling shoes and carbon fiber models.

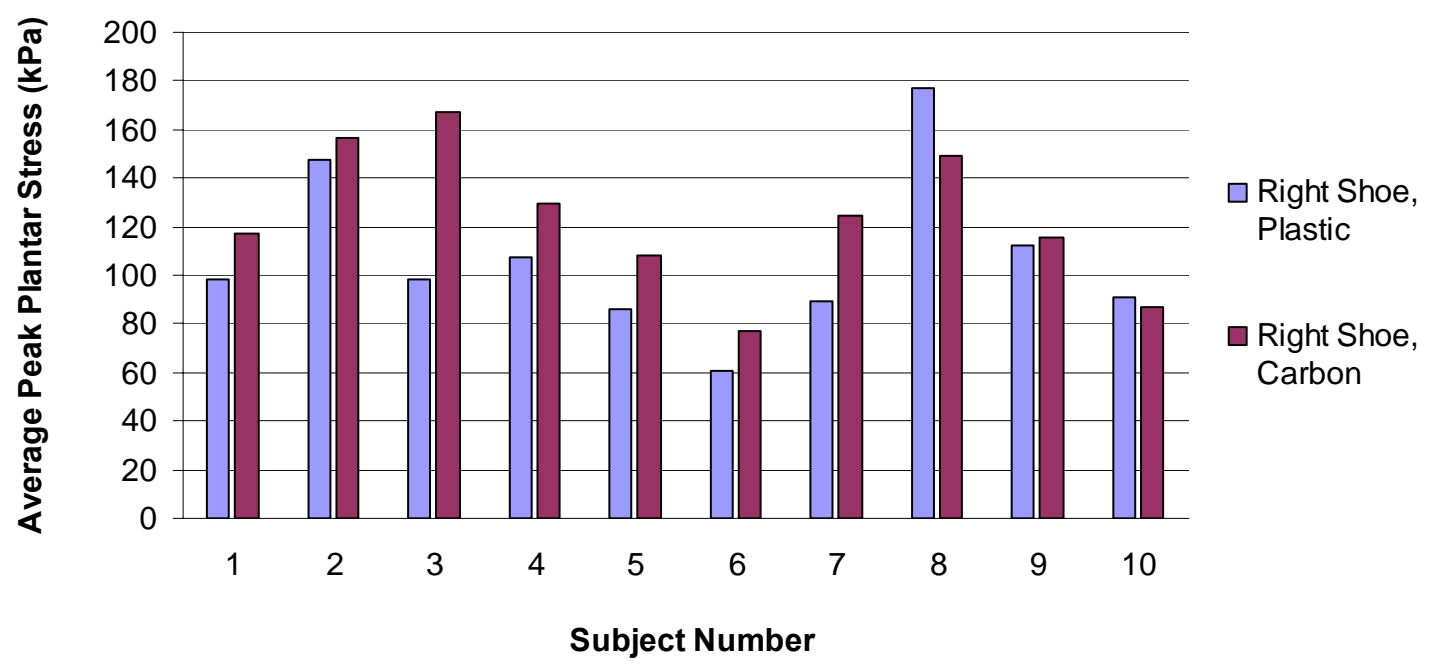

Figure 36. Average peak plantar stress results, right feet. 
For the recording of peak stress values, a "mask" was arranged in the Pedar software that specified the area of the insoles for the selection and recording of data values. The mask used in this study included the entire front half of the foot, including all the areas where maximum peak plantar stresses were expected to occur: the first metatarsal head, the hallux, and the fifth metatarsal.

Methods used in this study accepted maximum stress results from the entire forefoot when outputting peak stress values from the software for further analysis. Pedar software chose peak stress values for each data frame at a rate of $50 \mathrm{~Hz}$ and output results to a delimited text file for later analysis. Though the peak stresses recorded by the software could have occurred at areas other than the first metatarsal, there is information available in current literature that suggests the peak stress during cycling occurs typically at the first metatarsal head. Subjective inspection of plantar stress raw data files, files available before the "mask" procedure was run, show that highest stresses did indeed occur near the first metatarsal head. Data recorded in this study are consistent with Sanderson and Cavanagh, 1987 and Sanderson and Hennig, 2000 which each demonstrate maximum plantar stresses occur near the first metatarsal head during cycling activity.

Figures 37 and 38 show screen captures from Pedar software which indicate that peak stress from that particular pedal stroke was highest near the first metatarsal head (Figure 38 is a 3-dimensional plot of the same stresses shown in Figure 37). Both figures show that the first metatarsal sustained the greatest load during that particular cycle. Figures 37 and 38 are representative of the typical pattern of plantar stress recorded during other trials because other files were also checked that presented a similar pattern. 


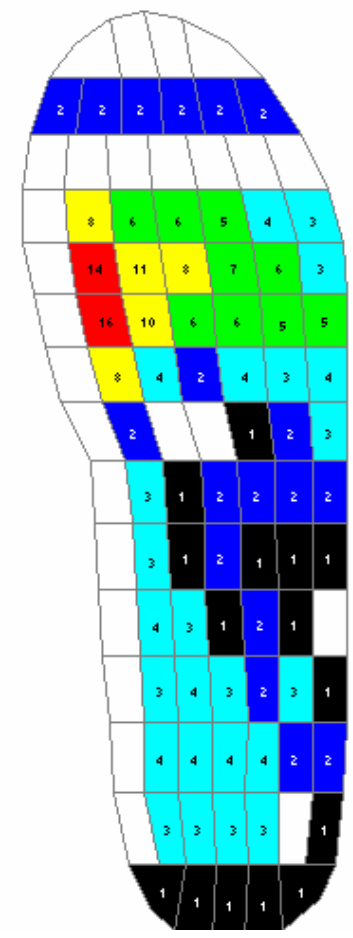

Figure 37. Two-dimensional plantar stress plot from Pedar software. The red indicates the highest stress $\left(\sim 14 \mathrm{~N} / \mathrm{cm}^{2}\right)$, followed by yellow, then green, then light blue. Dark blue and black indicate very low stress values.

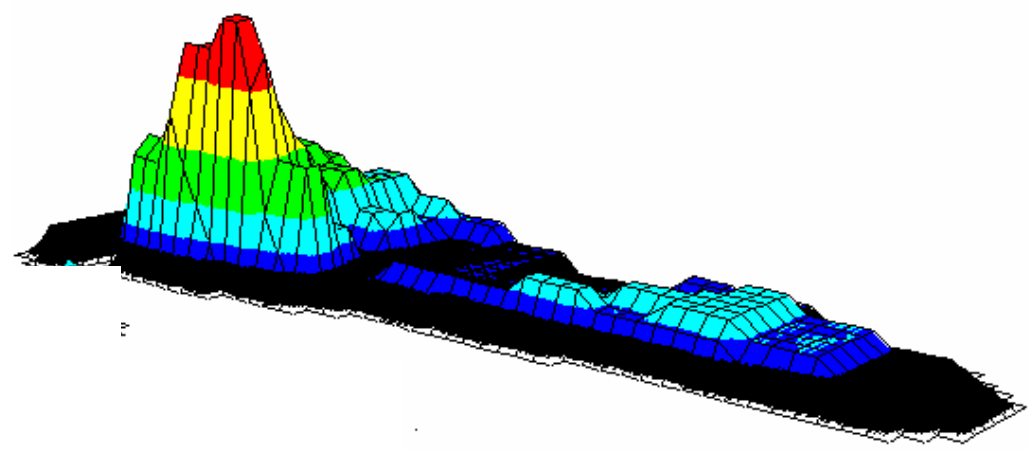

Figure 38. Three-dimensional graph of peak plantar stress recorded during one downstroke. The highest peak stress occurred near the first metatarsal head, which is consistent with existing literature on the subject. 


\section{Plantar Stress Statistical Analysis}

A two-way balanced analysis of variance (ANOVA), with repeated measures on both factors, was run on plantar stress data using Minitab statistical software. Three factors were considered in the analysis: shoe type (M152 or M220), shoe side (left or right), and subject number (1-10). The response/dependent variable in the analysis was peak stress. The formula entered into Minitab,

$$
\text { Subject } \mid \text { Shoe } \mid \text { Side - Subject * Shoe * Side }
$$

indicates that all factors were crossed together in the analysis, but that the particular interaction of subject/shoe/side was purposely excluded from the analysis because it simplified the analysis and because it was of no particular interest in this study.

Results of the ANOVA on the factor of interest in this study, average peak stress,

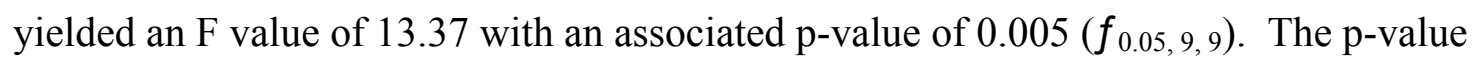
associated with this statistic indicates that there is a $0.5 \%$ chance that the peak stress measurements recorded in this study occurred due to random chance. The null hypothesis assumed that the both shoe types produced the same peak plantar stress values. The decision was made to reject the null hypothesis because the statistics suggest that the shoes are different.

Specific statistical results are listed in Table 3. "DF" stands for degree of freedom, "SS" is sum of squares, "MS" represents mean squares, "F" is the f statistic, and "P" is the p-value, or probability of the event taking place assuming the null hypothesis is correct (null $=$ shoes are identical). 
Table 3. Statistical results of a two-way ANOVA with repeated measures.

\begin{tabular}{|c|c|c|c|c|c|}
\hline Source & DF & SS & MS & F & P \\
\hline Subject & 9 & 19730.7 & 2192.3 & 7.31 & 0.003 \\
\hline Shoe Type & 1 & 4008.4 & 4008.4 & 13.37 & 0.005 \\
\hline Side & 1 & 625 & 625 & 2.09 & 0.183 \\
\hline $\begin{array}{c}\text { Subject*Shoe } \\
\text { Type }\end{array}$ & 9 & 2843.8 & 316 & 1.05 & 0.469 \\
\hline Subject*Side & 9 & 9573.3 & 1063.7 & 3.55 & 0.036 \\
\hline Shoe*Side & 1 & 119.6 & 119.6 & 0.4 & 0.543 \\
\hline Error & 9 & 2697.6 & 299.7 & & \\
\hline Total & 39 & 39598.5 & & & \\
\hline
\end{tabular}

One can see from Table 3 that shoe type had a significant effect on peak stress. The mean squares term (MS) under shoe type was almost double that of any other term in that column. Subject number is expected to produce different results because all subjects were different. Side (left or right) had a very small effect on peak stress and was not statistically significant because the $p$-value associated with that term was $0.183>0.05$. P-values $<0.05$ were considered statistically significant.

A paired t-test was also performed using part of the data for comparison to the ANOVA results, and for statistical power reinforcement. Average peak stress values from each subject were recorded by averaging both the left and the right shoes of the same shoe type together. The data used for this t-test is seen in Table 11 of Appendix II. The paired t-test for the left and right shoe combined produced a $t$ statistic of 3.71 at a pvalue of .0048 . The statistic again indicates that there is about a $0.5 \%$ chance of the numbers of Table 11 occurring due to random variation.

\section{CYCLING SHOE STIFFNESS TEST RESULTS}

\section{Longitudinal Bending Stiffness Results}

The force versus displacement curve of a typical shoe test is presented in Figure 39. Data were recorded within the range of 2300 to 2400 cycles. Hysteresis was present in the shoes, as evident by the shape of the force/displacement curve. The force curve in 
Figure 39 does not return along the same path on the downstroke as it does on the upstroke, indicating hysteresis and energy losses during flexure.

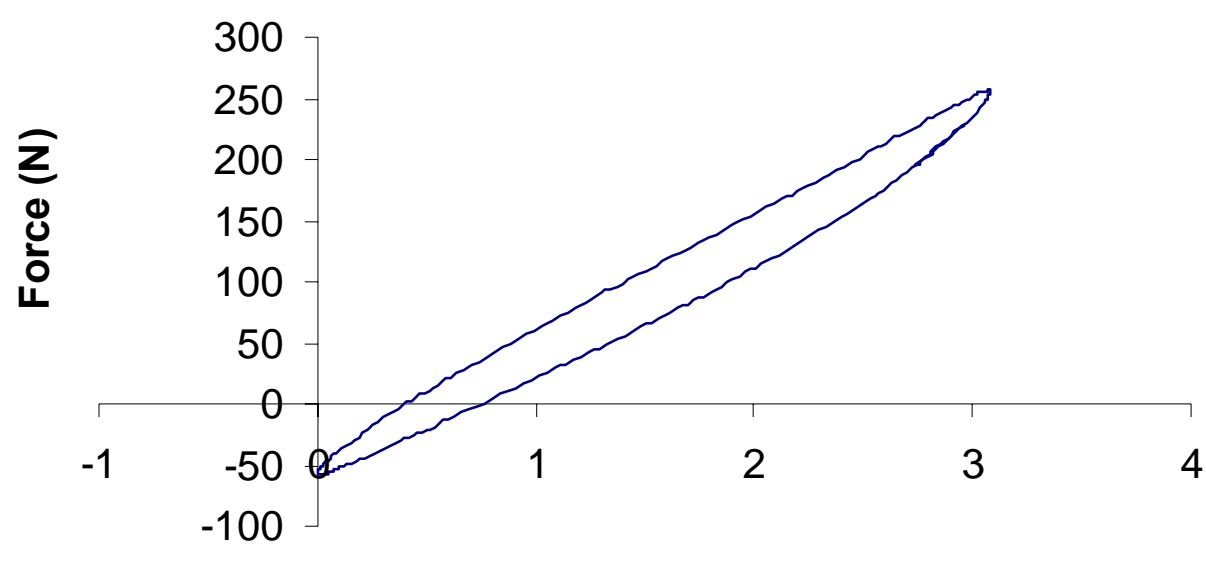

\section{Displacement $(\mathrm{cm})$}

Figure 39. Force/Displacement curve of a cycling shoe in longitudinal flexure per ASTM standard F-911. The characteristic curve was used to calculate the stiffness and damping characteristics of the shoe.

Stiffness values were taken from a linear best-fit curve produced within Microsoft Excel, which is demonstrated in Figure 40. Although the trendline did not travel exactly through the middle of the hysteresis curve, it gave an approximation that was considered precise enough for the purpose of this study, and was assumed repeatable across all trials due to the repetitive nature of the trendline function in Microsoft excel.

In addition to stiffness calculations, data such as those shown in Figure 39 were also used for damping calculations to help further quantify the behavior of each type of shoe. The damping characteristics were not directly related to the hypothesis in this study, but were calculated because the data was readily available. The damping characteristics were calculated more to satisfy curiosity than for their contribution to this particular study. Those interested in further examination of the damping characteristics of cycling shoes may peruse the calculations performed in Appendix III. 


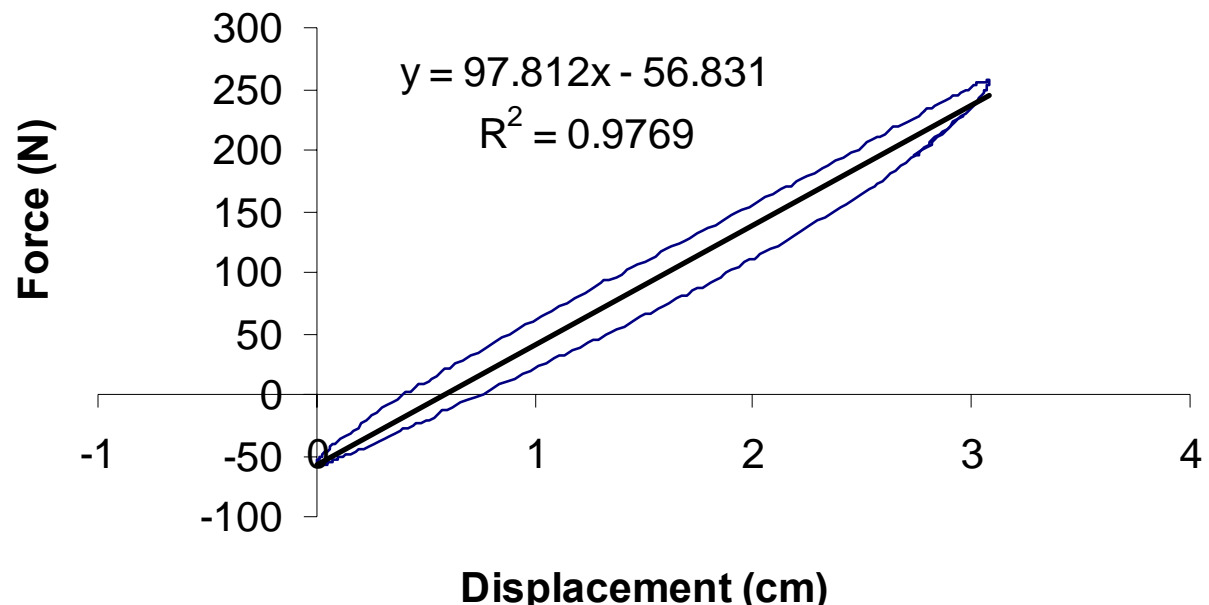

Figure 40. Force/Displacement curve with corresponding linear trendline. Data was collected per ASTM standard F-911. Slope of the trendline indicates the stiffness.

Stiffness values for three trials of each shoe were recorded. The stiffness of each shoe in longitudinal bending is shown in Figure 41. Shoes were each cycled through a known displacement; the stiffer the shoe, the more force was required to displace it. 


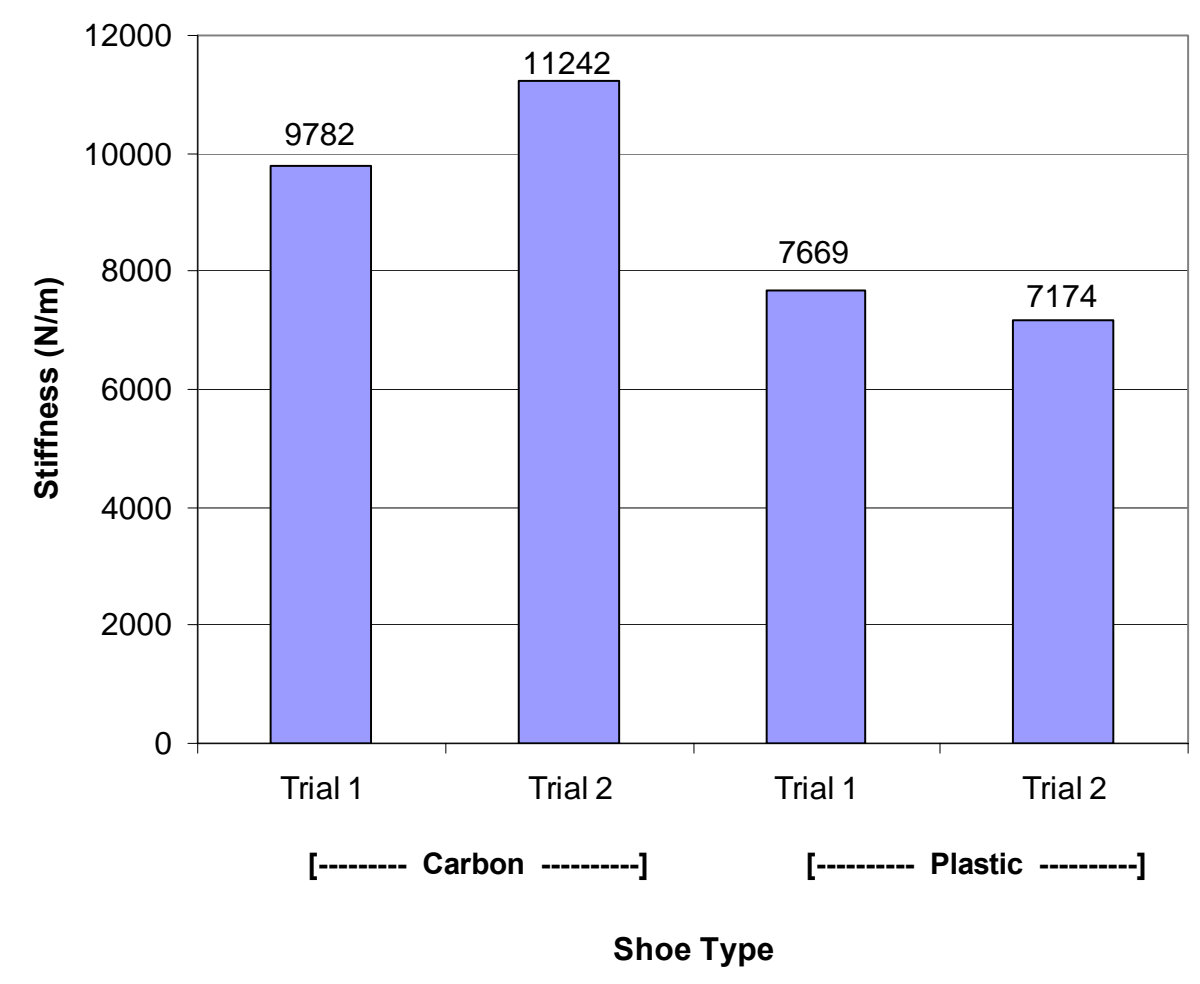

Figure 41. Stiffness values of two types of cycling shoes in ASTM F-911. Shoes with carbon fiber composite soles produced higher stiffness values.

Mean values for shoe stiffness in longitudinal bending are shown in Table 4. The carbon shoe produced mean stiffness values of approximately $10512 \mathrm{~N} / \mathrm{m}(60 \mathrm{lbf} / \mathrm{in})$ while the plastic shoes produced stiffness values of $7422 \mathrm{~N} / \mathrm{m}$ (42.3 lbf/in).

\begin{tabular}{|c|c|}
\hline \multicolumn{2}{|c|}{$\begin{array}{r}\text { Table 4. Average shoe } \\
\text { stiffness in longitudinal } \\
\text { bending per ASTM F-911. }\end{array}$} \\
\hline Shoe Type & $\mathbf{k}(\mathrm{N} / \mathrm{m})$ \\
\hline M220 & 10512 \\
\hline M152 & 7422 \\
\hline
\end{tabular}




\section{Three-Point Bending Stiffness Results}

The force versus displacement plot of shoes testing in the three-point bending arrangement revealed a nonlinear stiffness, as seen in Figure 42.

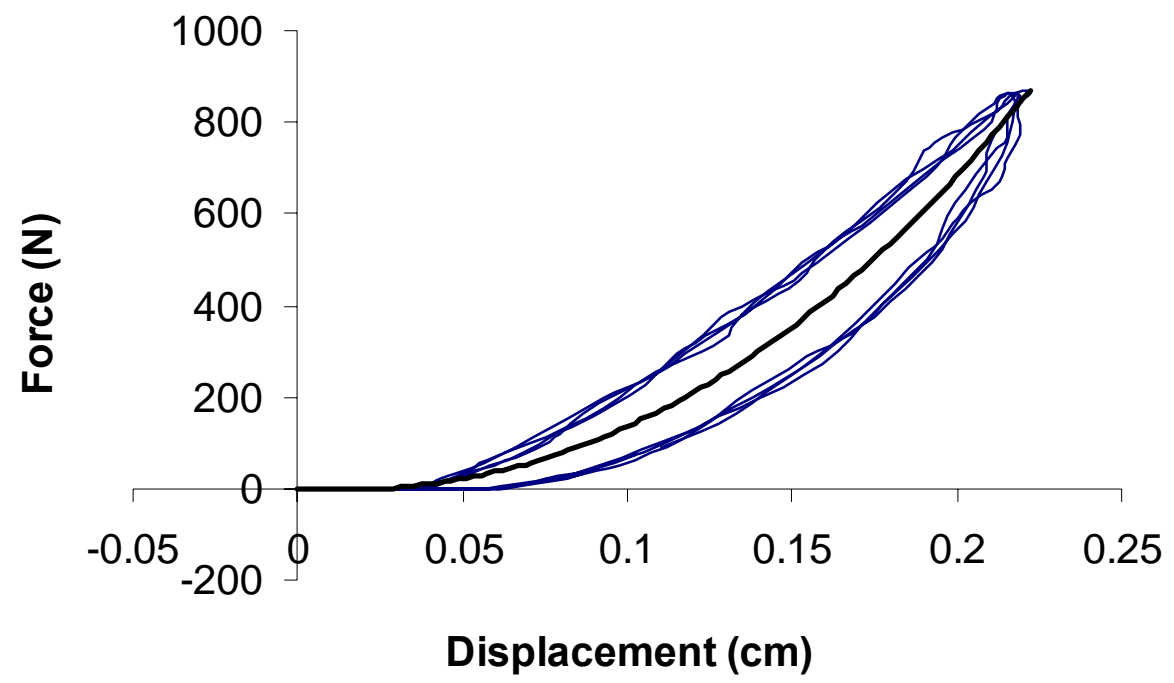

Figure 42. Force/displacement curve of a shoe in three-point bending. The stiffness of the shoe in three-point bending is nonlinear, as seen by the trendline.

Because of the nonlinearity in the three-point bending force/displacement loop, the previous method of performing a linear curve fit to assess stiffness was not applicable. An alternate method was therefore devised to make a linear stiffness approximation from the nonlinear hysteresis loop in a way that was repeatable across all samples. To find the stiffness, a line was first drawn from the minimum force and displacement value to the highest hysteresis loop value to establish a linear "target slope," as seen in Figure 43. The fourth-order polynomial equations of the upper and lower portions of the hysteresis loop, resulting from the curve fit, were then differentiated and solved for their respective tangency points to the slope of this "target slope." Figure 44 illustrates the tangency points established by this method. Tangency points were located using the methods demonstrated in Appendix III. 


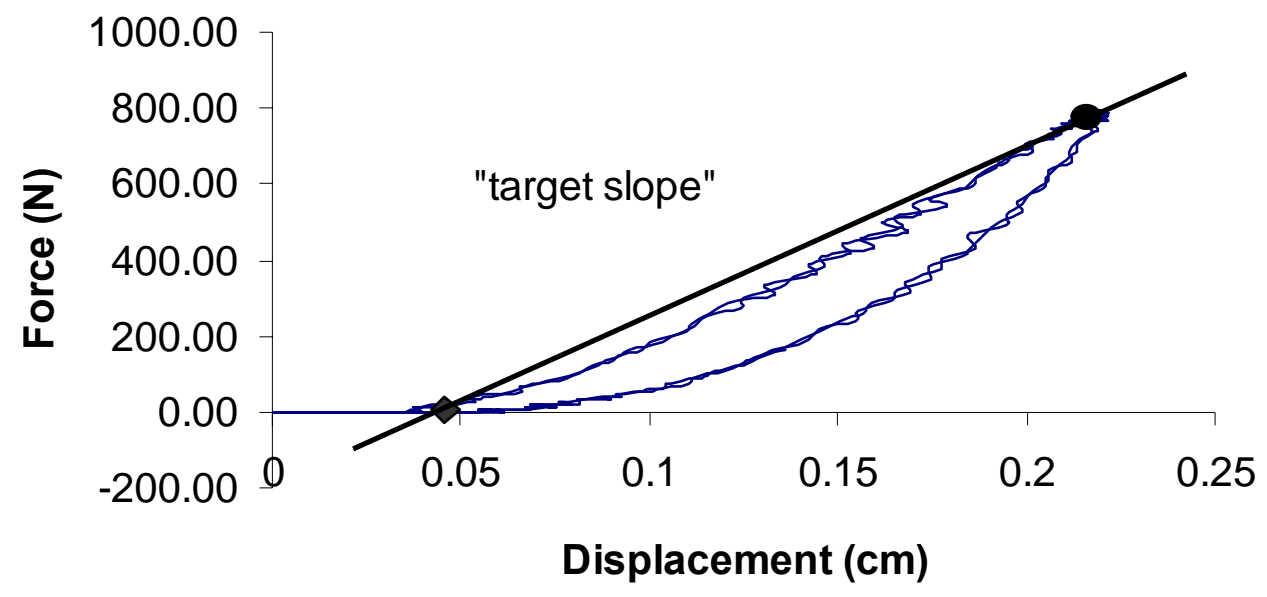

Figure 43. "Target slope" of a non-linear hysteresis loop. This procedure was the first step in the estimation of a stiffness value for nonlinear force/displacement plots.

After tangency points were found on the hysteresis curves a linear interpolation was performed to locate the midpoint between the two tangency points. A line was then established between this interpolated point and the maximum force and displacement location on the hysteresis loop to determine a final stiffness value for the shoe in question. Figure 45 illustrates the final step of the stiffness determination of shoes loaded in the three-point loading arrangement. 


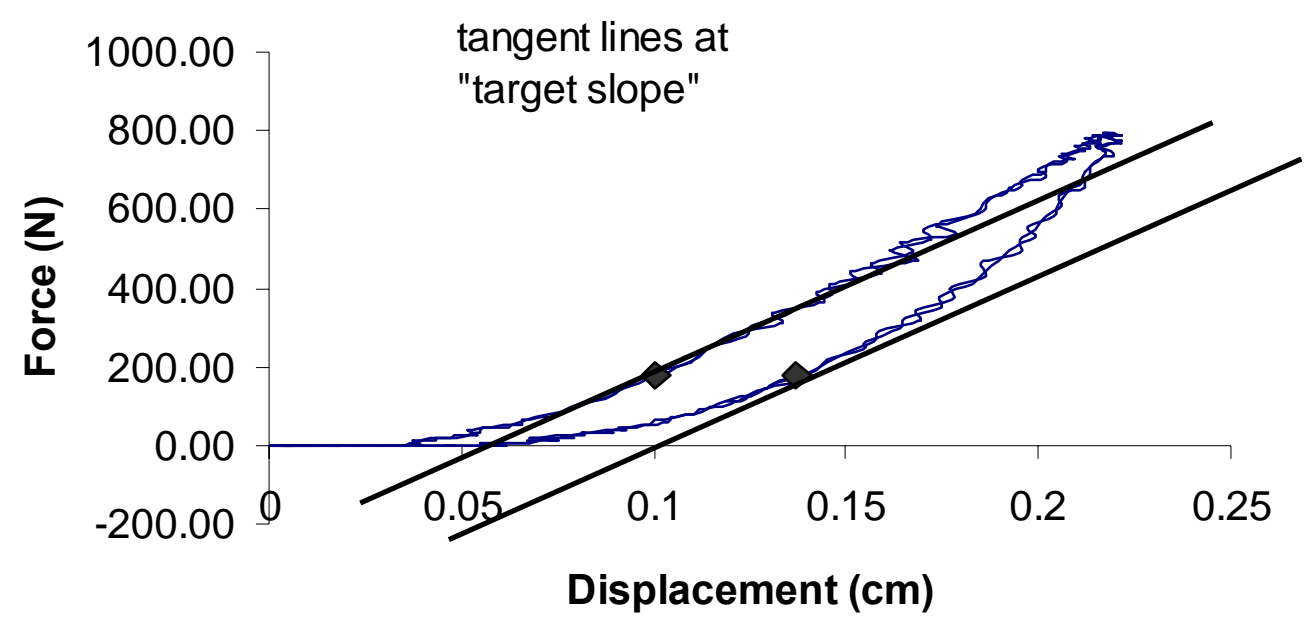

Figure 44. Drawing tangency lines to a non-linear hysteresis loop.

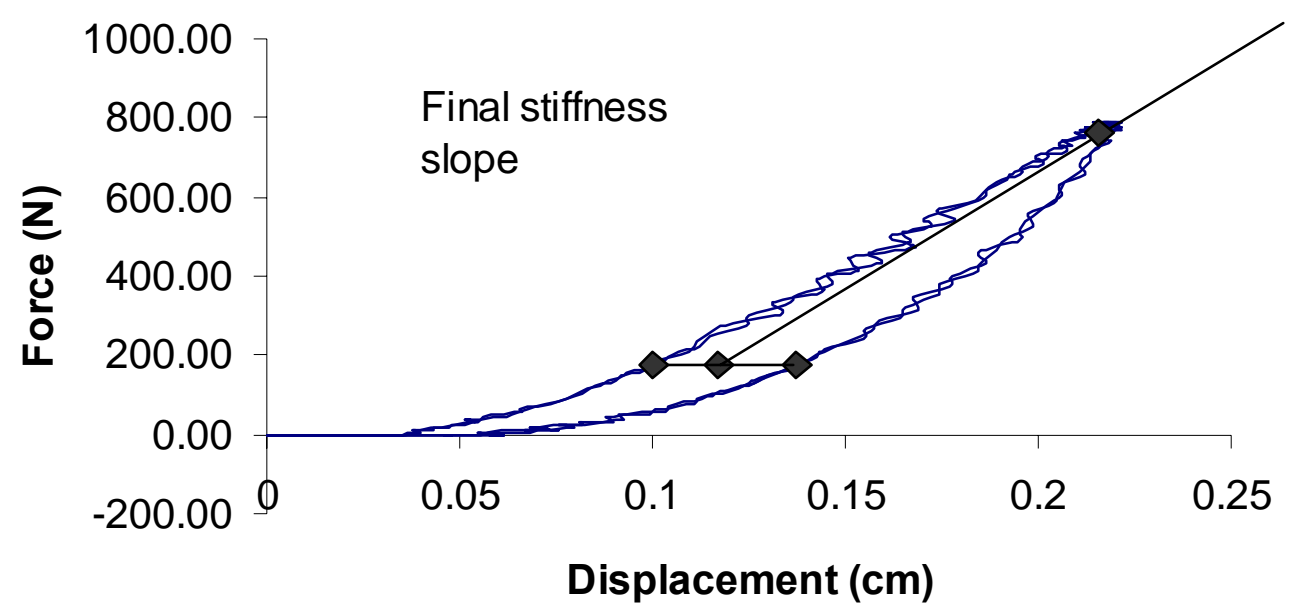

Figure 45. Final stiffness determination for a non-linear hysteresis loop.

Values of three-point bending stiffness are shown in Figure 46. Mean values for stiffness for shoes tested in the three-point bending arrangement are shown in Table 5. 


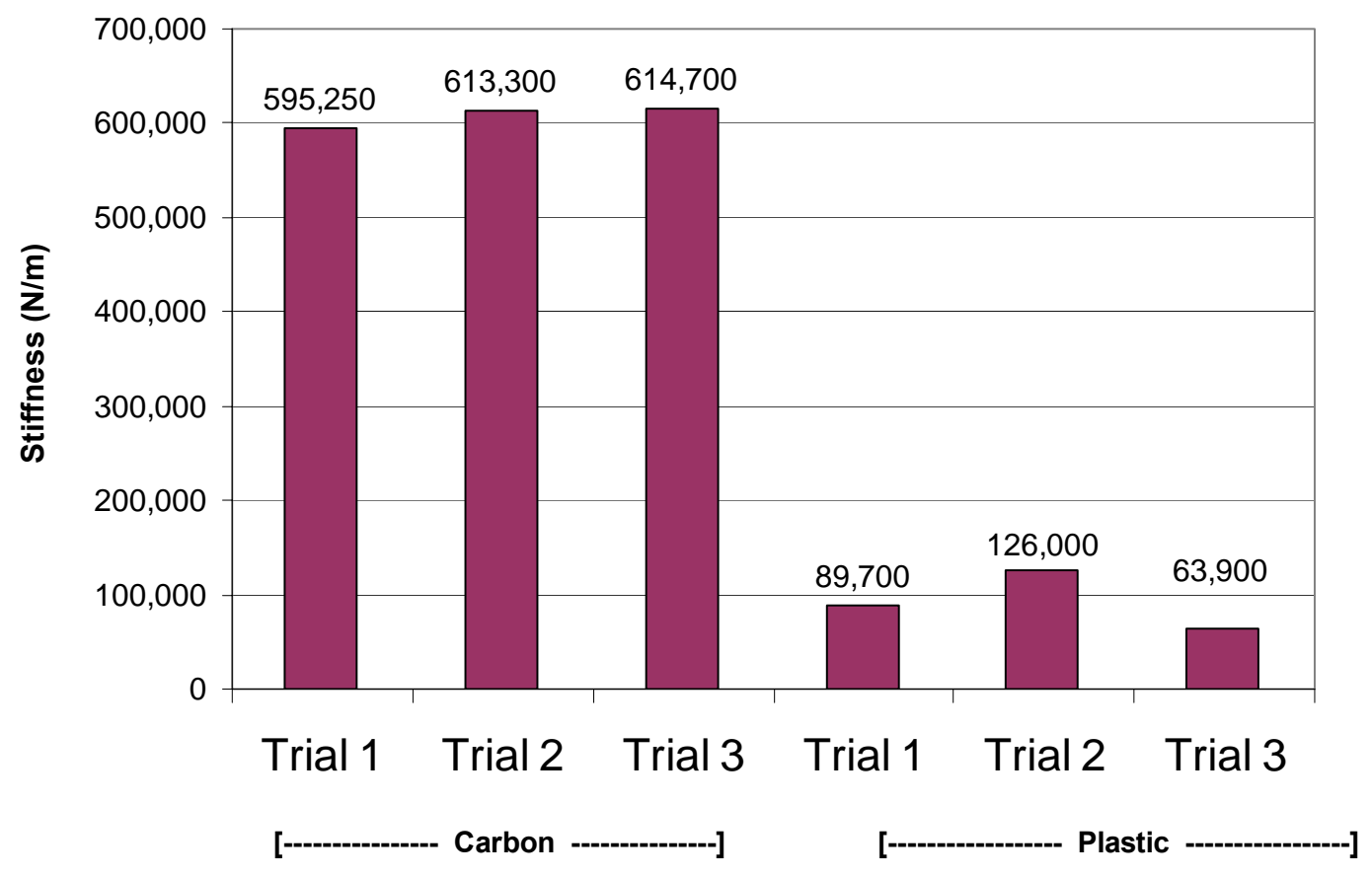

\section{Shoe Type}

Figure 46. Stiffness values of two types of cycling shoes in three-point bending. Shoes with carbon fiber composite soles produced much higher stiffness values.

The carbon shoe produced mean stiffness values of approximately $6.0 \times 10^{5} \mathrm{~N} / \mathrm{m}(3470$ lbf/in) while the plastic shoes produced stiffness values of $9.3 \times 10^{4} \mathrm{~N} / \mathrm{m}(532 \mathrm{lbf} / \mathrm{in})$. The carbon fiber shoes demonstrated a 550\% greater stiffness than the plastic-soled shoes.

\begin{tabular}{|c|c|}
\hline \multicolumn{2}{|c|}{$\begin{array}{l}\text { Table 5. Average shoe } \\
\text { stiffness in three-point } \\
\text { bending. }\end{array}$} \\
\hline Shoe Type & $\mathbf{k}(\mathrm{N} / \mathrm{m})$ \\
\hline M220 & 607,750 \\
\hline M152 & 93,200 \\
\hline
\end{tabular}




\section{DISCUSSION}

Shoes with carbon fiber composite midsoles produced significantly higher peak plantar stresses in the forefoot region than did cycling shoes made with a more traditional plastic sole. Dynamic mechanical testing indicated that carbon fiber shoes were stiffer than plastic shoes in both longitudinal bending ( $>42 \%)$ and three-point bending $(>550 \%)$. Large stiffness discrepancies, especially between shoes that are otherwise identical, lead one to believe that stiffness differences are the cause of increased peak plantar stresses.

The two pairs of shoes tested were manufactured by the same company, were the same size (European size 42), had the same lacing design (three-strap hook and loop or "Velcro"), had identical insole shape, and had identical outsole shape and tread patterns with identical grooves for cleat attachment. The only visible difference between the shoes in this study was the material used in the outsole.

The three-point bending test, the test that revealed the biggest difference in stiffness between shoes, was considered the more realistic cycling-related test of the two since it placed forces directly on the cleat as would happen during cycling with clipless pedals. Because force was applied directly to the shoe cleats during the three-point bending test, similar to actual forces encountered during normal use, the results were more representative of actual shoe behavior than the longitudinal bending test.

Unlike the Sanner et al. (2000) study, and the Sanderson et al. (1987) study, which compared stiffer cycling shoes to more flexible walking or running shoes, this study was a direct comparison between two types of stiff-soled cycling shoes. The running shoes in the Sanderson and Cavanagh study were extremely flexible compared to cycling shoes. The running shoes spread the stresses over a broader area than the cycling shoes, probably due in part to the thickness of foam between the metatarsal heads and the pedal surface. Because running shoes have cushioning greater than one centimeter thick between insole and outsole, they have a certain degree of vertical displacement upon loading.

The cycling shoes studied, however, had very little foam padding between the insole and the outsole, resulting in very little vertical compliance. It is unlikely that midsole compression of the cycling shoes tested would provide the appreciable stress distribution or stress reduction present in running shoes. 
Manufacturers claim that a stiffer shoe is better for competitive cycling because it is more efficient. Though not the primary focus of this study, the damping calculations performed during this study indicate that a plastic shoe, without carbon fiber, has a higher degree of damping than the carbon shoe, which indicates that larger energy losses will occur when using such a shoe. Damping losses reduce the overall efficiency of the cyclist/bicycle combination by absorbing the energy used to flex the shoe without returning that energy elastically after the load is removed. However, a shoe that flexes more to conform to foot contours, and that dampens vibration over rough terrain, is theorized to be a more comfortable and "safe" shoe.

Effort was made to conduct the current study under conditions that are considered standard among other cycling research professionals. A study by Sanderson, et al. (2000) evaluated effects of cycling cadence on force application. The power outputs used in the Sanderson study included a $400 \mathrm{~W}$ setting, which was the same power output used in this particular study. The crank speed, 90 RPM, was also within the range of crank speeds used by Sanderson, et al.

Sanner and O'Halloran (2000) stated that pressure on the entire lower extremity was about one-half a cyclist's body weight when riding seated, and up to three-times body weight when standing. Cyclists remained seated during the current study, so stresses remained relatively low. Further study that examines stresses during a standing posture, common among cyclists while climbing steep hills or while sprinting, may be necessary to note any further significant differences among cycling shoes.

The magnetic resistance unit used to monitor cyclists' workload in this study is repeatable to within $\pm 4 \%$ of the set value as long as the RPM and power setting remain constant, as demonstrated by data in Table 2. Cyclists each used the same gear ratio, cadence, and magnetic resistance unit power setting throughout the study so it is reasonable to assume that all cyclists participated under the same conditions. Subjects were tested in both types of shoes within a 30 minute time period. Any differences within the resistance unit over time, or due to bicycle tire wear, etc. were considered negligible. Tire pressure was adjusted before each subject began, and was held constant across all subjects, so any pedaling resistance variation due to tire friction was controlled and accounted for. 
Peak plantar stresses in the range of $100 \mathrm{kPa}(14.5 \mathrm{psi})$ to $120 \mathrm{kPa}(17.4 \mathrm{psi})$ were recorded during this study while cyclists pedaled seated at 400 Watts. Peak stresses recorded during walking by Randolf et al. (2000) using the F-scan/Tekscan plantar stress measurement system recorded values in the range of $95 \mathrm{kPa}$ (13.9 psi), which shows that stresses during seated cycling can be high enough to warrant consideration.

It is suggested that cycling shoe manufacturers produce carbon-soled shoes that are thinner and less stiff. Such shoes would be desirable for two reasons: lighter shoes would be more enticing to those cyclists intent on shaving weight from their equipment, and the shoes would be cheaper to manufacture because they would be made with less material. The thinner sole would theoretically provide greater comfort as increased deflection would allow for better stress distribution. It is also recommended, for maximum performance, that shoes be made with more elastic materials so the shoes will rebound elastically after deformation to return maximum energy back to the rider.

For those who only ride occasionally, an $18 \%$ difference in peak plantar stress per pedal stroke may not be of consequence, but some cyclists pedal so many revolutions that a small difference may have a cumulative effect over time. Typical training routines for competitive club cyclists or professionals include two or more hours per day, seven days a week, at a pedal rate of at least 90 RPM. These cyclists ride almost 365 days per year, for ten years or more, which add to a total of over 39 million pedal cycles! Due to the high number of lifetime pedal strokes, a foot stress reduction method that may be of interest to highly competitive cyclists is the use of two pairs of shoes, one pair for daily training and one for racing. If cyclists use the plastic-soled shoes for daily training and the stiffer carbon shoes on race day only, he or she would theoretically reduce the foot "wear and tear," especially over the course of several years. 


\section{CONCLUSIONS AND RECOMMENDATIONS}

Cycling shoes made with carbon fiber composite midsoles increased forefoot peak plantar stress by a statistically significant value over traditional plastic-soled shoes. Dynamic shoe testing revealed that the carbon shoes used in this study were stiffer in both longitudinal bending and three-point bending than plastic ones. Increased stiffness is suspected as a cause of increased plantar stress because the shoes tested were otherwise identical.

Though not critical for recreational riders who only ride occasionally, competitive or professional cyclists suffering from metatarsalgia or ischemia should be especially careful when using carbon fiber cycling shoes because current literature cites high plantar stress as a possible cause of such foot conditions. If extremely stiff carbon fiber composite shoes are to be worn, it is suggested that custom orthoses be utilized to avoid excessively high peak stress. Another possible stress-reducing alternative is to wear more traditional plastic shoes for daily training while saving the carbon shoes for race days.

A small number of shoes were tested in this study due to limited funding. Further study comparing several shoes of varying manufacturers and designs is expected to further clarify and define any relationship between shoe stiffness and peak plantar stress. 


\section{REFERENCES}

1. Anderson, J C; Sockler, J M: Effects of orthoses on selected physiologic parameters in cycling. Sports Med. 80(3): 161-165, 1990.

2. Chappell, J: Deceptive advertisement of athletic footwear, a letter to the editor. British Journal of Sports Medicine, 32:265-268, 1998.

3. Cooper, D: Method of applying the results of dynamic testing to rubber antivibration systems. Transaction of the Institution of the Rubber Industry held at the James Watt Memorial Institute, November 10, 1958.

4. Gregor, R J; Wheeler, J B: Biomechanical factors associated with shoe/pedal interfaces. Sports Med. 17(2): 117-131, 1994.

5. Mellion, M B: Common Cycling Injuries, Management and Prevention. Sports Medicine, 11(1):52-70, 1991.

6. Rau, S S: Mechanical Vibrations, $3^{\text {rd }}$ Edition. Reading, Massachusetts: AddisonWesley.

7. Randolph, A L; Nelson, M; Akkapeddi, S; Levin, A: Reliability of measurements of pressures applied on the foot during walking by a computerized insole sensor system. Arch Phys Med Rehabil, 81:573-578, 2000.

8. Sanderson, D J; Cavanagh, P R: An investigation of the in-shoe pressure distribution during cycling in conventional cycling shoes or running shoes. Jonsson (Ed) Biomechanics XB, pp. 903-907, Human Kinetics Publishers, Champaign, 1987.

9. Sanderson, D J; Hennig, E M: In-shoe pressure distribution in cycling and running shoes during steady-rate cycling. Proceedings of the Second North American Congress on Biomechanics, Chicago, August $24^{\text {th }}-28^{\text {th }}$, pp. 24-25, 1992.

10. Sanderson, D J; Hennig, E M; Black, A H: The influence of cadence and power output on force application and in-shoe pressure distribution during cycling by competitive and recreational cyclists. Journal of Sport Sciences. 18, 173-181, 2000. 
11. Sanner, W H; O'Halloran, W D: The biomechanics, etiology, and treatment of cycling injuries. Journal of the American Podiatric Medical Association. 90(7), 354376,2000 . 


\section{APPENDIX I. TRAINER TEST DATA}

When the values produced by the rotating magnetic resistance unit were compared at the 400 Watt setting, without regard to shaft speed, the data in Table 6 resulted. It was noted that when shaft speed varied, resistance device precision plummeted, as is evident in Table $7 .$.

Table 6. Magnetic resistance unit testing data collected at various shaft speeds.

\begin{tabular}{|c|c|c|}
\hline $\begin{array}{c}\text { Displayed } \\
\text { Power (Watts) }\end{array}$ & $\begin{array}{c}\text { Measured } \\
\text { Power (Watts) }\end{array}$ & $\begin{array}{c}\text { Percent } \\
\text { Difference (\%) }\end{array}$ \\
\hline 400 & 261.86 & -34.54 \\
\hline 400 & 281.46 & -29.64 \\
\hline 400 & 266.75 & -33.31 \\
\hline 400 & 255.73 & -36.07 \\
\hline 400 & 227.68 & -43.08 \\
\hline 400 & 213.42 & -46.65 \\
\hline 400 & 203.74 & -49.06 \\
\hline 400 & 203.74 & -49.06 \\
\hline 400 & 230.34 & -42.42 \\
\hline 400 & 213.85 & -46.54 \\
\hline 400 & 210.93 & -47.27 \\
\hline 400 & 223.22 & -44.19 \\
\hline 400 & 217.08 & -45.73 \\
\hline 400 & 185.58 & -53.60 \\
\hline 400 & 185.58 & -53.60 \\
\hline 400 & 188.09 & -52.98 \\
\hline 400 & 168.53 & -57.87 \\
\hline 400 & 182.85 & -54.29 \\
\hline 400 & 182.85 & -54.29 \\
\hline 400 & 180.91 & -54.77 \\
\hline 400 & 184.60 & -53.85 \\
\hline 400 & 180.91 & -54.77 \\
\hline
\end{tabular}

Table 7. Repeatability parameters recorded at varying shaft speeds and at 400 Watts.

\begin{tabular}{|c|c|c|c|}
\hline $\begin{array}{c}\text { Average percent } \\
\text { difference (\%) }\end{array}$ & $\begin{array}{c}\text { Average } \\
\text { (Watts) }\end{array}$ & $\begin{array}{c}\text { Standard } \\
\text { Deviation } \\
\text { (Watts) }\end{array}$ & Percentage \pm \\
\hline-47.16 & 211.35 & 31.86 & $15.07 \%$ \\
\hline
\end{tabular}


Table 8 below lists the raw data collected at one high-speed trial. "Cal a" and "Cal $b$ " refer to the values recorded during the shunt calibration. The "gain" is the amplifier gain and "excitation" is the Wheatstone bridge excitation voltage. Calculations were carried out as shown in Table 9.

\begin{tabular}{|c|c|c|c|}
\hline Test: $\mathbf{8 0 0 0 + ~ R P M}$ & $b=-668 m V$ & gain $=1.9$ & \\
\hline & $\mathrm{Cal} \mathrm{a}=676 \mathrm{mV}$ & exitation $=10 \mathrm{v}$ & \\
\hline Ib & $\mathbf{v}$ & ratio & \\
\hline 0.5 & 0.718 & 0.696 & \\
\hline 0.75 & 1.06 & 0.707 & \\
\hline 1 & 1.22 & 0.819 & \\
\hline 1.5 & 1.68 & 0.892 & \\
\hline 2 & 2.2 & 0.909 & \\
\hline 3 & 3.2 & 0.937 & \\
\hline 4 & 4.2 & 0.952 & \\
\hline $\begin{array}{c}\text { Displayed Speed } \\
\text { (km/hour) }\end{array}$ & $\begin{array}{c}\text { Displayed } \\
\text { Power (Watts) }\end{array}$ & $\begin{array}{c}\text { RPM } \\
\text { (optical } \\
\text { sensor) }\end{array}$ & $\begin{array}{c}\text { Average } \\
\text { Voltage } \\
\text { (Volts) } \\
\end{array}$ \\
\hline 43.8 & 400 & 8036 & 0.95 \\
\hline 45.2 & 400 & 8298 & 0.809 \\
\hline 46.4 & 301 & 8518 & 0.609 \\
\hline 43.8 & 282 & 8040 & 0.879 \\
\hline 43.8 & 480 & 8040 & 1.075 \\
\hline 43.8 & 470 & 8040 & 1.05 \\
\hline 43.8 & 450 & 8040 & 1 \\
\hline 43.8 & 420 & 8040 & 0.88 \\
\hline 43.8 & 370 & 8040 & 0.81 \\
\hline 43.8 & 500 & 8042 & 1.15 \\
\hline 43.8 & 530 & 8042 & 1.275 \\
\hline 43.8 & 590 & 8042 & 1.475 \\
\hline 43.8 & 640 & 8042 & 1.58 \\
\hline 43.8 & 620 & 8042 & 1.56 \\
\hline 43.8 & 610 & 8042 & 1.57 \\
\hline 43.8 & 590 & 8042 & 1.47 \\
\hline 43.8 & 400 & 8046 & 0.905 \\
\hline 43.8 & 380 & 8046 & 0.85 \\
\hline 43.8 & 360 & 8046 & 0.81 \\
\hline 43.8 & 340 & 8046 & 0.78 \\
\hline 43.8 & 310 & 8042 & 0.685 \\
\hline 45.2 & 310 & 8303 & 0.63 \\
\hline 45.2 & 340 & 8303 & 0.71 \\
\hline 45.2 & 370 & 8303 & 0.725 \\
\hline
\end{tabular}




\begin{tabular}{|c|c|c|c|}
\hline 45.2 & 400 & 8303 & 0.75 \\
\hline \multicolumn{4}{|c|}{ Table 8 (continued). Magnetic resistance unit raw test data. } \\
\hline $\begin{array}{c}\text { Displayed Speed } \\
\text { (km/hour) }\end{array}$ & $\begin{array}{c}\text { Displayed } \\
\text { Power (Watts) }\end{array}$ & $\begin{array}{c}\text { RPM } \\
\text { (optical } \\
\text { sensor) }\end{array}$ & $\begin{array}{c}\text { Average } \\
\text { Voltage } \\
\text { (Volts) }\end{array}$ \\
\hline 50 & 400 & 9186 & 0.745 \\
\hline 50 & 420 & 9186 & 0.772 \\
\hline 50 & 450 & 9186 & 0.79 \\
\hline 50 & 500 & 9186 & 0.933 \\
\hline 52 & 400 & 9186 & 0.735 \\
\hline 43.8 & 400 & 8047 & 0.875 \\
\hline 43.8 & 420 & 8047 & 0.9 \\
\hline 43.8 & 420 & 8041 & 0.899 \\
\hline 43.8 & 450 & 8041 & 1.05 \\
\hline 43.8 & 470 & 8041 & 1.063 \\
\hline 45.1 & 470 & 8290 & 1.042 \\
\hline 45.1 & 500 & 8290 & 1.053 \\
\hline 45.1 & 440 & 8290 & 0.93 \\
\hline 45.1 & 420 & 8290 & 0.872 \\
\hline 45.1 & 400 & 8290 & 0.802 \\
\hline 46.8 & 400 & 8600 & 0.774 \\
\hline 46.8 & 450 & 8600 & 0.808 \\
\hline 46.8 & 520 & 8600 & 1.055 \\
\hline 46.8 & 600 & 8600 & 1.372 \\
\hline 46.8 & 340 & 8600 & 0.678 \\
\hline 46.8 & 310 & 8600 & 0.621 \\
\hline 46.8 & 300 & 8600 & 0.566 \\
\hline
\end{tabular}




\begin{tabular}{|c|c|c|c|}
\hline \multicolumn{4}{|c|}{ Table 8 (continued). Magnetic resistance unit raw test data. } \\
\hline $\begin{array}{c}\text { Displayed Speed } \\
\text { (km/hour) }\end{array}$ & $\begin{array}{c}\text { Displayed } \\
\text { Power (Watts) }\end{array}$ & $\begin{array}{c}\text { RPM } \\
\text { (optical } \\
\text { sensor) }\end{array}$ & $\begin{array}{c}\text { Average } \\
\text { Voltage } \\
\text { (Volts) }\end{array}$ \\
\hline 43.8 & 400 & 8050 & 0.957 \\
\hline 43.8 & 283 & 8050 & 0.628 \\
\hline 43.8 & 500 & 8050 & 1.24 \\
\hline 43.8 & 283 & 8050 & 0.625 \\
\hline 43.8 & 510 & 8050 & 1.279 \\
\hline 43.8 & 320 & 8050 & 0.722 \\
\hline 43.8 & 370 & 8050 & 0.832 \\
\hline 43.8 & 400 & 8050 & 0.906 \\
\hline 43.8 & 370 & 8050 & 0.851 \\
\hline 43.8 & 340 & 8050 & 0.802 \\
\hline 43.8 & 320 & 8050 & 0.719 \\
\hline 43.8 & 300 & 8050 & 0.658 \\
\hline 43.8 & 350 & 8050 & 0.787 \\
\hline 43.8 & 400 & 8050 & 0.897 \\
\hline 43.8 & 400 & 8050 & 0.935 \\
\hline 43.8 & 380 & 8050 & 0.86 \\
\hline 43.8 & 350 & 8050 & 0.819 \\
\hline 43.8 & 310 & 8050 & 0.687 \\
\hline 43.8 & 400 & 8050 & 0.916 \\
\hline 43.8 & 440 & 8050 & 1.027 \\
\hline 43.8 & 295 & 8050 & 0.653 \\
\hline 43.8 & 370 & 8050 & 0.843 \\
\hline 43.80 & 599 & 8050 & 1.67 \\
\hline 55.66 & 370 & 10230 & 0.59 \\
\hline 55.66 & 420 & 10230 & 0.677 \\
\hline \multicolumn{4}{|l|}{ No Power Setting } \\
\hline Displayed Speed km/hour & Displayed Watts & RPM & Vavg \\
\hline 43.80 & 295 & 8050 & 0.661 \\
\hline 45.60 & 309 & 8380 & 0.652 \\
\hline 43.80 & 336 & 8050 & 0.761 \\
\hline 45.55 & 351 & 8371 & 0.781 \\
\hline 43.80 & 517 & 8050 & 1.262 \\
\hline 45.54 & 540 & 8370 & 1.25 \\
\hline
\end{tabular}




\begin{tabular}{|c|c|c|c|c|c|c|c|c|c|}
\hline$\omega(\mathrm{rad} / \mathrm{sec})$ & V actual & lbf & $\begin{array}{c}\text { Force } \\
\text { (Newtons) }\end{array}$ & $\begin{array}{c}\text { Moment } \\
\text { Arm } \\
\text { (meters) }\end{array}$ & $\begin{array}{c}\text { Torque } \\
\left(\mathbf{N}^{*} \mathrm{~m}\right)\end{array}$ & $\begin{array}{c}\text { Watts } \\
\text { displayed }\end{array}$ & $\begin{array}{c}\text { Watts } \\
\text { Calculated }\end{array}$ & $\begin{array}{c}\mathrm{km} / \mathrm{hr} \\
\text { (calculated) }\end{array}$ & $\begin{array}{c}\text { mph } \\
\text { (calculated) }\end{array}$ \\
\hline 841.53 & 0.95 & 0.72 & 3.18 & 0.09 & 0.27 & 400.00 & 227.68 & 42.41 & 26.35 \\
\hline 868.96 & 0.81 & 0.57 & 2.55 & 0.09 & 0.22 & 400.00 & 188.09 & 43.80 & 27.21 \\
\hline 892.00 & 0.61 & 0.37 & 1.64 & 0.09 & 0.14 & 301.00 & 124.64 & 44.96 & 27.93 \\
\hline 841.95 & 0.88 & 0.64 & 2.86 & 0.09 & 0.24 & 282.00 & 204.86 & 42.43 & 26.37 \\
\hline 841.95 & 1.08 & 0.84 & 3.75 & 0.09 & 0.32 & 480.00 & 268.17 & 42.43 & 26.37 \\
\hline 841.95 & 1.05 & 0.82 & 3.63 & 0.09 & 0.31 & 470.00 & 260.09 & 42.43 & 26.37 \\
\hline 841.95 & 1.00 & 0.77 & 3.41 & 0.09 & 0.29 & 450.00 & 243.94 & 42.43 & 26.37 \\
\hline 841.95 & 0.88 & 0.64 & 2.87 & 0.09 & 0.24 & 420.00 & 205.18 & 42.43 & 26.37 \\
\hline 841.95 & 0.81 & 0.57 & 2.55 & 0.09 & 0.22 & 370.00 & 182.57 & 42.43 & 26.37 \\
\hline 842.16 & 1.15 & 0.92 & 4.09 & 0.09 & 0.35 & 500.00 & 292.47 & 42.44 & 26.37 \\
\hline 842.16 & 1.28 & 1.05 & 4.65 & 0.09 & 0.40 & 530.00 & 332.86 & 42.44 & 26.37 \\
\hline 842.16 & 1.48 & 1.25 & 5.55 & 0.09 & 0.47 & 590.00 & 397.48 & 42.44 & 26.37 \\
\hline 842.16 & 1.58 & 1.35 & 6.03 & 0.09 & 0.51 & 640.00 & 431.40 & 42.44 & 26.37 \\
\hline 842.16 & 1.56 & 1.33 & 5.94 & 0.09 & 0.50 & 620.00 & 424.94 & 42.44 & 26.37 \\
\hline 842.16 & 1.57 & 1.34 & 5.98 & 0.09 & 0.51 & 610.00 & 428.17 & 42.44 & 26.37 \\
\hline 842.16 & 1.47 & 1.24 & 5.53 & 0.09 & 0.47 & 590.00 & 395.86 & 42.44 & 26.37 \\
\hline 842.58 & 0.91 & 0.67 & 2.98 & 0.09 & 0.25 & 400.00 & 213.42 & 42.47 & 26.39 \\
\hline 842.58 & 0.85 & 0.61 & 2.73 & 0.09 & 0.23 & 380.00 & 195.64 & 42.47 & 26.39 \\
\hline 842.58 & 0.81 & 0.57 & 2.55 & 0.09 & 0.22 & 360.00 & 182.71 & 42.47 & 26.39 \\
\hline 842.58 & 0.78 & 0.54 & 2.42 & 0.09 & 0.21 & 340.00 & 173.01 & 42.47 & 26.39 \\
\hline 842.16 & 0.69 & 0.45 & 1.99 & 0.09 & 0.17 & 310.00 & 142.23 & 42.44 & 26.37 \\
\hline 869.49 & 0.63 & 0.39 & 1.74 & 0.09 & 0.15 & 310.00 & 128.50 & 43.82 & 27.23 \\
\hline 869.49 & 0.71 & 0.47 & 2.10 & 0.09 & 0.18 & 340.00 & 155.18 & 43.82 & 27.23 \\
\hline
\end{tabular}




\section{APPENDIX I. (CONTINUED) MATHCAD CALCULATION SHEETS}

Mathcad 2000 Professional was used to calculate the required test speeds and torques for testing. Calculations used are as follows:

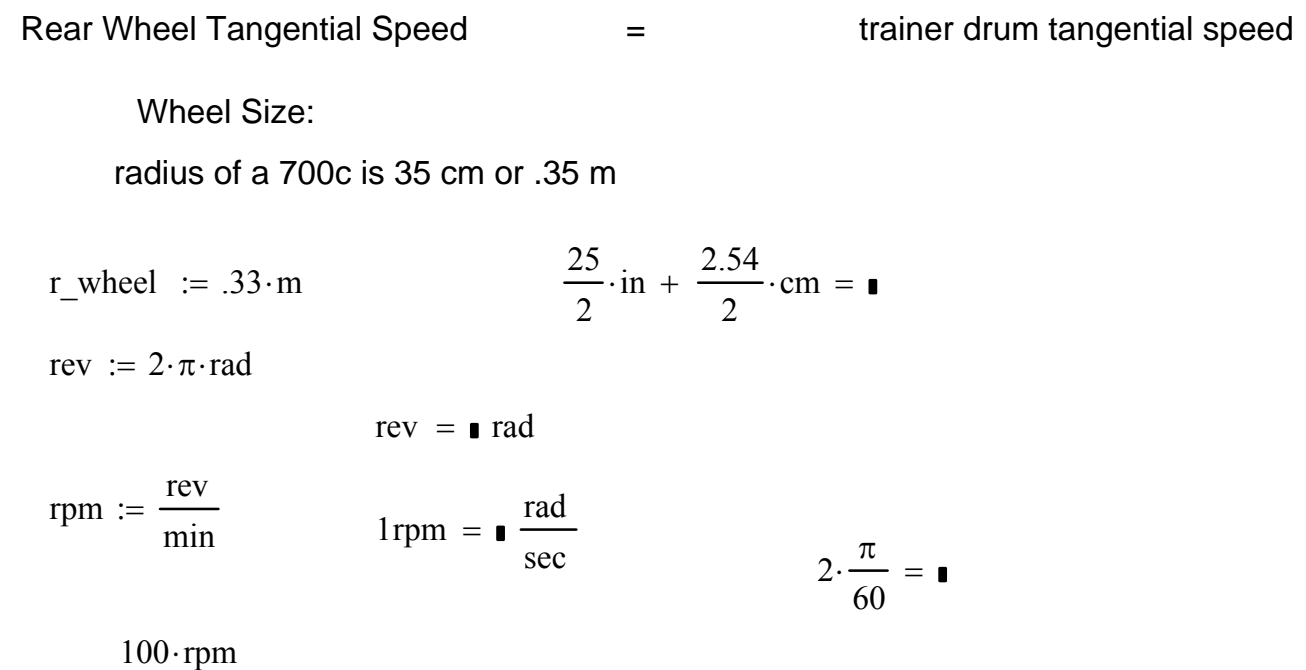

Desired pedal rate for study is 90 RPM

pedal_rate $:=90 \cdot \mathrm{rpm}$

$$
\begin{aligned}
\text { pedal_rate } & =\frac{\mathrm{rad}}{\mathrm{sec}} \\
\text { gear_ratio } & :=\frac{53}{17}
\end{aligned}
$$$$
\text { pedaling rate or }
$$$$
\text { crank speed }
$$$$
\text { The study used a } 53 \text { tooth chainring in the front and a } 17
$$
tooth sprocket in the rear.

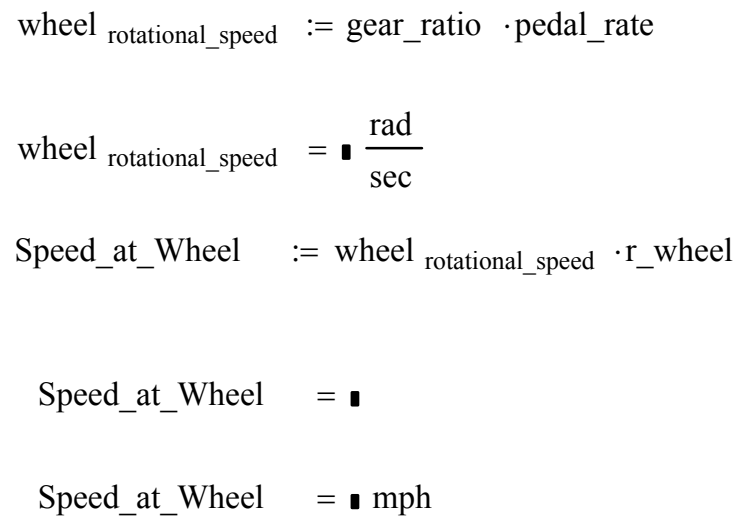




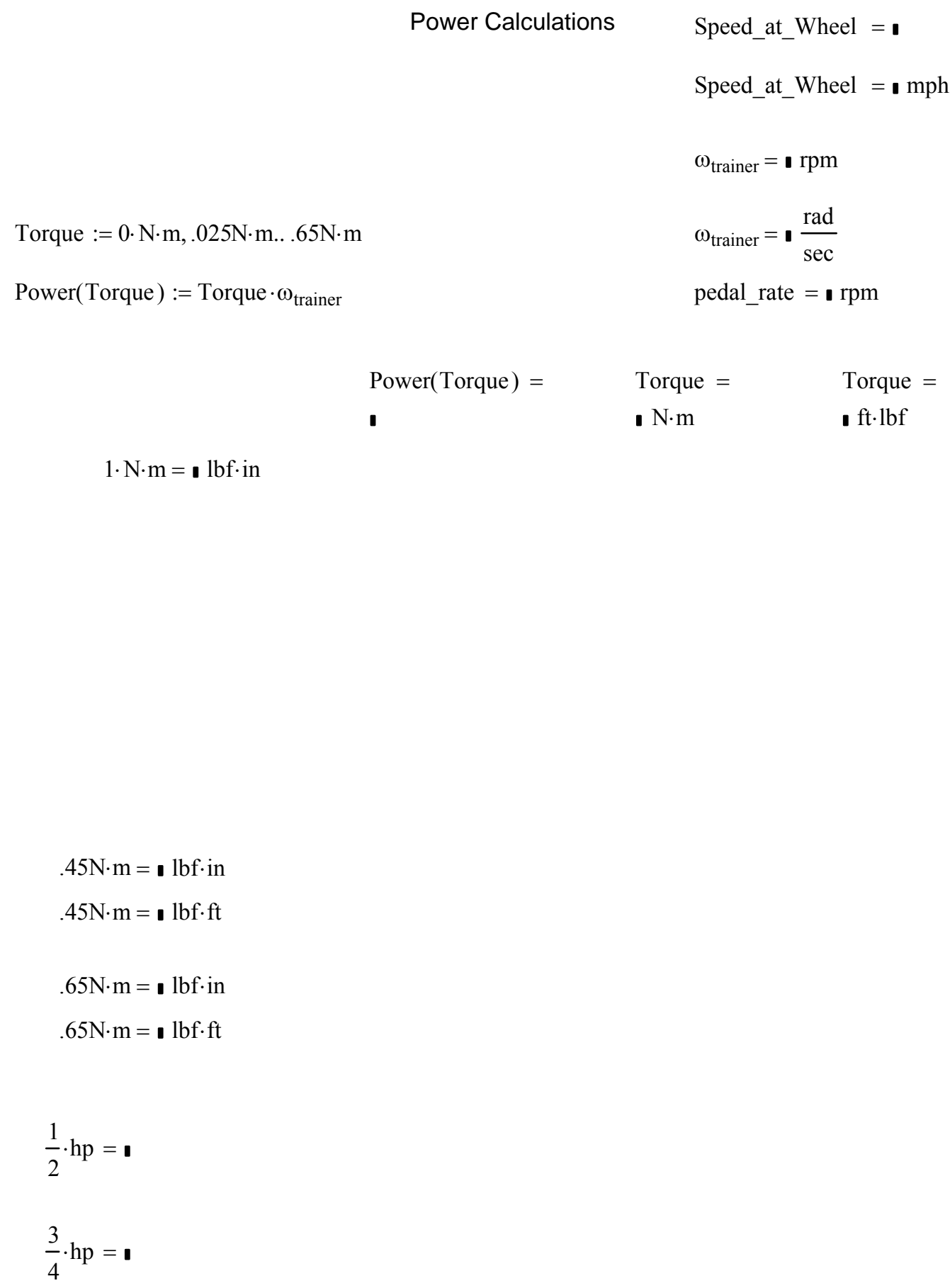


Torque $:=.425 \cdot \mathrm{lbf} \cdot \mathrm{ft}$

Moment_Arm $:=0.25 \cdot \mathrm{in}, .55 \cdot \mathrm{in} . .12 \cdot \mathrm{in}$

Moment_Arm =

\begin{tabular}{|l|}
\hline 0.25 \\
\hline 0.55 \\
\hline 0.85 \\
\hline 1.15 \\
\hline 1.45 \\
\hline 1.75 \\
\hline 2.05 \\
\hline 2.35 \\
\hline 2.65 \\
\hline 2.95 \\
\hline 3.25 \\
\hline 3.55 \\
\hline 3.85 \\
\hline 4.15 \\
\hline 4.45 \\
\hline 4.75 \\
\hline 5.05 \\
\hline 5.35 \\
\hline 5.65 \\
\hline 5.95 \\
\hline 6.25 \\
\hline 6.55 \\
\hline 6.85 \\
\hline 7.15 \\
\hline 7.45 \\
\hline 7.75 \\
\hline 8.05 \\
\hline 8.35 \\
\hline 8.65 \\
\hline 8.95 \\
\hline 9.25 \\
\hline 9.55 \\
\hline 9.85 \\
\hline
\end{tabular}

Force(Moment_Arm) =

\begin{tabular}{|r|}
\hline 20.4 \\
\hline 9.273 \\
\hline 6 \\
\hline 4.435 \\
\hline 3.517 \\
\hline 2.914 \\
\hline 2.488 \\
\hline 2.17 \\
\hline 1.925 \\
\hline 1.729 \\
\hline 1.569 \\
\hline 1.437 \\
\hline 1.325 \\
\hline 1.229 \\
\hline 1.146 \\
\hline 1.074 \\
\hline 1.01 \\
\hline 0.953 \\
\hline 0.903 \\
\hline 0.857 \\
\hline 0.816 \\
\hline 0.779 \\
\hline 0.745 \\
\hline 0.713 \\
\hline 0.685 \\
\hline 0.658 \\
\hline 0.634 \\
\hline 0.611 \\
\hline 0.59 \\
\hline 0.57 \\
\hline 0.551 \\
\hline 0.534 \\
\hline 0.518 \\
\hline
\end{tabular}

$$
\text { Force(Moment_Arm) }:=\frac{\text { Torque }}{\text { Moment_Arm }}
$$

$8 \mathrm{~cm}=3.15 \mathrm{in} \quad$ so I need $1.5 \mathrm{lbf}$ 


\section{APPENDIX II. PEAK PLANTAR STRESS DATA}

Data used for statistical analysis of plantar stress listed in Table 10.

\begin{tabular}{|c|c|c|c|}
\hline Subject Number & Shoe Type & Side & $\begin{array}{c}\text { Average Peak } \\
\text { Plantar Stress } \\
\text { (kPa) } \\
\end{array}$ \\
\hline 1 & 152 & Left & 86.36383 \\
\hline 1 & 152 & Right & 98.26901 \\
\hline 1 & 220 & Left & 105.9819 \\
\hline 1 & 220 & Right & 117.2672 \\
\hline 2 & 152 & Left & 174.6033 \\
\hline 2 & 152 & Right & 147.5275 \\
\hline 2 & 220 & Left & 166.9187 \\
\hline 2 & 220 & Right & 156.5733 \\
\hline 3 & 152 & Left & 102.8248 \\
\hline 3 & 152 & Right & 98.27877 \\
\hline 3 & 220 & Left & 140.7059 \\
\hline 3 & 220 & Right & 167.5602 \\
\hline 4 & 152 & Left & 97.61723 \\
\hline 4 & 152 & Right & 107.319 \\
\hline 4 & 220 & Left & 99.3367 \\
\hline 4 & 220 & Right & 129.8738 \\
\hline 5 & 152 & Left & 128.061 \\
\hline 5 & 152 & Right & 86.34848 \\
\hline 5 & 220 & Left & 127.7 \\
\hline 5 & 220 & Right & 108.3296 \\
\hline 6 & 152 & Left & 103.6656 \\
\hline 6 & 152 & Right & 60.92608 \\
\hline 6 & 220 & Left & 119.8923 \\
\hline 6 & 220 & Right & 77.28963 \\
\hline 7 & 152 & Left & 81.65199 \\
\hline 7 & 152 & Right & 89.57115 \\
\hline 7 & 220 & Left & 122.7255 \\
\hline 7 & 220 & Right & 124.988 \\
\hline 8 & 152 & Left & 76.81019 \\
\hline 8 & 152 & Right & 176.6402 \\
\hline 8 & 220 & Left & 106.9314 \\
\hline 8 & 220 & Right & 149.3419 \\
\hline 9 & 152 & Left & 50.125 \\
\hline 9 & 152 & Right & 112.2339 \\
\hline 9 & 220 & Left & 125.0465 \\
\hline 9 & 220 & Right & 115.8214 \\
\hline 10 & 152 & Left & 53.00321 \\
\hline 10 & 152 & Right & 91.24561 \\
\hline 10 & 220 & Left & 74.27146 \\
\hline 10 & 220 & Right & 86.95329 \\
\hline
\end{tabular}




\begin{tabular}{|c|c|c|}
\hline \multicolumn{3}{|c|}{ Table 11. Averaged peak stress data with left and right shoes combined. } \\
\hline Subject & Shoe Model M152 & Shoe Model M220 \\
\hline 1 & 92.32 & 111.62 \\
\hline 2 & 161.07 & 161.75 \\
\hline 3 & 107.70 & 154.13 \\
\hline 4 & 98.39 & 114.61 \\
\hline 5 & 107.20 & 118.01 \\
\hline 6 & 91.07 & 98.59 \\
\hline 7 & 85.61 & 123.86 \\
\hline 8 & 126.73 & 128.14 \\
\hline 9 & 89.78 & 120.43 \\
\hline 10 & 69.69 & 80.61 \\
\hline
\end{tabular}




\section{APPENDIX III. CYCLING SHOE STIFFNESS AND DAMPING}

Fourth-order polynomials such as those in Figures 48 and 49 were entered into Mathcad. Target slopes such as that of Figure 43 were used to find the tangency points such as those in Figure 42 using the following Mathcad commands.

$$
\begin{aligned}
& \text { lower curve } \\
& 2 E+06 x 4-275257 x 3+21761 \times 2-873.93 x+13.339 \\
& \text { Lower(x) := } 2 \cdot 10^{6} \cdot x^{4}-275257 \cdot x^{3}+21761 \cdot x^{2}-873.93 x+13.339 \\
& \operatorname{Lower}^{\prime}(\mathrm{x}):=\frac{\mathrm{d}}{\mathrm{dx}} \operatorname{Lower}(\mathrm{x}) \\
& \text { upper curve } \\
& -683966 \times 4+102205 \times 3-41.199 \times 2-84.399 x+0.5539 \\
& \operatorname{Upper}(\mathrm{x}):=-683966 \mathrm{x}^{4}+102205 \mathrm{x}^{3}-41.199 \mathrm{x}^{2}-84.399 \mathrm{x}+.5539 \\
& \operatorname{Upper}^{\prime}(\mathrm{x}):=\frac{\mathrm{d}}{\mathrm{dx}} \operatorname{Upper}(\mathrm{x}) \\
& \text { Lower }(x) \rightarrow 2000000 x^{4}-275257 x^{3}+21761 \cdot x^{2}-873.93 x+13.339 \\
& \text { Lower' }(x) \rightarrow 8000000 x^{3}-825771 \cdot x^{2}+43522 x-873.93 \\
& \operatorname{Upper}(x) \rightarrow-683966 x^{4}+102205 x^{3}-41.199 x^{2}-84.399 x+.5539 \\
& \operatorname{Upper}^{\prime}(\mathrm{x}) \rightarrow-2735864 \mathrm{x}^{3}+306615 \mathrm{x}^{2}-82.398 \mathrm{x}-84.399
\end{aligned}
$$

copy and paste answers from above into these first derivative formulas to initialize:

$$
\text { lower curve }
$$

$$
\begin{gathered}
\text { Lower }(\mathrm{x}) \rightarrow 2000000 \mathrm{x}^{4}-275257 \mathrm{x}^{3}+21761 \cdot \mathrm{x}^{2}-873.93 \mathrm{x}+13.339 \\
\text { Lower' }(\mathrm{x}):=8000000 \mathrm{x}^{3}-825771 \cdot \mathrm{x}^{2}+43522 \mathrm{x}-873.93
\end{gathered}
$$

upper curve

$$
\begin{aligned}
& \operatorname{Upper}(\mathrm{x}) \rightarrow-683966 \mathrm{x}^{4}+102205 \mathrm{x}^{3}-41.199 \mathrm{x}^{2}-84.399 \mathrm{x}+.5539 \\
& \operatorname{Upper}^{\prime}(\mathrm{x}):=-2735864 \mathrm{x}^{3}+306615 \mathrm{x}^{2}-82.398 \mathrm{x}-84.399
\end{aligned}
$$




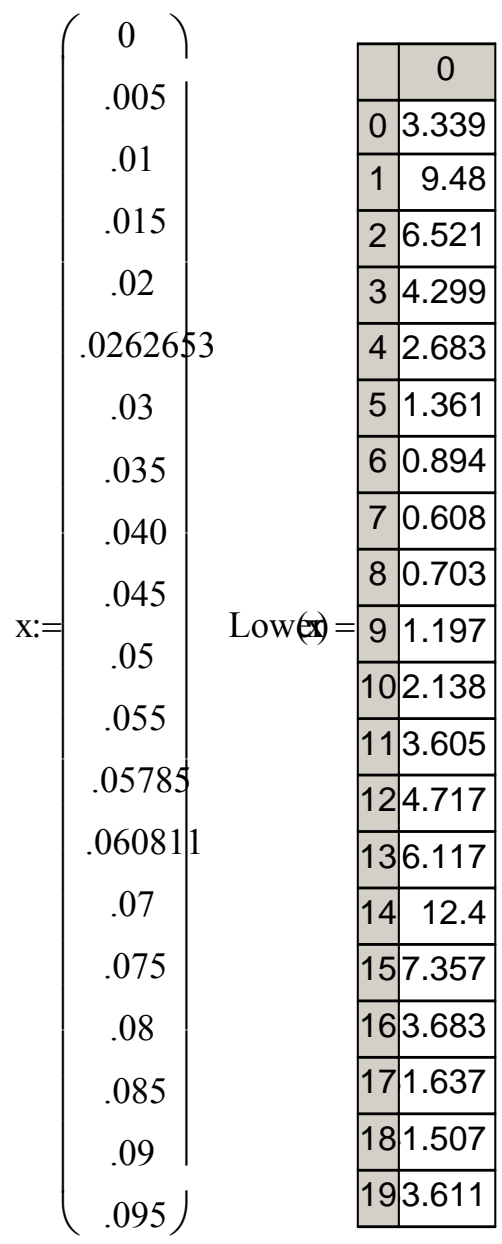

lower curve

First Derivative

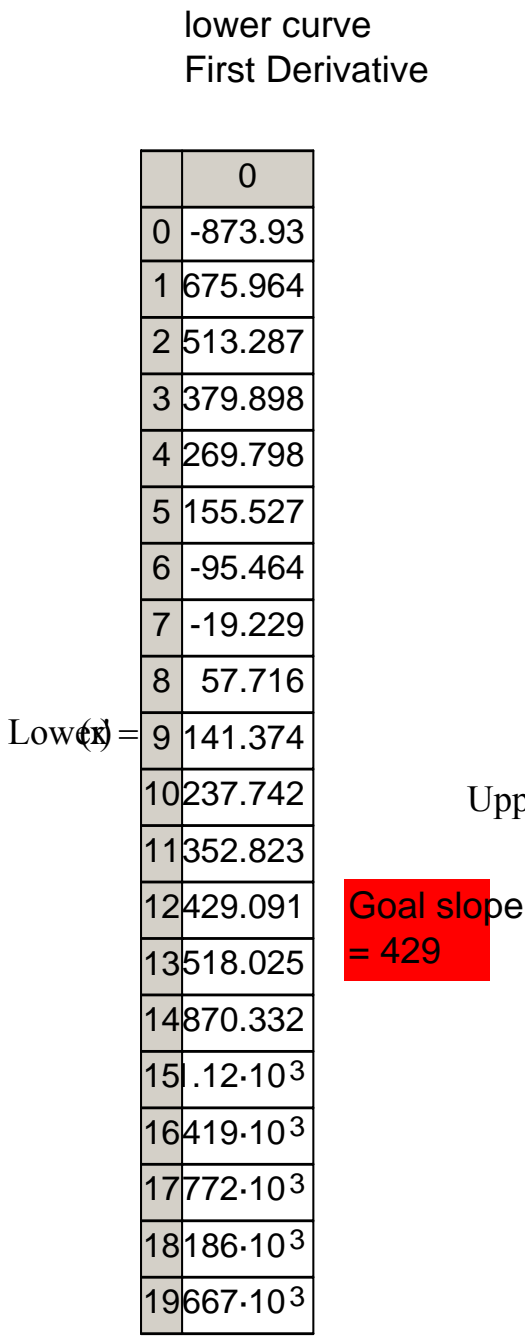

$x$ at desired slope on bottom curve is:

.05785 upper curve

First Derivative

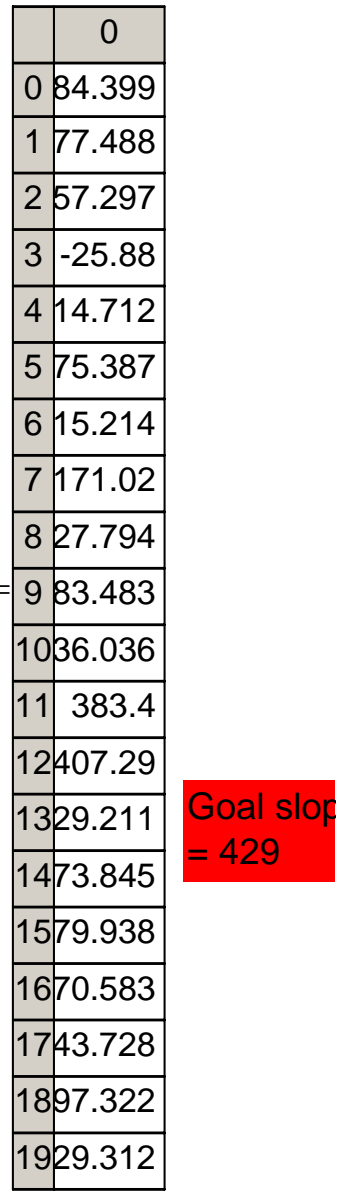

$x$ at desired slope on top curve is:

.0608 


\section{APPENDIX III. (CONTINUED) SHOE DAMPING CHARACTERISTICS}

Several damping related characteristics of cycling shoes were calculated by first finding the area inside each hysteresis loop (Figure 47). The textbook by Rao and the paper by Cooper describe these calculations. Area inside the hysteresis loops were found using the following steps:

a) Equations of lines across the upper bounds of the loops were found using Excel.

b) Equations of lines across the bottom borders were found using Excel.

c) The area under each curve equation generated in steps " $a$ " and " $b$ " was integrated using Mathcad.

d) The area of the lower curve was subtracted from the upper curve area giving the area between the curves.

Figures 48 and 49 display the equations of the upper and lower portions of a typical flexural force/displacement loop.

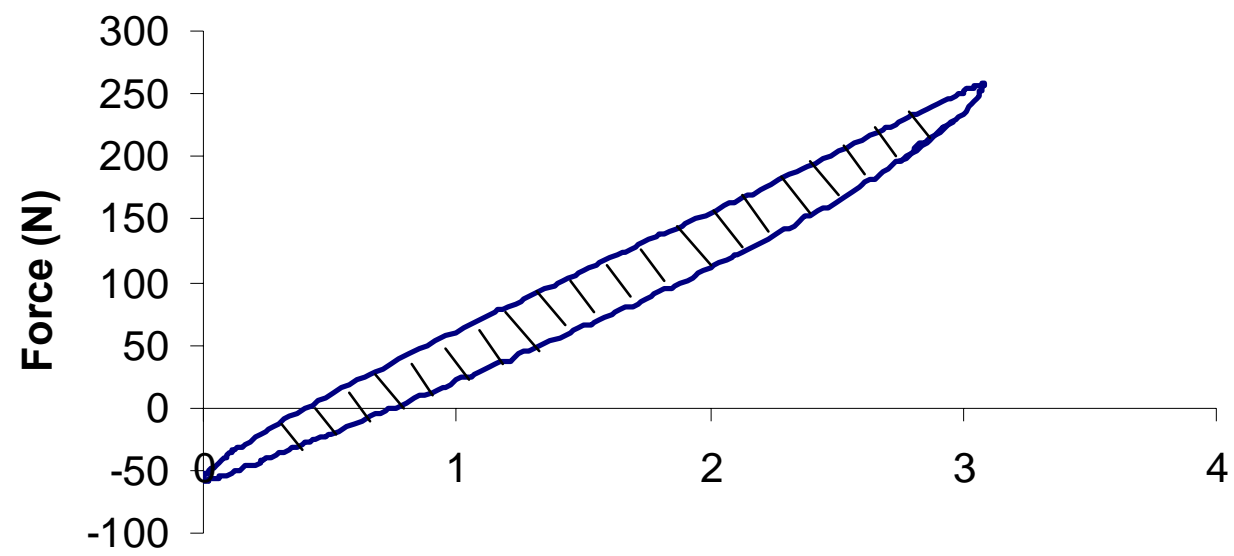

Displacement (cm)

Figure 47. Area inside a hysteresis loop. The area enclosed by the upper and lower bounds is a measure of energy lost inelastically per flex cycle. Area was found by subtracting the area under the top curve by that under the bottom curve. 


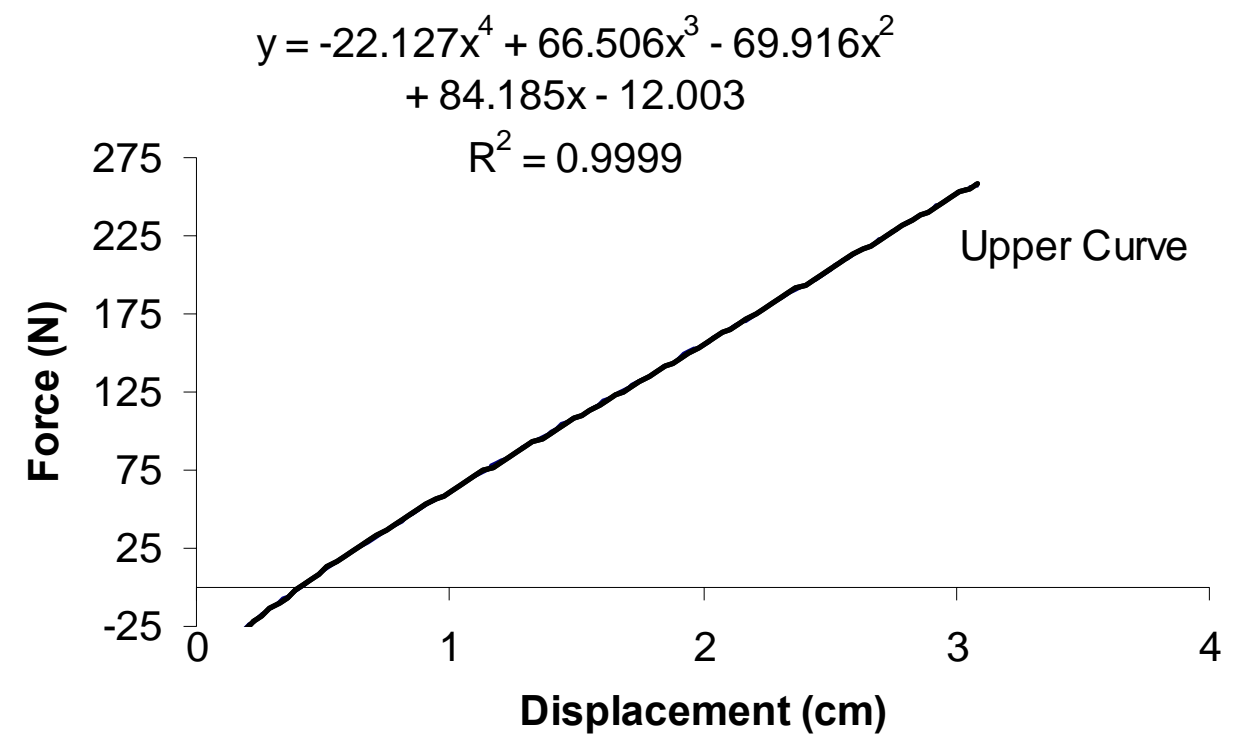

Figure 48. Force/displacement hysteresis curve upper boundary polynomial.

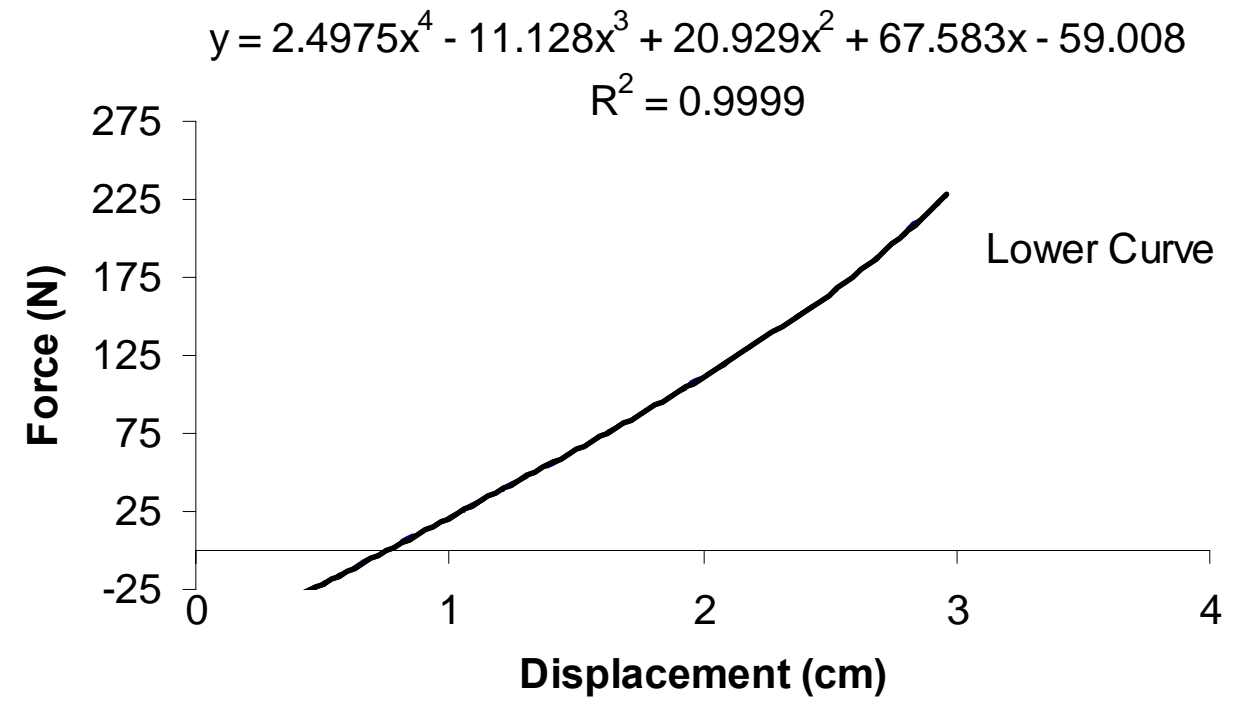

Figure 49. Force/displacement hysteresis curve lower boundary polynomial. 


\section{Damping Calculations}

After the equations of the hysteresis curve were established for both the upper and lower portions, each was integrated over the range of displacement about which each curve took place. An example of this calculation procedure is shown in Equations 3-5 below. The area under the curve in Figure 48, the upper bound, was found by using

$$
\text { Upper_area }:=\int_{0}^{\mathrm{X} \_} 8
$$

where $\mathrm{X} \_8$ is the displacement that the shoe underwent during that trial. The area under the lower curve was calculated in a similar manner using

$$
\text { Lower_area }:=\int_{0}^{\mathrm{X} \_8} 23.371 \cdot \mathrm{x}^{4}-40.997 \cdot \mathrm{x}^{3}+30.356 \mathrm{x}^{2}+38.593 \mathrm{x}-13.266 \mathrm{dx}
$$

where $\mathrm{X} \_8$ is the displacement that the shoe underwent during that specific trial. The area inside the curve, designated $\Delta \mathrm{W} 8$, was the energy loss per cycle due to internal shear losses. $\Delta \mathrm{W} 8$ was found by subtracting the area under the lower portion from that of the upper portion of the hysteresis loop using

$$
\Delta \mathrm{W} 8:=\text { Upper_area }- \text { Lower_area }
$$

A hysteresis damping constant, $\mathrm{h}$, was calculated using

$$
\mathrm{h} 8:=\frac{\Delta \mathrm{W} 8}{\pi \cdot \mathrm{X} \_8^{2} \cdot \omega \_ \text {bend }}
$$

where $\mathrm{h} 8$ is the hysteresis constant for trial $8, \Delta \mathrm{W} 8$ is the loss of energy per cycle for trial 8 calculated using the area inside the hysteresis curve (using equations 3-5), X_8 is the displacement recorded for trial 8 , and $\omega_{-}$bend is the frequency of oscillation during the test, in radians per second, which in this experiment was $4.712(.75 \mathrm{~Hz})$. The hysteretic damping ratio, $\beta$, was calculated using 


$$
\beta 8:=\frac{\mathrm{h} 8}{\mathrm{k} 8}
$$

where $\mathrm{k} 8$ is the stiffness chosen as described in Figure 40 or 45, depending on the test. Note that $\beta$ is simply the hysteretic damping constant h normalized by the stiffness. A logarithmic decrement calculation was also performed using

$$
\delta 8:=\pi \cdot \beta 8
$$

Finally, a corresponding viscous damping ratio, $\zeta$, was calculated with

$$
\zeta 8:=\frac{\delta 8}{\sqrt{(2 \cdot \pi)^{2}+\delta 8^{2}}}
$$

where $\delta 8$ is the logarithmic decrement of trial 8 .

Damping and vibration parameters for shoes in longitudinal bending are displayed in Figures 50 through 53. 


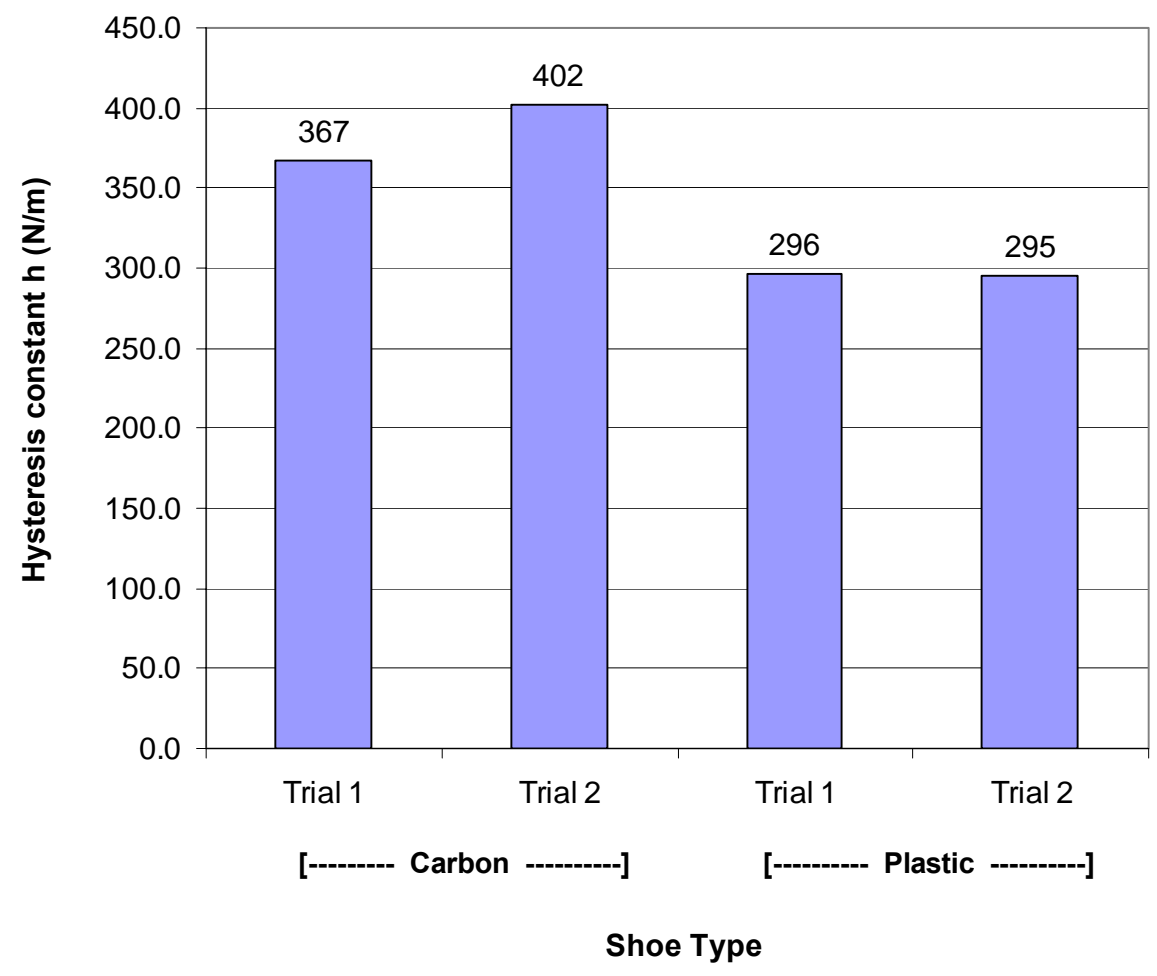

Figure 50. Hysteretic damping constant (h) of shoes in longitudinal bending.

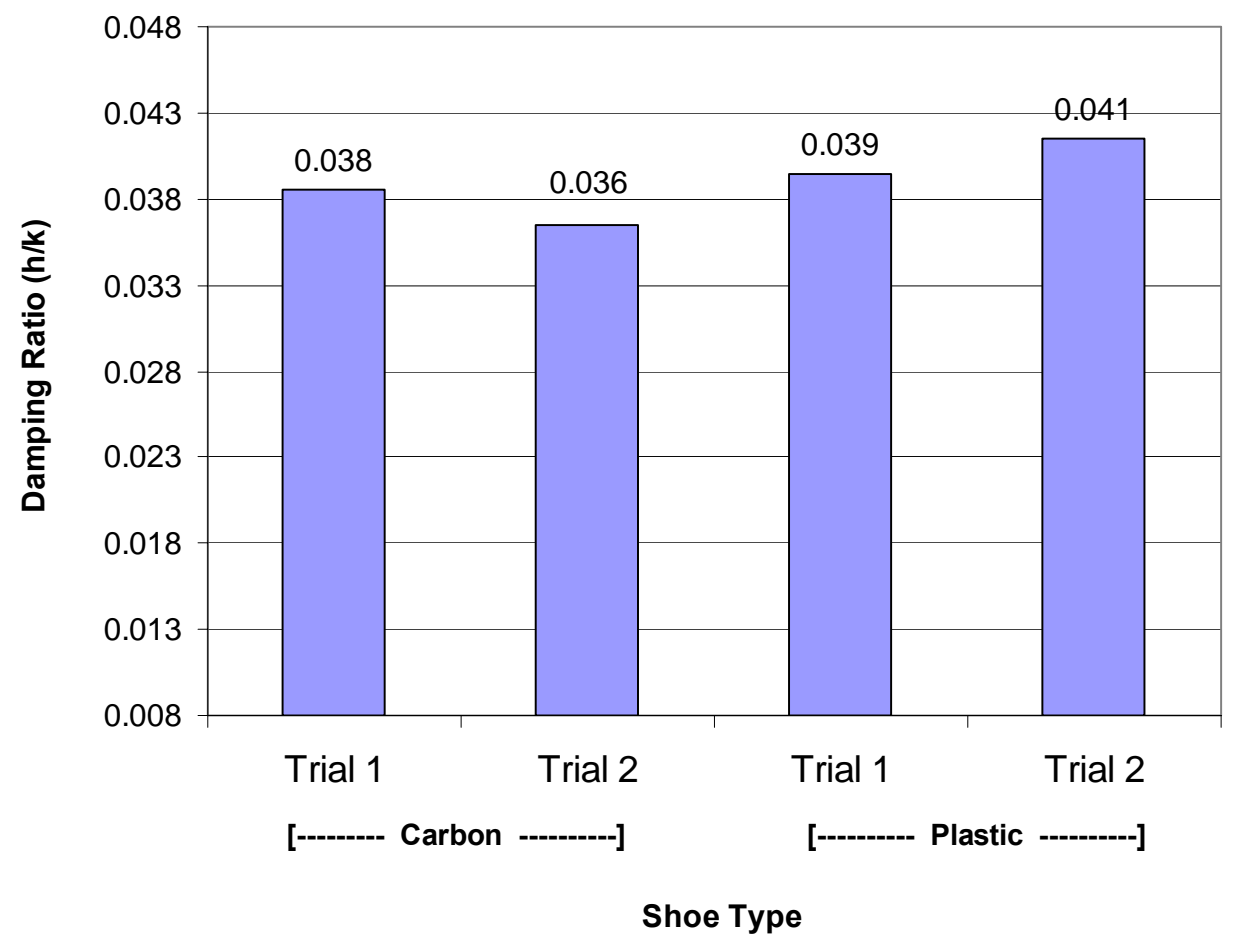

Figure 51. Hysteretic damping ratio ( $\beta$ )of shoes in longitudinal bending. 


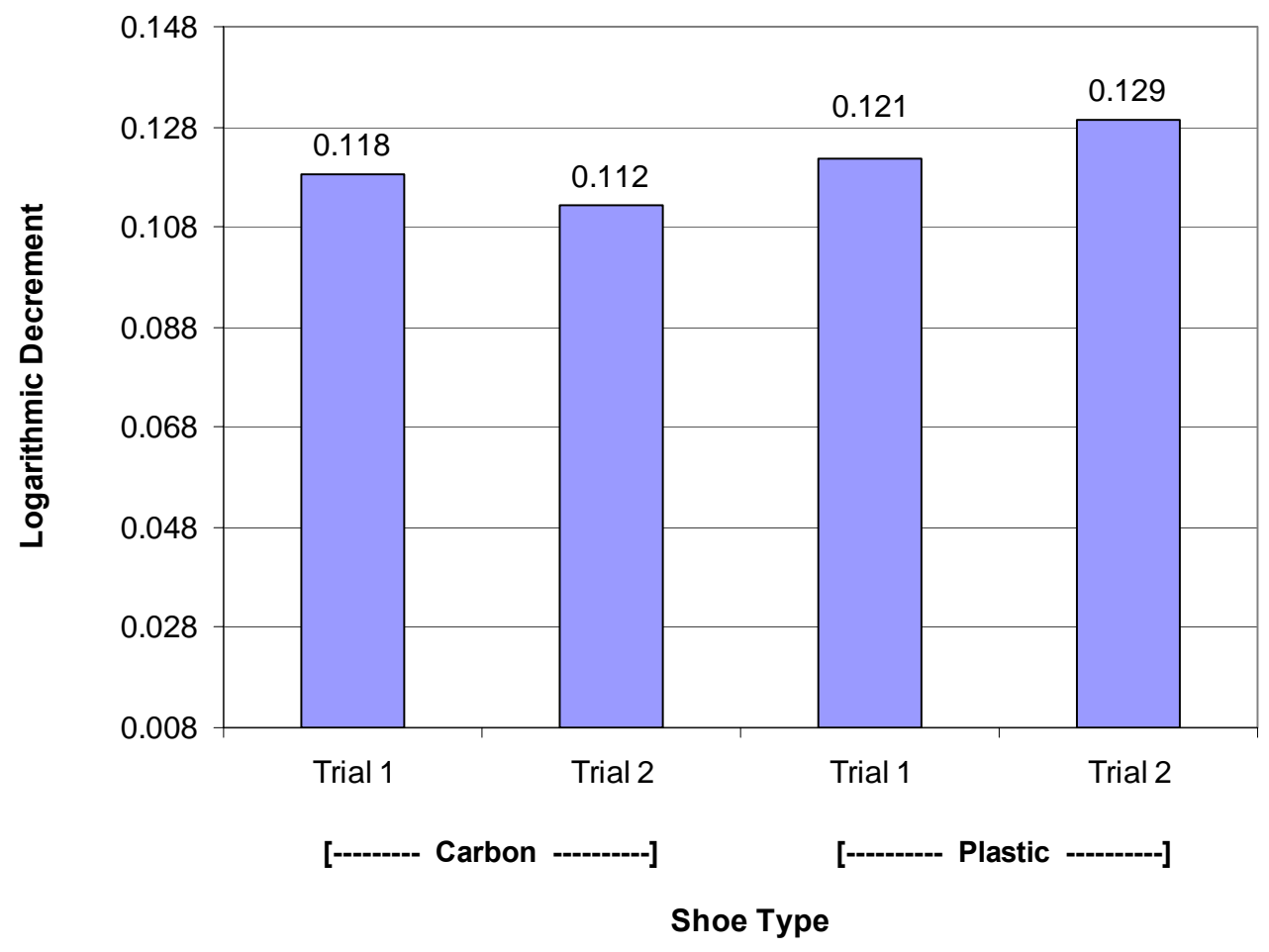

Figure 52. Logarithmic decrement $(\delta)$ of shoes in longitudinal bending.

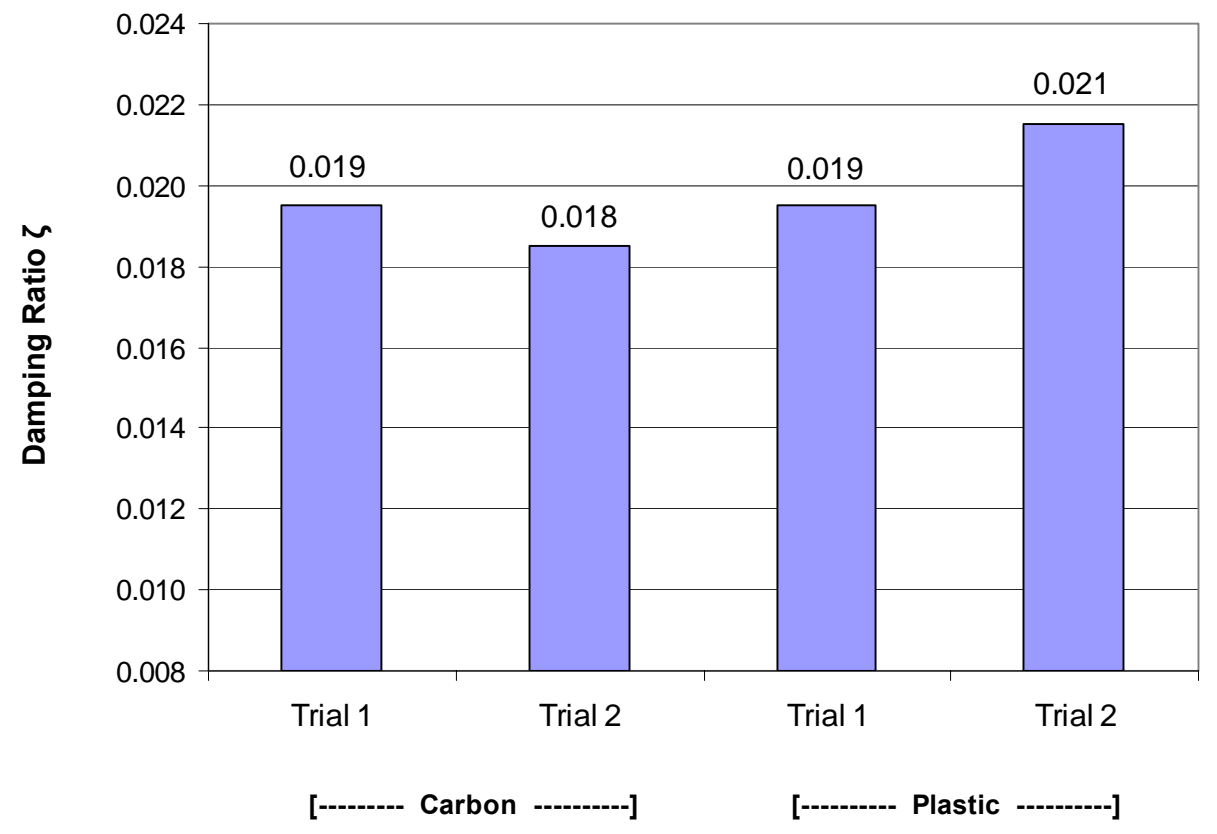

Shoe Type

Figure 53. Equivalent viscous damping ratio $(\xi)$ of cycling shoes in longitudinal bending. 
Mean values for hysteretic damping constant, hysteretic damping ratio, logarithmic decrement, and equivalent viscous damping ratio for shoes in longitudinal bending are shown in Table 12.

\begin{tabular}{|c|c|c|c|c|}
\hline \multicolumn{5}{|c|}{ Table 12. Damping of shoes in longitudinal bending per ASTM F-911. } \\
\hline Shoe Type & $\mathbf{h}(\mathrm{N} / \mathrm{m})$ & $\boldsymbol{\beta}$ & $\boldsymbol{\delta}$ & $\boldsymbol{\zeta}$ \\
\hline M220 & 384 & 0.037 & 0.115 & 0.019 \\
\hline M152 & 295 & 0.040 & 0.125 & 0.020 \\
\hline
\end{tabular}

\section{Damping Calculations in Three-Point Bending}

Damping and vibration parameters of shoes tested in the three-point bending test, calculated using Equations 3-9 are displayed in Figures 54 through 57. Calculations to determine $\mathrm{h}, \beta, \delta$, and $\zeta$ of the shoes in the three-point bending arrangement were repeated using Equations 3-9 established previously for the longitudinal bending test.

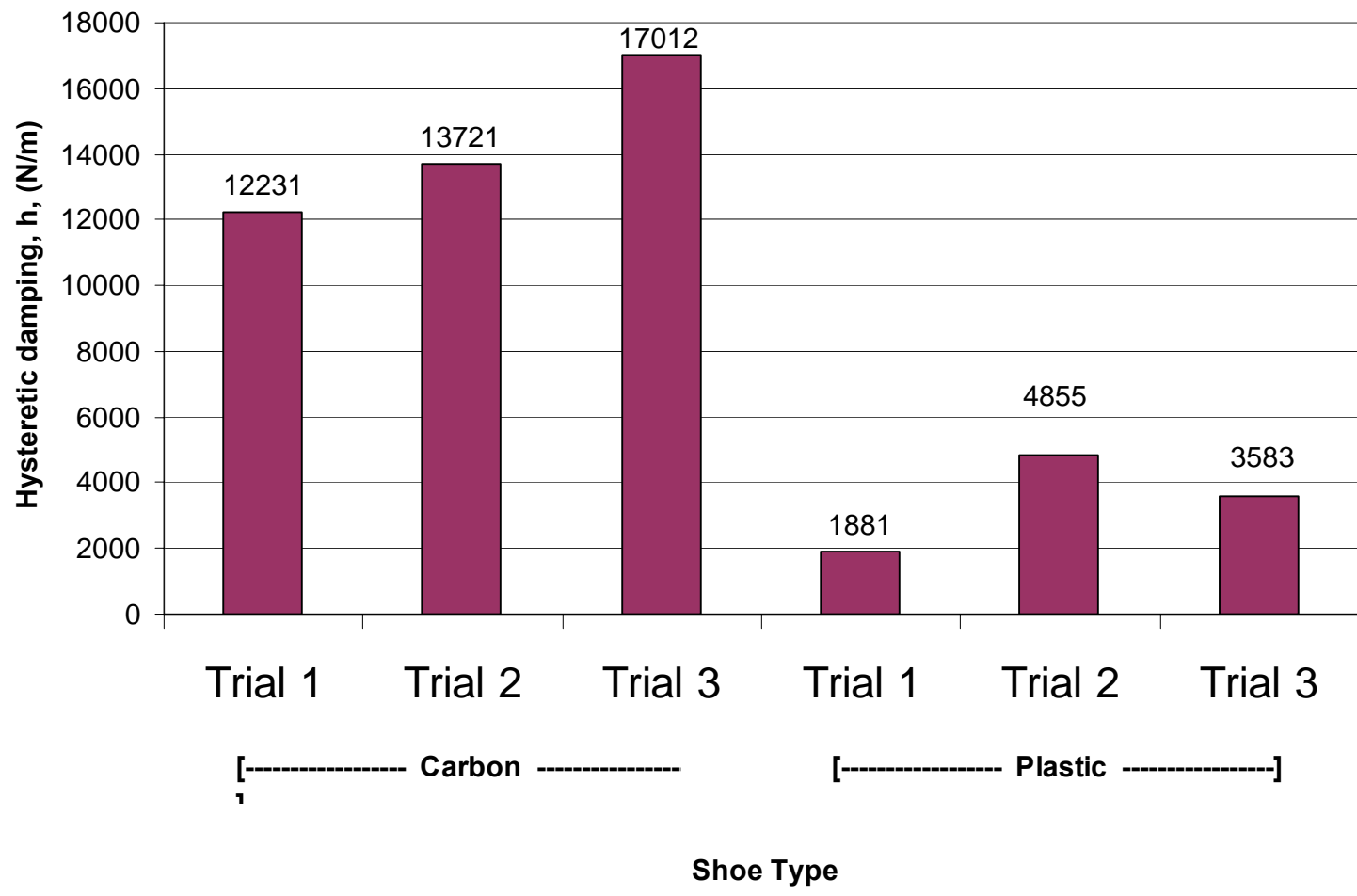

Figure 54. Hysteretic damping constant (h) of cycling shoes in three-point bending test. 


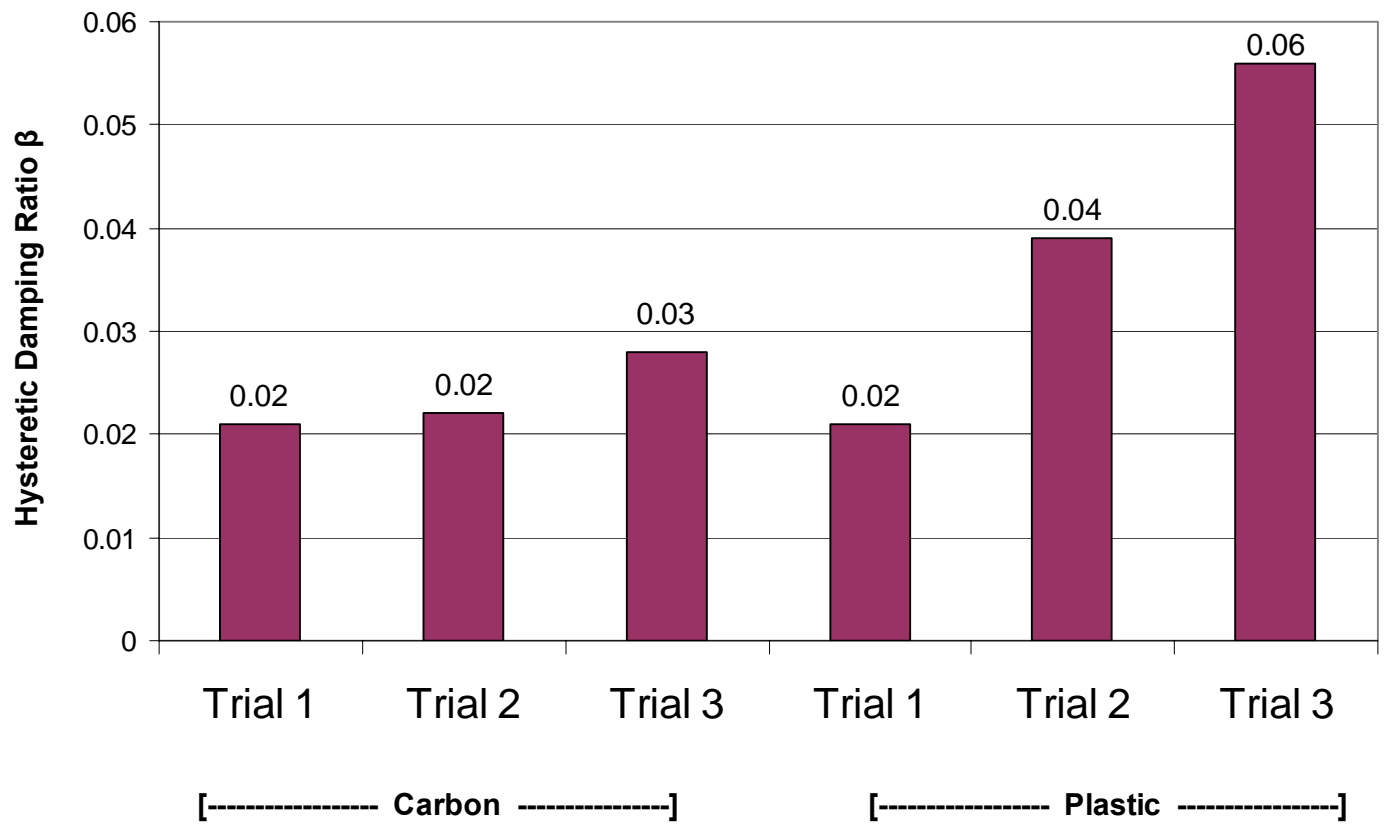

Shoe Type

Figure 55. Hysteretic damping ratio $(\beta)$ of cycling shoes in three-point bending.

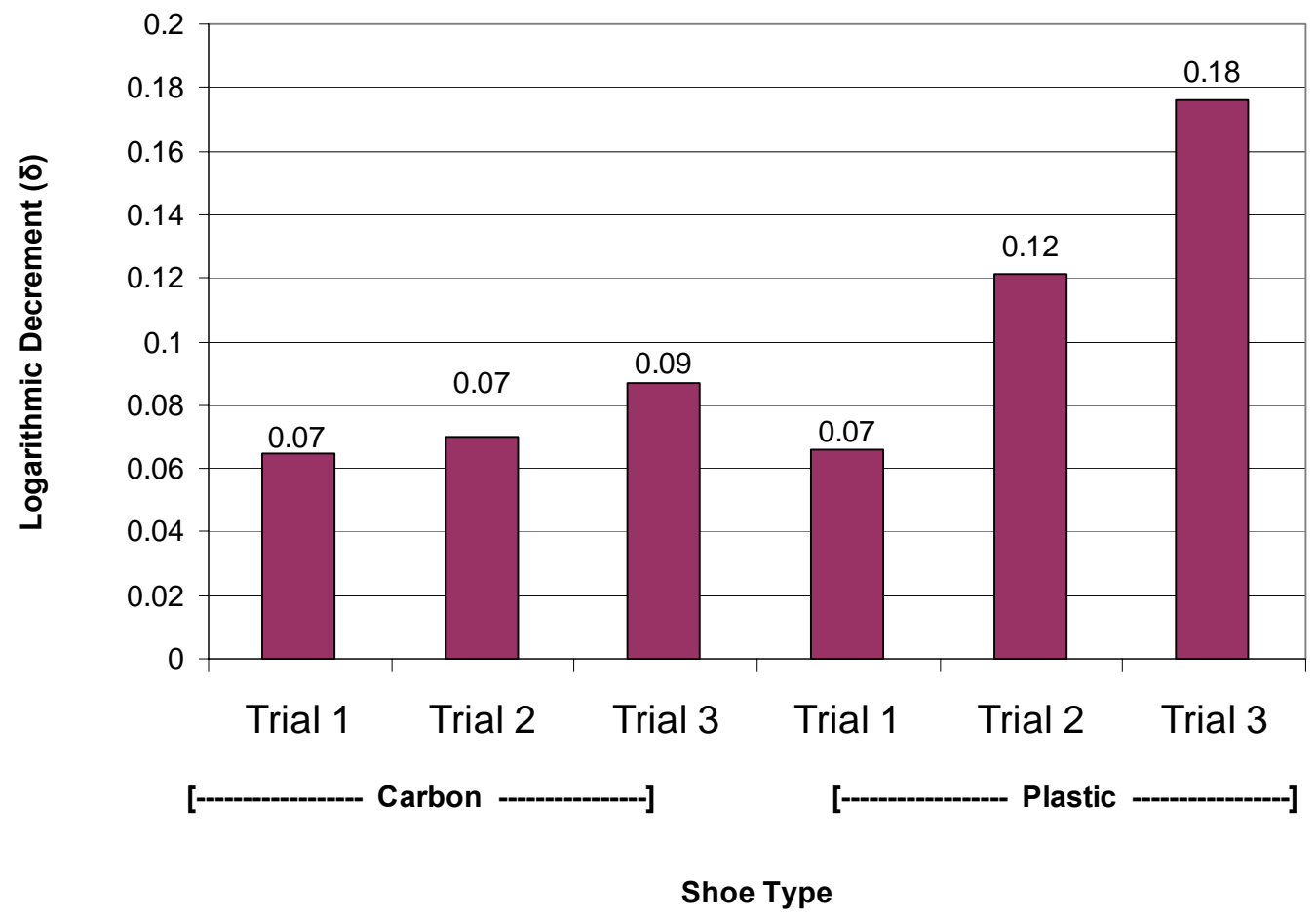

Figure 56. Logarithmic decrement $(\delta)$ of cycling shoes in three-point bending. 


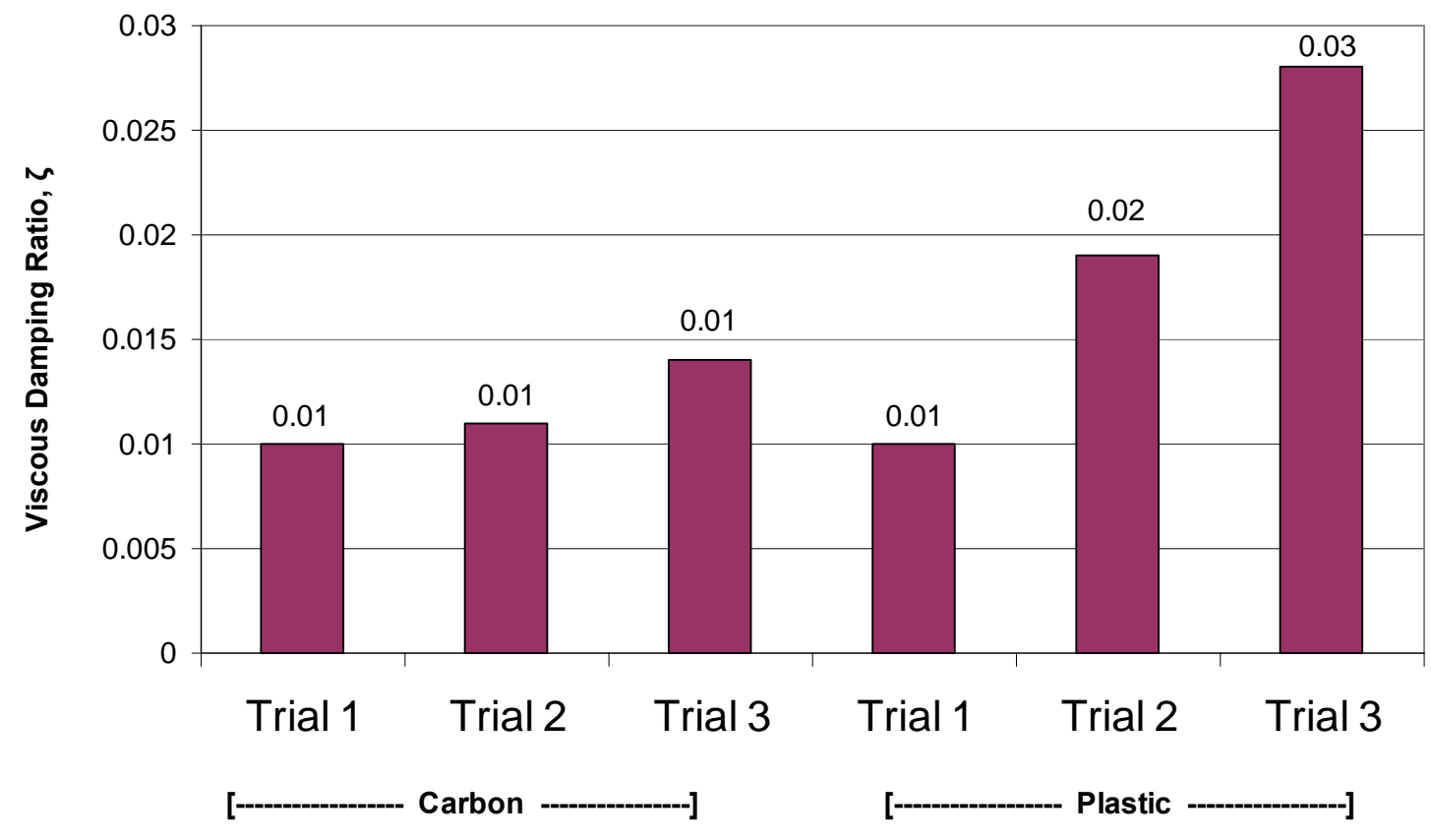

Shoe Type

Figure 57. Equivalent viscous damping ratio $(\zeta)$ of shoes in three-point bending.

Mean values for hysteretic damping constant, hysteretic damping ratio, logarithmic decrement, and equivalent viscous damping ratio for shoes tested in the three-point bending arrangement are shown in Table 13.

\begin{tabular}{|c|c|c|c|c|}
\hline \multicolumn{5}{|c|}{ Table 13. Damping of shoes in three-point bending. } \\
\hline Shoe Type & $\mathbf{h}(\mathrm{N} / \mathrm{m})$ & $\boldsymbol{\beta}$ & $\boldsymbol{\delta}$ & $\zeta$ \\
\hline M220 & 14,321 & 0.024 & 0.074 & 0.012 \\
\hline M152 & 3439 & 0.039 & 0.121 & 0.019 \\
\hline
\end{tabular}




\title{
VITA
}

\section{Nathan Edward Jarboe}

NJ@asme.org

\section{Education}

\author{
1995 - present University of Louisville Speed Scientific School, Louisville \\ Bachelor of Science in Mechanical Engineering: May 2001 \\ Masters of Engineering in Mechanical Engineering: Sept 11, 2002. \\ GPA: 3.1 Undergraduate / 3.6 Graduate \\ $1991-1994 \quad$ University of Kentucky, Lexington \\ Bachelor of Science in Biology: May 1994 \\ GPA: 3.0

\section{Experience} \\ 08/01 - present University of Louisville, Graduate Teaching Assistant \\ Construct measurements experiments and grade engineering lab reports \\ 03/01 - 08/01 University of Louisville Bio-MEMS, Graduate Lab Assistant \\ Microfabricated pulse ultrasonic transducers using MEMS technology \\ 12/99 - 05/00 Trim Masters Inc. Engineer/ Engineering Co-op II and III \\ $08 / 00-12 / 00 \quad$ Managed a project for collection and reporting of flammability data \\ 05/99 - 08/99 Medventure Technology Corporation: Engineer/Co-op I \\ Used Solid Works 98Plus, lathe, mill, and other tools \\ 09/94 - 08/98 Frazier Rehab Center, Technologist, Physical Therapy Department \\ Used Pedar and Novell plantar stress measurement devices \\ 08/93 - 05/94 University of Kentucky, Independent Research in Biomechanics
}

\section{Technical Skills}

- Solid Works, Solid Edge, and I-DEAS parametric solid modeling software

- MATLAB, Excel, Mathcad, LabVIEW data analysis, simulation, and calculation software

- Strain gage transducers. Novel, and F-scan plantar stress measurement devices

- End mill, lathe, band saw, TIG welding, basic electric circuits

\section{Accomplishments and Awards}

- University of Kentucky Undergraduate Research Award in Biomechanics, 1994

- Engineer-in-Training Certification (EIT)

- Patel Engineering Scholarship, 2001-2002

- American Society of Mechanical Engineers (ASME), Local Student Section President

- Kentucky Mountain Bike Association, Secretary $\left(2^{\text {nd }}\right.$ term of service $)$ 